2014

\title{
IMPROVING STARTABILITY AND REDUCING EMISSIONS IN FLEXFUEL SPARK IGNITION DIRECT INJECTION VARIABLE CAM TIMING ENGINE
}

Vaibhav S. Kale

Michigan Technological University

Follow this and additional works at: https://digitalcommons.mtu.edu/etds

Part of the Mechanical Engineering Commons

Copyright 2014 Vaibhav S. Kale

Recommended Citation

Kale, Vaibhav S., "IMPROVING STARTABILITY AND REDUCING EMISSIONS IN FLEXFUEL SPARK IGNITION DIRECT INJECTION VARIABLE CAM TIMING ENGINE", Dissertation, Michigan Technological University, 2014.

https://doi.org/10.37099/mtu.dc.etds/822

Follow this and additional works at: https://digitalcommons.mtu.edu/etds

Part of the Mechanical Engineering Commons 


\title{
IMPROVING STARTABILITY AND REDUCING EMISSIONS IN FLEXFUEL SPARK IGNITION DIRECT INJECTION VARIABLE CAM TIMING ENGINE
}

\author{
By \\ Vaibhav S Kale \\ A DISSERTATION \\ Submitted in partial fulfillment of the requirements for the degree of \\ DOCTOR OF PHILOSOPHY \\ In Mechanical Engineering-Engineering Mechanics
}

MICHIGAN TECHNOLOGICAL UNIVERSITY

2014

(C2014 Vaibhav S. Kale 
This dissertation has been approved in partial fulfillment of the requirements for the Degree of DOCTOR OF PHILOSOPHY in Mechanical Engineering-Engineering Mechanics.

Department of Mechanical Engineering - Engineering Mechanics

Dissertation Advisor: Dr. Jeff Naber

Committee Member: Dr. Scott Miers

Committee Member: Dr. John Beard

Committee Member: Dr. Nilufer Onder

Department Chair: Dr. William W. Predebon 


\section{Contents}

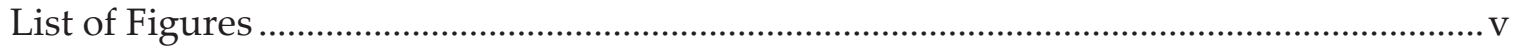

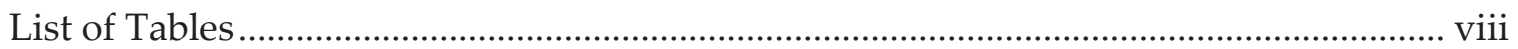

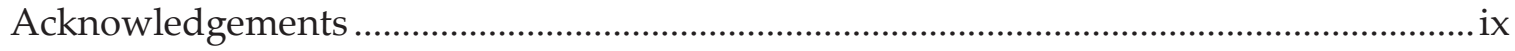

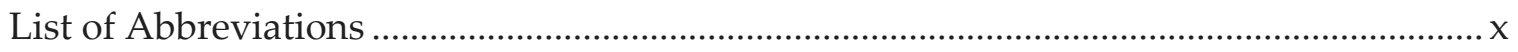

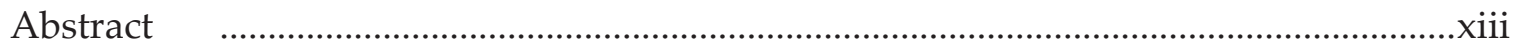

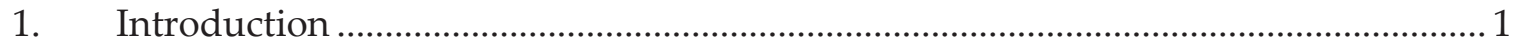

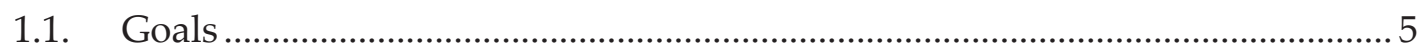

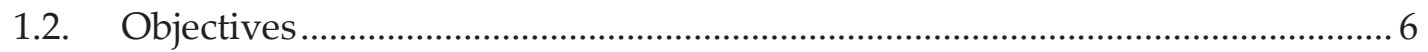

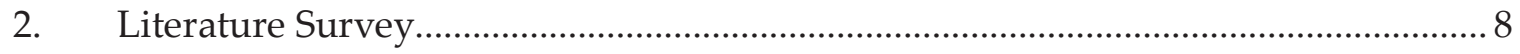

2.1. Engine hardware based improvements ........................................................ 8

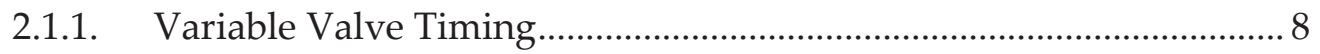

2.1.2. 2-stage Intake Valve Lift.................................................................... 9

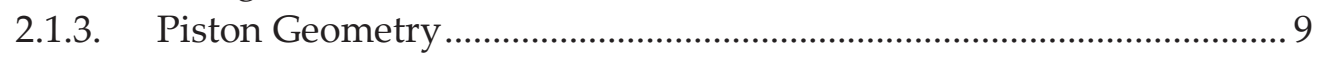

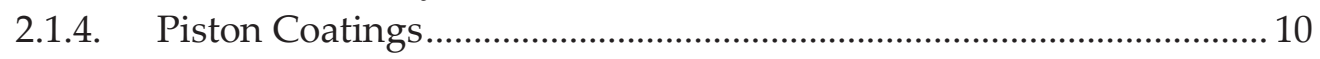

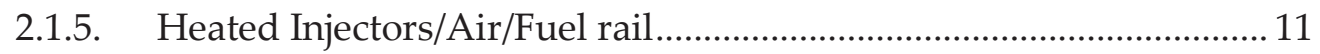

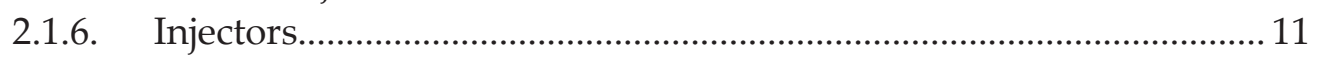

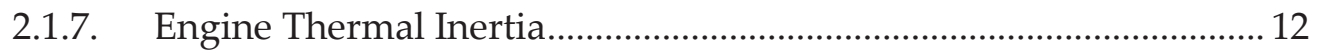

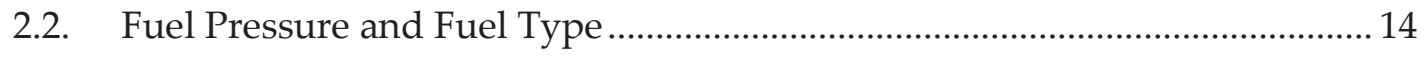

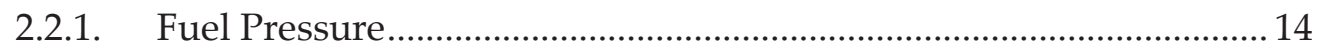

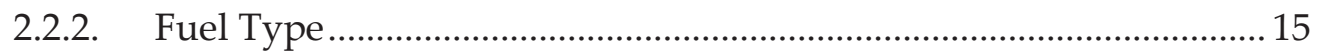

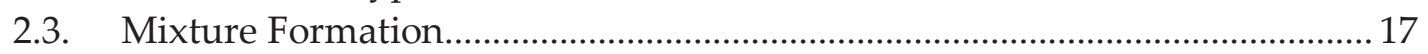

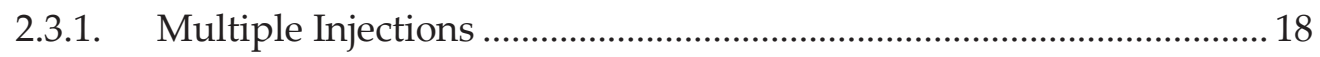

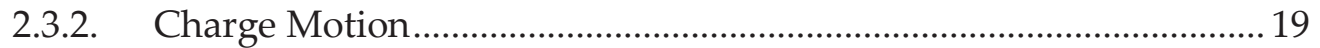

2.3.3. Exhaust Gas Residuals (EGR) Usage ................................................ 21

2.3.4. Mixing at cylinder wall boundary layer .......................................... 21

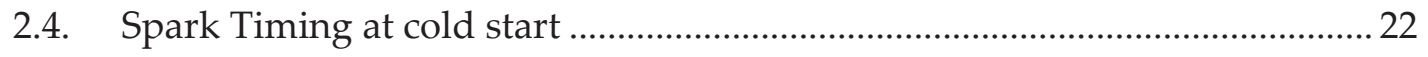

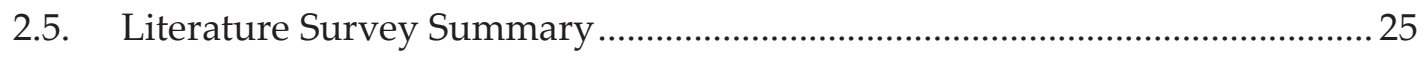

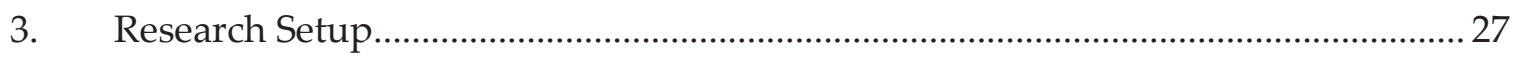

3.1. Single Cylinder Research Engine................................................................... 27

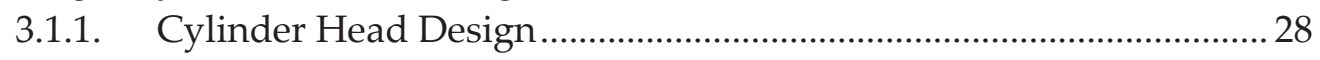

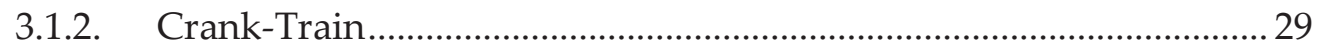

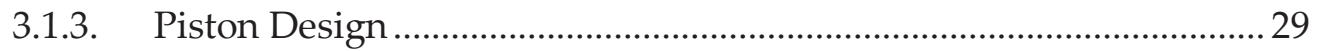

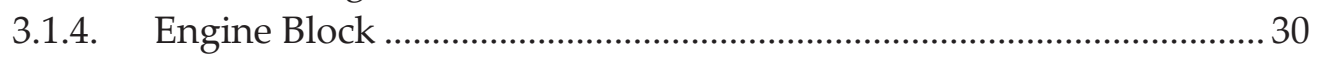

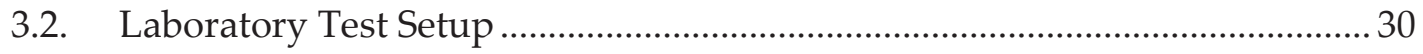

3.2.1. Engine Coolant System ................................................................. 30 


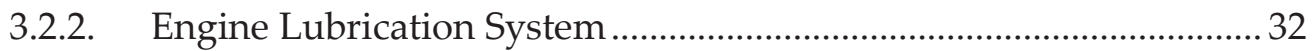

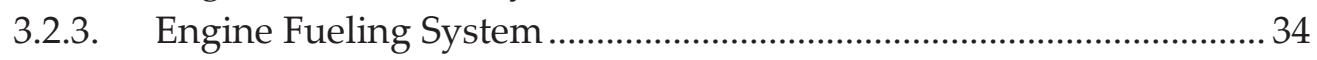

3.2.4. Engine Control Unit (ECU) ................................................................ 36

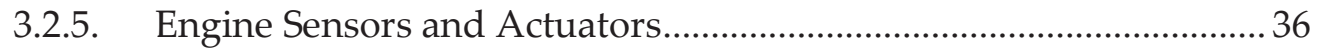

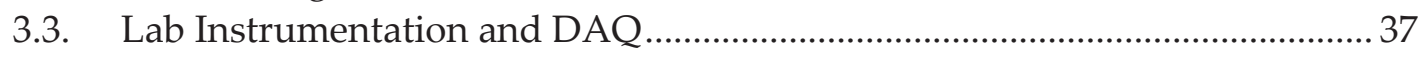

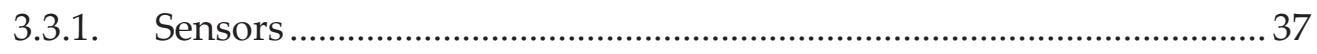

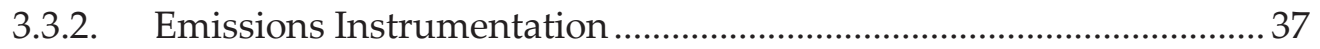

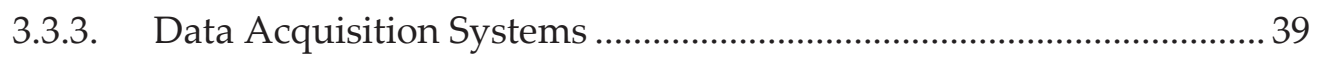

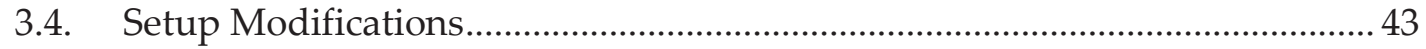

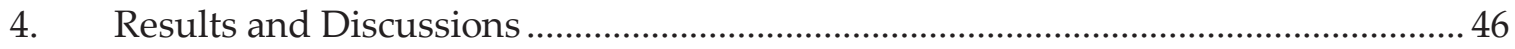

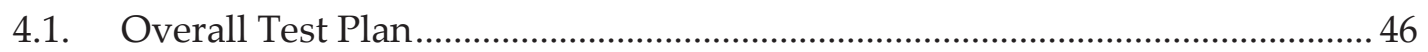

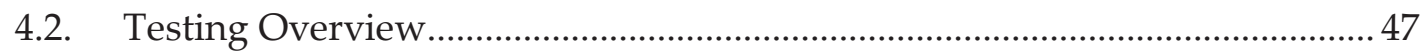

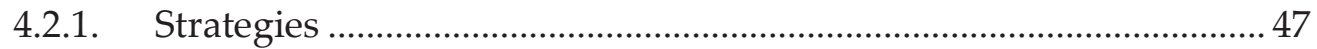

4.2.2. Phase 1 - Startability Test Plan ......................................................... 48

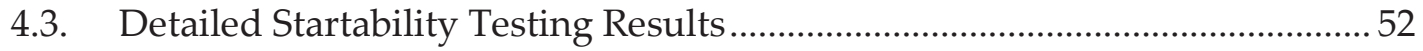

4.3.1. Gasoline Testing ..................................................................................... 53

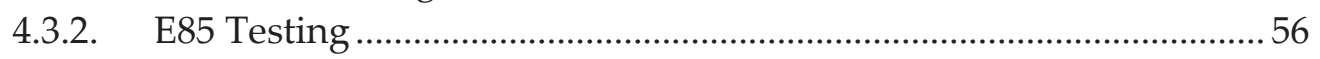

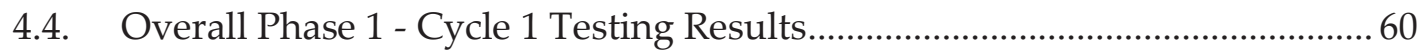

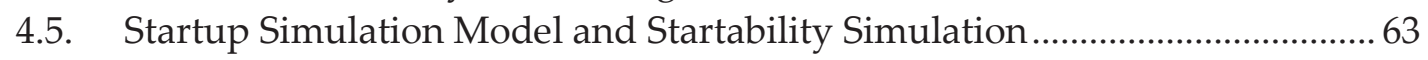

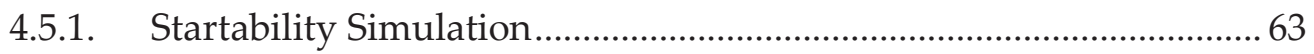

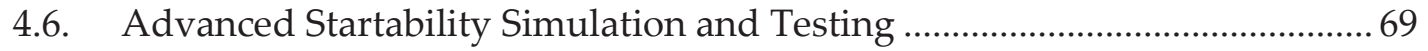

4.6.1. Advanced Startability Simulation work ............................................. 69

4.6.2. Experimental Testing........................................................................... 72

4.7. Phase 2 - Simulation and Experimental Emissions Testing for $2^{\text {nd }} \& 3^{\text {rd }}$

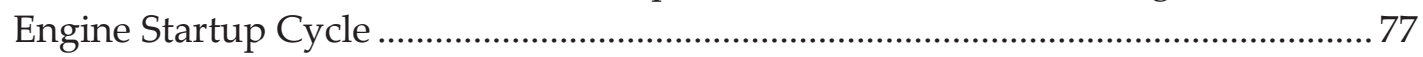

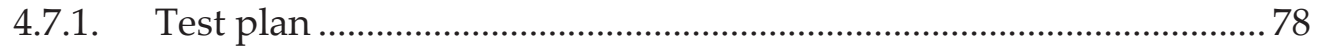

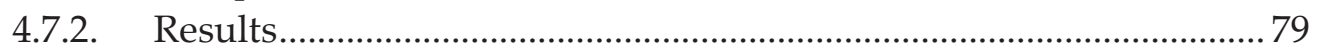

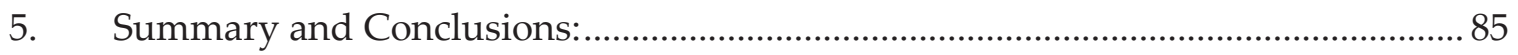

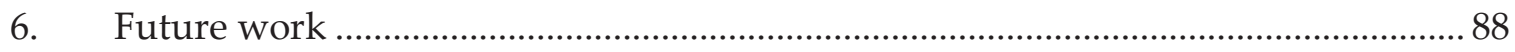

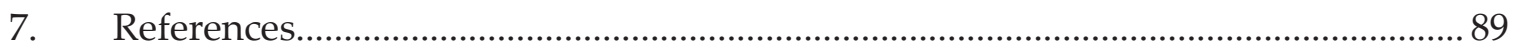

Appendix ECU1 - ECU Program Modifications for Skip-Fire Testing ............................... 94

Appendix ECU2 - ECU Specifications.............................................................................. 97 


\section{List of Figures}

Figure 1: Direct Injection SI engine [8], (academic use permitted) ...................................... 1

Figure 2: Cold start conditions vs. Time; generated from data in [13] ................................ 2

Figure 3: Cause and effect diagram at cold start; includes data in [18].............................. 3

Figure 4 : Cold start ethanol enrichment requirements vs. ambient temperature; created from data from [19]. SIDI: Spark Ignited Direct Injection. PFI: Port Fuel Injection LP: Low fuel pressure start (3-4bar), HP: High pressure stratified start (40bar), Ethanol blend used: E85................................ 4

Figure 5: Cold start engine and tail out HC emissions; generated from data in [17] .......... 5

Figure 6: Effect of strategies on gas temperature, data from [23]....................................... 8

Figure 7: 2-stage VVT and Lift control [28] ..................................................................... 9

Figure 8: Swirl sustaining piston comparison with normal piston; generated based on

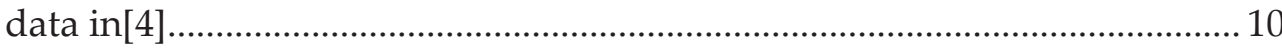

Figure 9: Fuel injected quantity deviation at fuel pressure of 100 bar vs. fuel quantity in $\mathrm{mg}$; generated from data in [6] ................................................................. 12

Figure 10 : Coolant control spacer and its effect on wall surface temperature; created based on [28]

Figure 11: Fuel required for Multi-Port Injection (MPI) and DISI engine at two injection pressures; based on data in[41] ......................................................................... 14

Figure 12: Reid vapor pressures (predicted Dry Vapor Pressure Equivalent) for ethanol-gasoline blends and values for an ideal mixture; created based on data in $[1,2]$.

Figure 13 : Mixture constituent's vs. temperature data from [45]...................................... 16

Figure 14: Fuel quantity required vs RVP at -30C; created based on data in [45] ............. 17

Figure 15: Effect of multiple injections on injection duration with ethanol Hom: Homogenous Ethanol: E100 ; created from data in [50]

Figure 16 : HC reduction comparison for optimized swirl and tumble only configurations; created based on data in [52]

Figure 17 : Comparison of swirl and tumble only configuration for intensity and COV [52].

Figure 18: Heat release(\%) vs CA50 at 1200 rpm, 2.5bar IMEP, 20C; generated based on data in [3].

Figure 19: Mass flow into crevices vs engine crank angle; generated based on data in [66]

Figure 20: HC accounting vs CA50 in rich, high swirl conditions; created from data in [66].

Figure 21: Exhaust HC vs CA50 at lean and rich conditions; created from data in[66].... 24

Figure 22: Hydra Single Cylinder Research Engine on a test stand ..................................27

Figure 23 : SCRE cylinder head CAD model . 28 
Figure 24 : Section view of cylinder head showing injector, spark plug and piston position

Figure 25: Engine Cooling schematic used in $1^{\text {st }}$ phase testing ......................................... 31

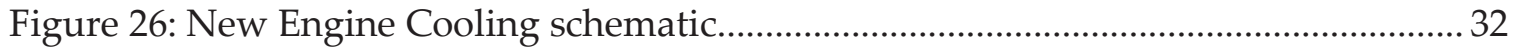

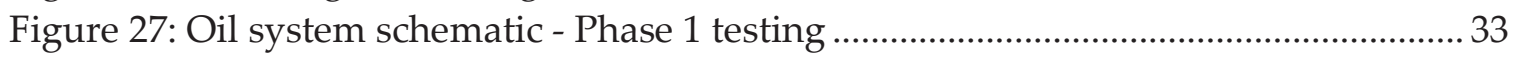

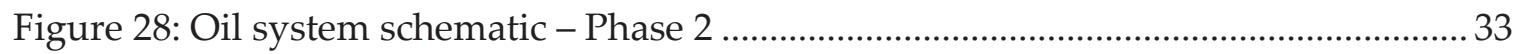

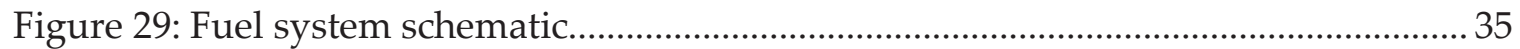

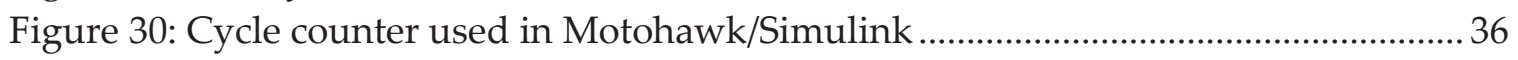

Figure 31: FRF data for resonance identification lies close to marked 3Hz/180 rpm 1st line.

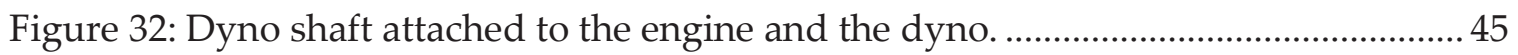

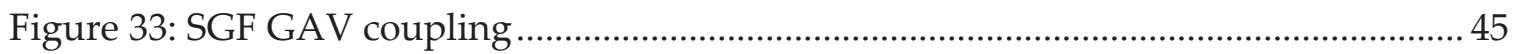

Figure 34 : Startup trace from a GM vehicle showing engine speed, fuel pressure, firing cylinder number, MAP (data from GM) ............................................ 46

Figure 35: Relationships between variables for finding the minimum starting $\varnothing$............ 48

Figure 36 : Startability testing process for a baseline for test matrix 1 , * indicates optimal value for the variable at that stage...................................................50

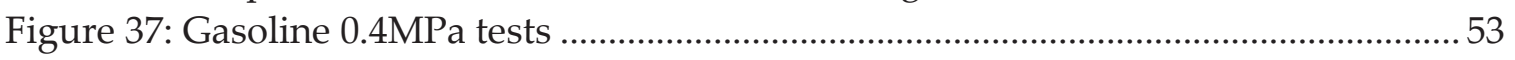

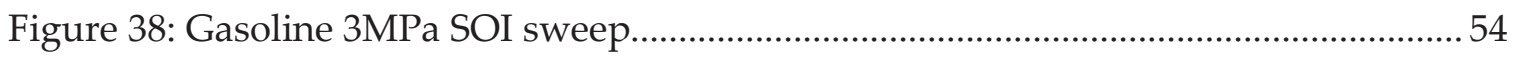

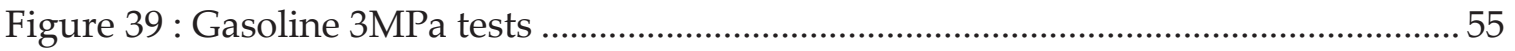

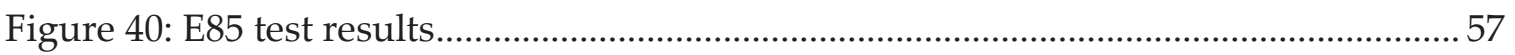

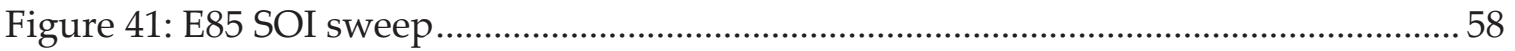

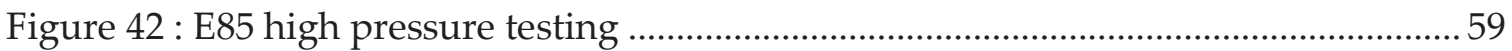

Figure 43: Effect of increase in fuel pressure from low to high on starting $\varnothing$ for both

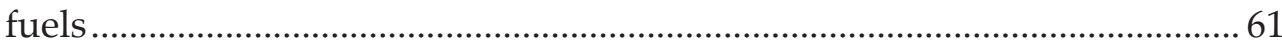

Figure 44: Effect of use of bowl piston instead of a flat top piston on starting $\varnothing$ for both

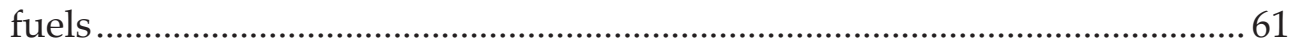

Figure 45: Effect of increase in CR from 11 to 15 on starting $\varnothing$ for both fuels ................... 61

Figure 46: Overall IMEP envelope plot for all datasets ....................................................62

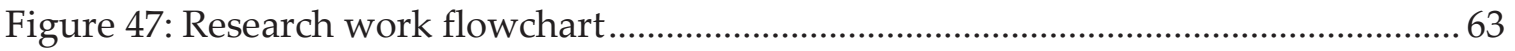

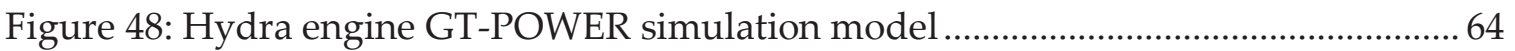

Figure 49: Residuals after 1st cycle firing at 180 RPM 0.95bar MAP .................................. 65

Figure 50: Estimated 1 ${ }^{\text {st }}$ cycle IMEP without residuals at 180 RPM MAP 0.95 bar............. 66

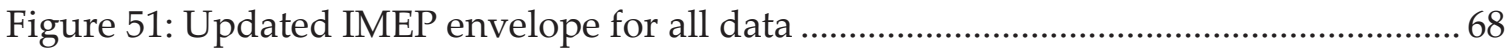

Figure 52: Residuals in cam phasing space at $225 \mathrm{rpm}, 0.95$ bar MAP............................... 69

Figure 53: Maximum cycle temperature at 225 RPM - nonfiring case................................ 70

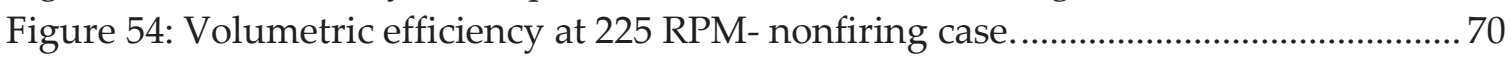

Figure 55: Maximum IMEP possible for $1^{\text {st }}$ cycle.................................................................. 71

Figure 56: 3MPa fuel pressure SOI sweep for E10 fuel CR11F at 225 RPM.......................74

Figure 57: Test points at 3MPa fuel pressure for E10 fuel CR11F at 225 RPM ..................75 
Figure 58: Second and third cycle combustion and emissions data for baseline 8 and

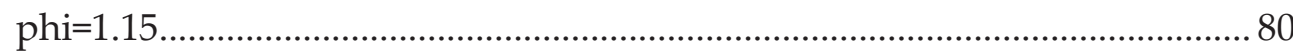

Figure 59: Comparison of E10 fuel baselines with optimal SOI's and $\varnothing=1.15$................... 81

Figure 60: Comparison of E85 fuel baselines with optimal SOI and $\varnothing=1.15 \ldots \ldots \ldots \ldots \ldots \ldots \ldots . . . .82$

Figure 61: Cycle counter data being fed into variables.......................................................... 94

Figure 62: Cycle number data read and processed to select injection duration and start

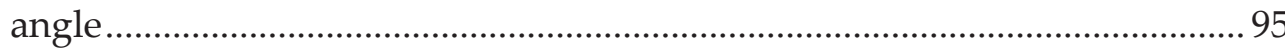

Figure 63: Subsystem 1 in more details, chooses the current injector duration based on cycle number............................................................................................ 96 


\section{List of Tables}

Table 1 : Gasoline (E00, E10) and Ethanol blends (E85) properties (created from data in

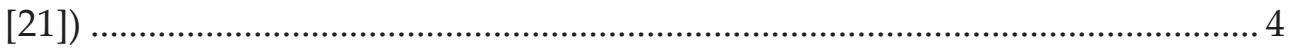

Table 2: Injection Strategies at 200 RPM created based on data in [5] ............................... 18

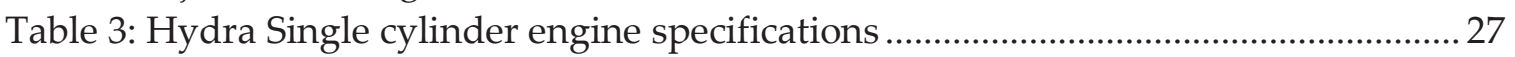

Table 4: Piston design details along with compression ratio and type ...............................29

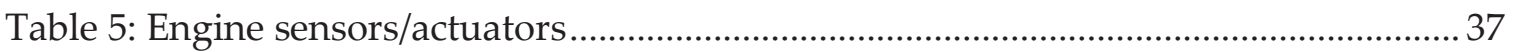

Table 6: Gases and Regulators needed for Horiba emissions bench .................................. 38

Table 7: Gases and Regulators needed for FFID and NDIR emissions instruments ......... 39

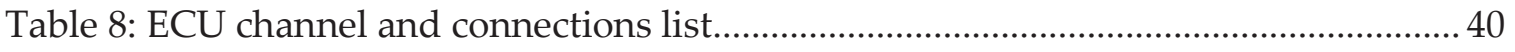

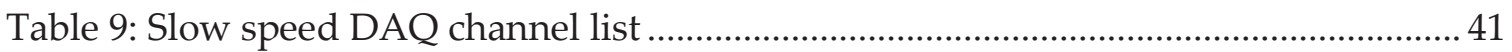

Table 10: NI PCI- 6602 Counter Timer Channel listing …...................................................... 41

Table 11: High Speed DAQ Channel List, all channels are 0-5V ....................................... 41

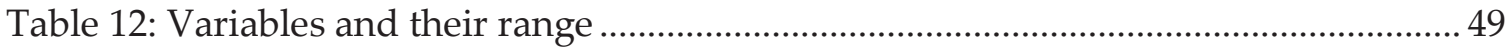

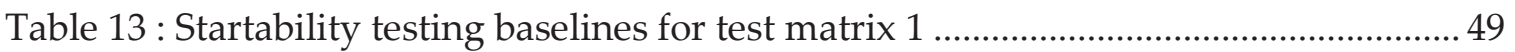

Table 14 : Demonstration of testing a baseline using the process flowchart ...................... 51

Table 15 : Minimum $\varnothing$ required for $0.4 \mathrm{MPa}$ fuel pressure testing and the corresponding IMOP position for gasoline and E85 for each piston............. 60

Table 16: Optimum SOI for $3 \mathrm{MPa}$ fuel pressure testing for gasoline and E85 for each

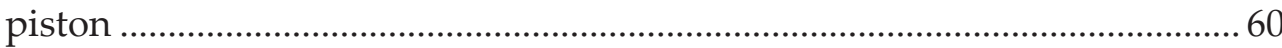

Table 17: Minimum $\varnothing$ required for $3 \mathrm{MPa}$ fuel pressure testing and the corresponding

IMOP position for gasoline and E85 for each piston ...................................... 60

Table 18: Cycle 1 low pressure testing results - updated with estimated actual $\varnothing$.......... 67

Table 19: Cycle 1 high pressure testing results - updated with estimated actual $\varnothing \ldots . . . . .67$

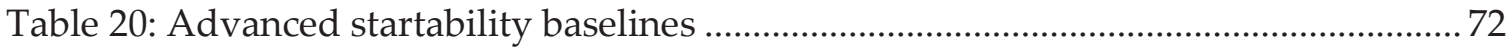

Table 21: Test matrix for baseline 1 .................................................................................... 73

Table 22: Actual $\varnothing$ computed from simulation residuals and injected fuel at 225 RPM

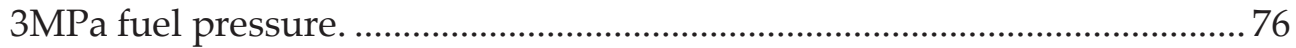

Table 23: Residuals at chosen cam phasing test points at both $225 \mathrm{rpm}$ and $1000 \mathrm{rpm}$

(test points crossed out for cam positions not feasible to run) ...................... 77

Table 24: Baselines for phase 2 emissions testing for $2^{\text {nd }}$ and $3^{\text {rd }}$ cycle testing .................... 78

Table 25: Testpoints for baseline 8 (EMOP:-126 and IMOP:100) ........................................ 79

Table 26 : Optimum SOI and cam position for 2nd and 3rd cycle testing for E10 and E85 for CR11F

Table 27 : HC and CO reductions for CR11 flat top piston with new optimal cam positions vs. LAF park ..................................................................................... 84 


\section{Acknowledgements}

This thesis research work was supported by GM via MIEEG project funding with site support by Keweenaw Research Center of Michigan Technological University for the initial $1^{\text {st }}$ cycle engine startup testing work. The $2^{\text {nd }}$ phase of the research was conducted on campus in the sub-basement SI engines lab, thanks to lab manager Paul Dice for supporting the lab setup.

Support from the discussions and feedback with Craig Marriott, Halim Santoso, Dustin Loveland and Matthew Wiles of GM is also greatly appreciated.

The suggestions and feedback received from my thesis defense committee is also deeply appreciated.

I would like to very much thank my Advisor Dr. Jeff Naber and Jeremy Worm for all the guidance over the years. It was wonderful experience working and learning from you.

As well as help received from lab mates and friends working on the project including Brandon Rouse, Chris Polonoski, Yeliana Yeliana, Brandon Pennela, Jason Socha, Paul Demay, Kraig Kadletz, Mark Johnson, Daniel Madison, Wei Chen and Ryan Foley is greatly appreciated.

Special thanks to Jaclyn Johnson who helped support my research even though she was not directly involved in it.

Finally I would like to thank my parents and my sister who patiently supported me during this time; along with all my MTU friends especially Madhana Sunder, Nishidh Parekh, Harsha Surenahalli, Subodh Kanikdale, Harshal Kudupley, Ajinkya Gujar, Shreerang Dabhe and Koustubh Pendharkar whose support and friendship enabled me to finish this work through the years and made me feel at home all the way up in the upper peninsula of Michigan.

Thank you all for being a constant source of encouragement for me. 


\section{List of Abbreviations}

\begin{tabular}{|l|l|}
\hline AFR & Air Fuel Ratio \\
\hline aTDC & After TDC \\
\hline bTDC & Before TDC \\
\hline CA & Crank Angle in degrees \\
\hline CA50 & Crank Angle at which 50\% of air-fuel mixture has burnt \\
\hline CCC & Close Coupled Catalyst \\
\hline CFD & Computational Fluid Dynamics \\
\hline CMCV & Charge Motion Control Valve \\
\hline CO & Carbon monoxide \\
\hline CO2 & Carbon dioxide \\
\hline COV & Co-efficient Of Variation \\
\hline CR & Compression Ratio \\
\hline DC & Direct Current \\
\hline DI & Direct Injection \\
\hline DICP & Dual Independent Cam Phasing \\
\hline DOE & Design Of Experiments \\
\hline E10 & Ethanol 10\% blend with rest gasoline \\
\hline E85 & Ethanol $85 \%$ blend with rest gasoline \\
\hline ECU & Engine Control Unit \\
\hline EGR & Exhaust Gas Residuals / Recirculation \\
\hline EMOP & Exhaust Maximum Opening Position \\
\hline EPA & US Environmental Protection Agency \\
\hline EQR & Equivalence Ratio \\
\hline FFID & Fast Flame Ionization Detector \\
\hline FID & Fast Ionization Detector \\
\hline FP & Fuel Pressure \\
\hline FRF & Frequency Response Function \\
\hline FSN & Filter Smoke Number \\
\hline FTP & Federal Test Procedure (emissions testing) \\
\hline FTP75 & Federal Test Procedure for city driving cycle \\
\hline GDI & Gasoline Direct Injection \\
\hline GIMEP & Gross Indicated Mean Effective Pressure \\
\hline GM & General Motors \\
\hline & \\
\hline
\end{tabular}




\begin{tabular}{|l|l|}
\hline GPF & Gasoline Particulate Filter \\
\hline GOW- & Engine simulation software \\
\hline HC & HydroCarbons \\
\hline HCCI & Homogenous Compression Charge Ignition \\
\hline HP & High Pressure \\
\hline HPSS & High Pressure Stratified Start \\
\hline IC & Internal Combustion \\
\hline IMEP & Indicated Mean Effective Pressure \\
\hline IMOP & Intake Maximum Opening Position \\
\hline KVM & Keyboard, Video and Mouse \\
\hline LFE & Laminar Flow Element \\
\hline LP & Low Pressure \\
\hline MAP & Manifold Absolute Pressure \\
\hline MBT & Maximum Brake Torque \\
\hline MPI & Multi-Port Injection \\
\hline NDIR & Non-Dispersive Infra-Red \\
\hline NMHC & Non-Methane HydroCarbons \\
\hline NOx & Nitrogen Oxides \\
\hline NVH & Noise Vibration and Harshness \\
\hline$\varnothing$ & Phi / Equivalence ratio \\
\hline PFI & Port Fuel Injection \\
\hline PID & proportional-integral-derivative \\
\hline PLIF & Planar Laser Induced Fluorescence \\
\hline PN & Particulate Number \\
\hline pPm & Parts per million ppm \\
\hline PWM & Pulse Width Modulation \\
\hline RVP & Reed Vapor pressure \\
\hline SCRE & Single cylinder research engine \\
\hline SFC & Specific Fuel Consumption \\
\hline SI & Spark ignition \\
\hline SMD & Saunders Mean Diameter \\
\hline SOI & Start of injection \\
\hline STD & Standard deviation \\
\hline TDC & Top dead center \\
\hline
\end{tabular}




\begin{tabular}{|l|l|}
\hline TKE & Turbulent Kinetic Energy \\
\hline TWC & Three Way Catalyst \\
\hline VCT & Variable Cam Timing \\
\hline VE & Volumetric Efficiency \\
\hline VTC & Variable Timing Control \\
\hline VVT & Variable Valve Timing \\
\hline WOT & Wide Open Throttle \\
\hline
\end{tabular}




\section{Abstract}

Experimental work and analysis was done to investigate engine startup robustness and emissions of a flex-fuel spark ignition (SI) direct injection (DI) engine. The vaporization and other characteristics of ethanol fuel blends present a challenge at engine startup. Strategies to reduce the enrichment requirements for the first engine startup cycle and emissions for the second and third fired cycle at $25^{\circ} \mathrm{C} \pm 1^{\circ} \mathrm{C}$ engine and intake air temperature were investigated.

Research work was conducted on a single cylinder SIDI engine with gasoline and E85 fuels, to study the effect on first fired cycle of engine startup. Piston configurations that included a compression ratio change (11 vs 15.5) and piston geometry change (flattop vs bowl) were tested, along with changes in intake cam timing $(95,110,125)$ and fuel pressure (0.4 MPa vs $3 \mathrm{MPa})$. The goal was to replicate the engine speed, manifold pressure, fuel pressure and testing temperature from an engine startup trace for investigating the first fired cycle for the engine.

Results showed bowl piston was able to enable lower equivalence ratio engine starts with gasoline fuel, while also showing lower IMEP at the same equivalence ratio compared to flat top piston. With E85, bowl piston showed reduced IMEP as compression ratio increased at the same equivalence ratio. A preference for constant intake valve timing across fuels seemed to indicate that flattop piston might be a good flex-fuel piston. Significant improvements were seen with higher CR bowl piston with high fuel pressure starts, but showed no improvement with low fuel pressures.

Simulation work was conducted to analyze initial three cycles of engine startup in GT-POWER for the same set of hardware used in the experimentations. A steady state validated model was modified for startup conditions. The results of which allowed an understanding of the relative residual levels and IMEP at the test points in the cam phasing space. This allowed selecting additional test points that enable use of higher residual levels, eliminating those with smaller trapped mass incapable of producing required IMEP for proper engine turnover.

The second phase of experimental testing results for $2^{\text {nd }}$ and $3^{\text {rd }}$ startup cycle revealed both E10 and E85 prefer the same SOI of 240 ${ }^{\circ}$ TDDC at second and third startup cycle for the flat top piston and high injection pressures. E85 fuel optimal cam timing for startup showed that it tolerates more residuals compared to E10 fuel. Higher internal residuals drives down the $\varnothing$ requirement for both fuels up to their combustion stability limit, this is thought to be direct benefit to vaporization due to increased cycle start temperature. Benefits are shown for an advance IMOP and retarded EMOP strategy at engine startup.

Overall the amount of residuals preferred by an engine for E10 fuel at startup is thought to be constant across engine speed, thus could enable easier selection of optimized cam positions across the startup speeds. 


\section{Introduction}

Engine startup is a challenging issue that has been a subject of considerable attention since the use of alternative fuels and blends became common amidst tightening emissions legislations over the years. This is particularly the case with the upcoming CARB LEV III[7], EPA Tier III [8]and EURO6 [9] regulations. "Minimizing emissions in spark ignited (SI) internal combustion (IC) engines (SI Direct Injection (DI) engine cylinder shown in Figure 1) results in compromises for fast, reliable engine starts. The trade-off in robust combustion and emissions is further compounded by the range of fuel blends for gasoline and ethanol."[10] Engine start being the initial cranking and firing of the engine at ambient temperature before the engine reaches it designated idle speed.

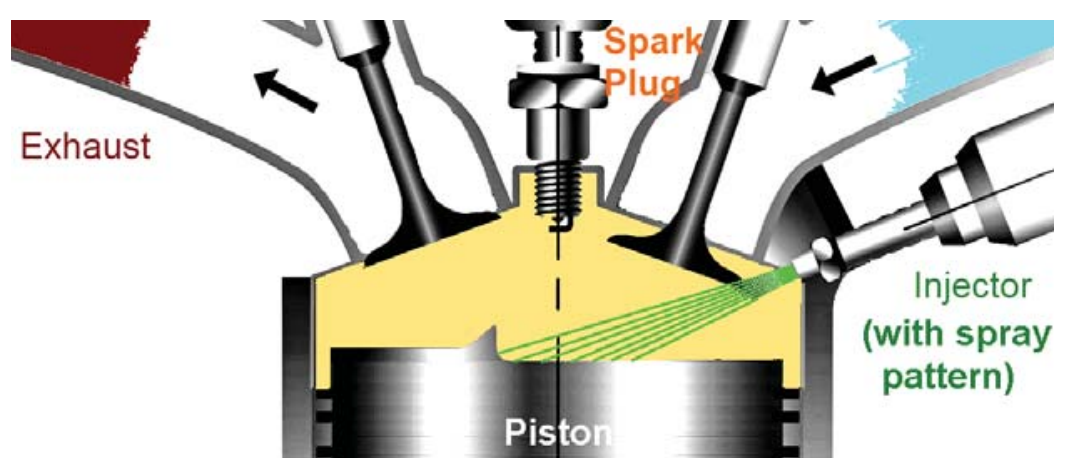

Figure 1: Direct Injection SI engine, figure based on [6]

Emissions at startup are an issue due to the lack of catalyst operation during startup. Since the catalyst in the catalytic converter is yet to reach its "light-off" temperature at engine startup (estimated time to reach the temperature varies from 30-120 seconds after a start [11]), a large portion of the emissions $(\mathrm{HC}+\mathrm{CO})$ from the engine during crankstart, run-up, and initial idle slip through the catalyst and emerge at the tailpipe. While the ability to get a robust start is primarily a calibration issue, emissions are greatly affected by the type of fuel used and combustion system.

Shown in Figure 2 is a graph [12] that outlines the typical conditions encountered at ambient cold start. The engine rpm rises at start from its cranking speed of $220 \mathrm{rpm}$ and finally settles down at a high idle speed of $1100 \mathrm{rpm}$. The Manifold Absolute Pressure (MAP) decreases during this time, while the fuel pressure rises up to its nominal operating value. The MAP and fuel pressure at each engine cycle during startup vary significantly and depends on the combustion of the previous cycle. This complicates startup analysis and methods to ensure robustness. 


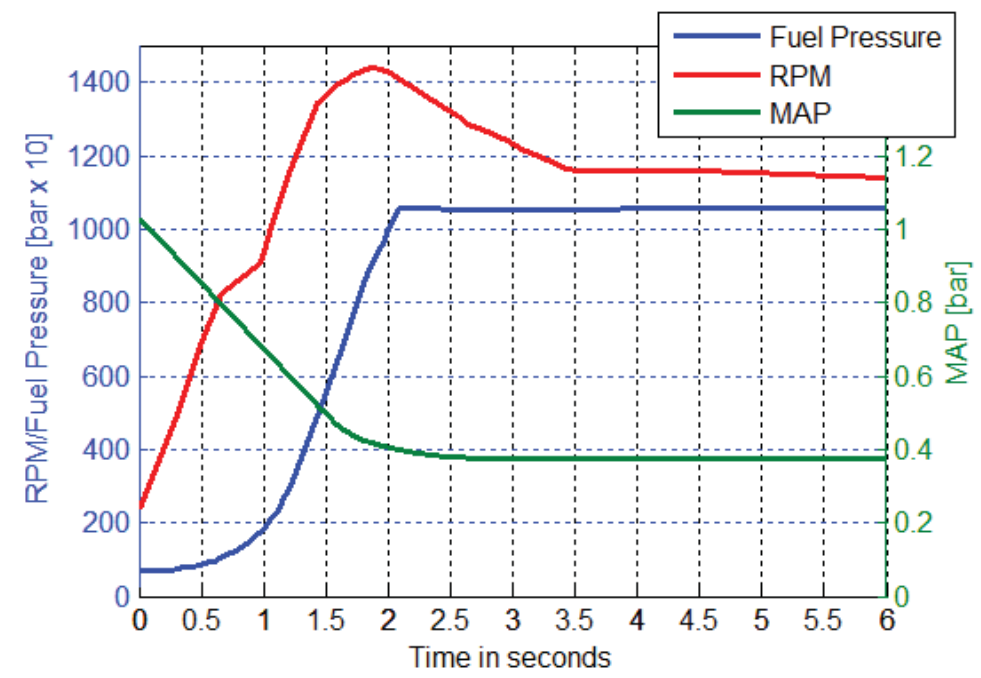

Figure 2 : Cold start conditions vs. Time; generated from data in [12]

Further the factors having a significant impact on the current engine startup routine are:

- Operating temperature of the engine/coolant which is usually around $90^{\circ} \mathrm{C}$ at steady state is at ambient temperature for cold start. [12]

- Manifold pressure is at atmospheric pressure and thus needing corresponding amount of fuel for the first few cycles. [12]

- Fuel pressure starts as low as 3\% to up to $25 \%$ of steady state operating fuel pressure, which results in lowering of the air-fuel mixture preparation effectiveness. As a result significantly more fuel enrichment is needed to get the engine started. [12]

- Cam phasing is inoperative due to lack of oil pressure and hence cams are at their park positions. As a result intake air trapping/management is sub-optimal.

- The engine is running in open loop mode due to Air/Fuel Ratio (AFR) feedback mechanism via Lambda or AFR sensor not being available yet.

- Fuel properties such as high enthalpy of vaporization/ low Reed Vapor Pressure (RVP) greatly increase the fueling requirements.

In conjunction with the factors discussed above, a detailed cause and effect diagram for cold start that leads to increased enrichment requirements and emissions is shown in Figure 3. It highlights the effect of engine conditions and the fuel properties on $\mathrm{HC}, \mathrm{CO}$ and $\mathrm{CO}_{2}$ emissions at startup. The two main mechanisms driving the increased need for enrichment are reduced fuel air mixing and reduced combustion efficiency; these along with higher frictional losses and lack of catalyst operation lead to higher $\mathrm{HC}$ and $\mathrm{CO}$ emissions.

With increasingly tighter EPA emissions standards that are required to be complied by the engines manufactured today, working towards even more rigorous standards including California LEV III and EPA Tier III requirements, cold start is an increasing 
challenge. A review of the emissions legislation and technologies done by Johnson [1315] is important in understanding the challenges it poses to the engine developers as well as calibrators. He noted new LEVIII requirements that will start in 2015 reduces the fleet average emissions to $75 \%$ of SULEV levels. Further there was a shift towards E10 certification for gasoline, increasing the vehicle emissions durability requirement up to 150,000 miles. With respect to Europe, EURO6 regulations which are applicable to vehicles manufactured after September 2014, Particulate Number (PN) emissions requirements were established which requires developing Gasoline Particulate Filters (GPF's) or alternatives. He further notes that considerable amount of work is being done on GPF's as well as Three Way Catalyst (TWC) to improve its startup characteristics including reducing its light-off time. These PN emissions legislation in particular directly impacts cold start, since cold start is a large contributor to it compared to steady state emissions. The contribution of cold start emissions to total (Federal Test Procedure) FTP cycle emissions is found to be as much as 90 percent [16].

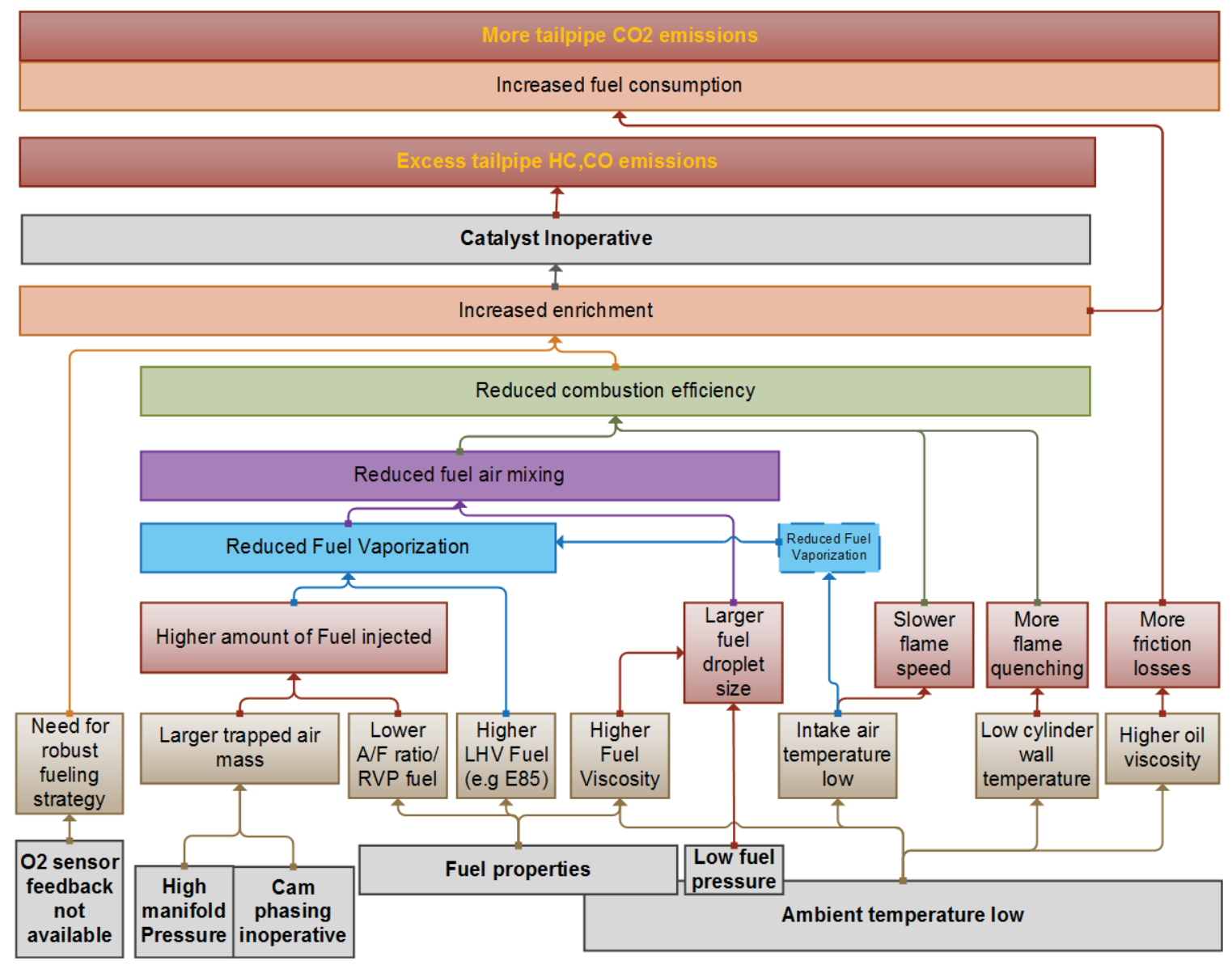

Figure 3: Cause and effect diagram at cold start; includes relationships between variables shown in diagram in [17] 
Table 1 : Gasoline (E00, E10) and Ethanol blends (E85) properties (created from data in [20])

\begin{tabular}{|c|c|c|c|c|}
\hline \multirow{2}{*}{ Fuel } & $\begin{array}{c}\text { Enthalpy of } \\
\text { vaporization }\end{array}$ & $\begin{array}{c}\text { Stoic } \\
\text { AFR }\end{array}$ & Density & LHV \\
\cline { 2 - 5 } & $\mathrm{kJ} / \mathrm{kg}$ & - & $\mathrm{kg} / \mathrm{L}$ & $\mathrm{mJ} / \mathrm{kg}$ \\
\hline E00 & 305 & 14.6 & 0.74 & 44.0 \\
\hline E10 & 362 & 14.0 & 0.74 & 42.2 \\
\hline E85 & 764 & 9.8 & 0.78 & 29.3 \\
\hline
\end{tabular}

With the trend of gasoline engines towards increased ethanol blend usage, cold start becomes a more difficult problem due to low vaporization of ethanol fuel at ambient temperatures; thus requiring higher equivalence ratio which also complicates emissions control.

Table 1 shows the difference in physical properties between gasoline and ethanol. The enthalpy of vaporization for ethanol is more than two times that of gasoline. As ethanol has a constant boiling point of $78.5^{\circ} \mathrm{C}$, the ethanol content of an ethanol blended fuel mostly does not vaporize at subzero cold starts, rather only the lighter carbon compounds made of $C_{4}, C_{5}$ in the fuel evaporate [19]. Thus considerably more fuel needs to be injected to produce adequate vaporized fuel in order to support combustion. Shown in Figure 4 are the enrichment requirements for gasoline and ethanol blend (E85) fuels for cold start across a range of ambient temperatures. The effect of fuel pressure is clearly visible in case of ethanol fuel; lower fuel pressure starts need considerably higher fuel enrichment ratio $(\varnothing)$ compared to high pressure starts. The reason for which can be attributed to the lower percentage of fuel vaporization. This also leads to a corresponding increase in the hydrocarbons $(\mathrm{HC})$ and carbon monoxide $(\mathrm{CO})$ emissions at the tailpipe during startup.

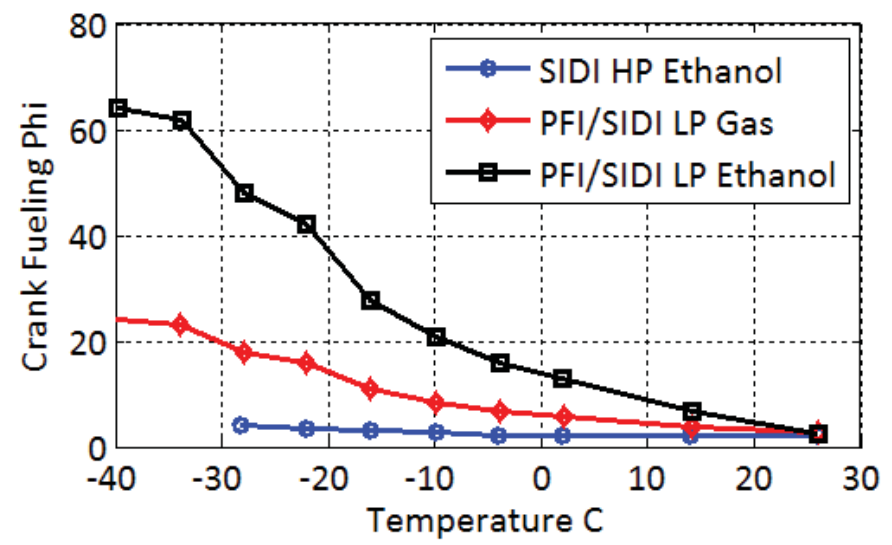

Figure 4 : Cold start ethanol enrichment requirements vs. ambient temperature; created from data from [18]. SIDI: Spark Ignited Direct Injection. PFI: Port Fuel Injection LP: Low fuel pressure start (3-4bar), HP: High pressure stratified start (40bar), Ethanol blend used: E85 
The instantaneous $\mathrm{CO}$ emissions characteristic for a cold start operation of a gasoline Port Fueled Injection (PFI) engine was studied in [11]. Exhaust CO concentrations up to $12 \%$ were seen for the cold startup operation before the engine goes to idle operation, most likely due to misfires. A similar trend can be seen in Figure 5 for the HC emissions which go as high as 18000 ppm $C_{3}$ basis or up to $5.4 \%$ of the exhaust flow at startup. This highlights the need for robust calibration to avoid misfires and meet emissions regulations.

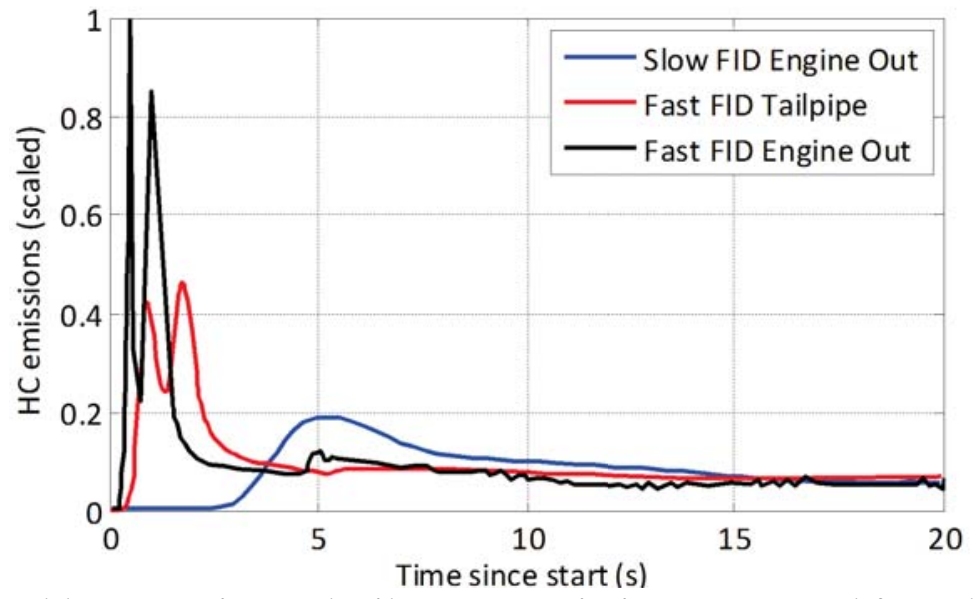

Figure 5: Cold start engine and tail out HC emissions; generated from data in [16]

A number of strategies have been used over the years in liquid fuelled SI engines to combat engine startup reliability and meet emissions requirements. Some of these are based on:[10]

- Physical hardware design including pistons having flat or bowl shapes, Direct Injection (DI) vs. Port Fuel Injection (PFI) etc.

- Control variable based changes have also been tested such as advanced or retarded spark timing, different intake and exhaust cam phasing, injection timing, etc.

- After-treatment based changes such as higher efficiency/lower light off temperature catalysts, multiple catalysts such as a Close Coupled Catalyst (CCC) and underfloor positioned catalyst, HC traps, Gasoline Particulate Filters (GPF), etc.

\subsection{Goals}

The goals of this research, also discussed before in [10]

- "Taking into account and analyzing information from a SI DI engine startup trace, simulate the engine's initial combustion cycles including engine speed, manifold pressure and fuel pressure. 
- Using representative set-points $\mathcal{E}$ control for spark timing, fueling parameters and cam phasing isolate and determine the impact of these factors on individual cycle combustion and emissions.

- Provide an optimized set of set-point / control for a set of pistons which include changes in compression ratio and piston geometry for the first fired cycle.

- Consider the impact E85 fuel has in comparison to a reference gasoline/E10 blend on combustion and emissions and determine an optimized parameter set for each fuel".

\subsection{Objectives}

To meet these goals the following objectives are outlined:

- Develop and modify the MTU-GM Hydra single cylinder DI-SI, VCT test bed to conduct ambient cold start tests; consisting of setup modifications, ECU control, instrumentation development and integration.

- Develop methods and constraints to simulate engine cold start and study the effect of physical engine variables including piston compression ratio, piston shape, fuel type and control variables including fuel pressure, fuel injection timing, equivalence ratio (Ø), intake cam phasing and exhaust cam phasing.

- Determine the impact of control parameters and characterize startability by examining the first fired cycle of the single cylinder research engine operating at cranking speed. With startability being defined as being able to have reliable combustion in the first cycle every time fuel is injected into the cylinder.

- Determine control parameter impact and characterize reliable firing along with the $\mathrm{HC}$ and $\mathrm{CO}$ emissions on the second and third fired cycle while minimizing emissions.

- Develop a GT-POWER Hydra model for startup conditions simulation to determine the cam phasing space that needs to be explored in the experimental testing for the second phase.

"The hypothesis these goals and objectives are based upon is that, advanced actuators including electrified components along with optimal engine hardware and compression ratio and/or integration into a hybrid powertrain provide the additional actuation control through high pressure fuel injection \& cam phasing at crank, startup that combustion and emissions can be significantly improved over the baseline".[10]

The organization of this thesis is detailed as:

- Chapter 2 is a review of literature relevant to cold start of gasoline and ethanol blend fueled SI engines.

- Chapter 3 explains the setup of the engine and test cell along with controls, instrumentation and sensors. 
- Chapter 4 outlines the research for $1^{\text {st }}$ startup cycle, which includes the test plan, brief explanation of strategies used, explains the simulation work done in GTPOWER, advanced startability work, explains the work on cycle 2 and 3 emissions focused testing.

- Chapter 5 is summary and conclusions

- Chapter 6 gives future work

- Chapter 7 is acknowledgements

- Chapter 8 gives the nomenclature used

- Chapter 9 gives the references 


\section{Literature Survey}

An extensive literature survey was done to classify the recent advances in engine startup research. These are discussed along the boundaries of hardware, fuel pressure/type, and mixture formation issues in the sections below. While some factors impact multiple areas, these are categorized and detailed in the area that they have the most impact.

\subsection{Engine hardware based improvements}

Hardware solutions have been commonly attempted to address better engine startability and lower emissions. Various options considered included use of optimized cam park positions, changes and optimization of piston geometry, injector's spray patterns, using heated PFI injectors, heated intake air and heated fuel rail. More analysis included use of higher engine compression ratio, higher pressure/displacement fuel pump, multi electrode spark plug, dual spark plugs [21], higher heat range spark plugs and low heat mass spark plugs[4].

A study comparing various methods to improve cold start with ethanol [22], such as higher compression piston, hot air intake, valve timing optimization showed results as shown in Figure 6 which indicate that variable valve timing is amongst the most effective method at raising gas temperature when the initial air temperature was at $10^{\circ} \mathrm{C}$.

\subsubsection{Variable Valve Timing}

One of the main constraints at engine start with respect to cam phasing, is that it cannot be operated due to lack of sufficient oil pressures in hydraulically actuated cam phasers till at least 3 seconds [23]. Further if adequate pressure is not built up before the phaser is operated, the control system might not be able to control the phasing. Being able to either cam phase at startup or hold the cam position at a certain optimized position (instead of park position) would enable better startup and entail lower emissions. Engine cam phaser park position is inherently a compromise between starting position requirements and steady state cam phasing range requirements. A hydraulic Valve Timing Control(VTC) system was reported to be developed[23] where there

\section{Gas Temp@TDC ( $\left.{ }^{\circ} \mathrm{C}\right)$}

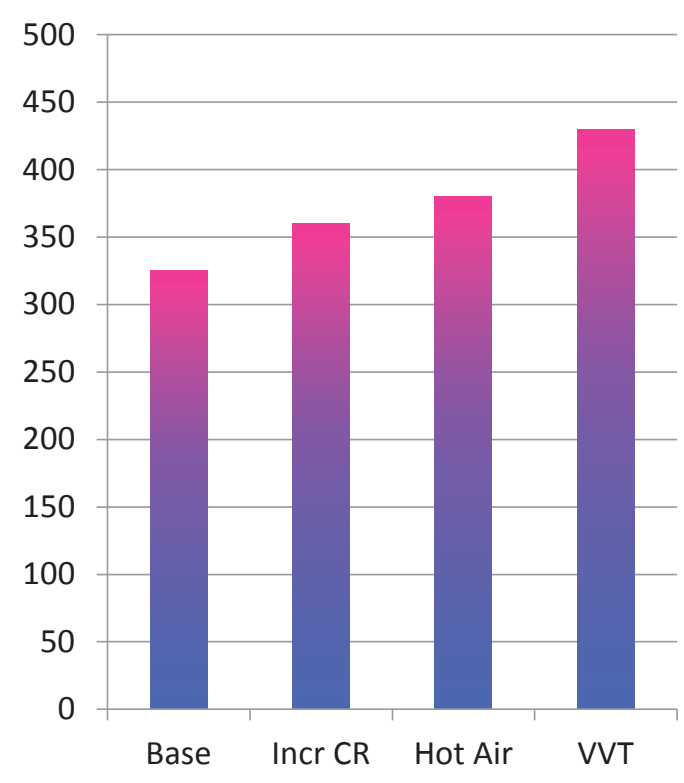

Figure 6: Effect of strategies on gas temperature, data from [22] 
was a locking pin that holds the VTC system to an optimized valve timing before engine shutdown. They note that a ratchet mechanism for returning to optimal cam timing is present in case of an engine stall, which uses the natural engine torque/cam fluctuations. This makes possible increased overlap and larger air charge enabling higher combustion efficiency and emissions reductions up to $40 \%$ from baseline, without compromising on the cam phasing range of the engine. Electric VCT[24, 25] mechanisms allow cam phasing even at startup, these represent the future where cam phasing at engine start will not be an issue for production engines. Further these are reported to have up to 100 crank angle degrees of cam phasing which enables development of SI engine capable of operating in HCCI mode[26].

\subsubsection{2-stage Intake Valve Lift}

Further the use of low intake lift cam for lower engine speed range and higher intake lift cam for higher engine speed range has been put into production by some manufacturers[27] as shown in Figure 7. It shows engine torque vs. engine speed with red line showing torque obtained from low lift intake cam while the blue line indicates the torque for the high lift intake cam. This would enable use of low lift cam at cold start speeds, thus also providing engine de-throttling benefits at startup. This also opens up the possibility of using advanced intake cam timing strategies based on low lift intake cam that might benefit engine startup.

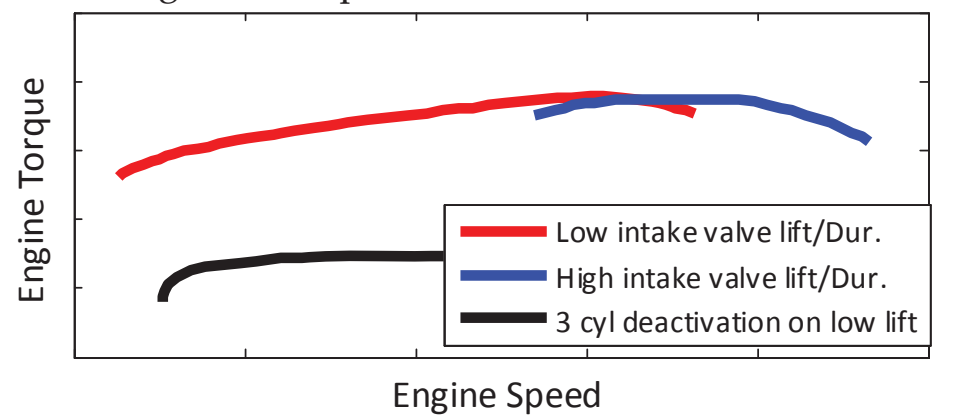

Figure 7: 2-stage VVT and Lift control, data from [27]

\subsubsection{Piston Geometry}

Piston shape optimization has been one of the most commonly used options to improve cold start behavior. The effect of piston cavity shape on the performance of a GDI engine was analyzed by Shizuo Abe et.al [28]. CFD tools were used to simulate air fuel mixture formation with different piston cavity shapes. They found that oval shaped wall cavity is better at getting richer mixtures near the spark plug, improved fuel consumption and HC emissions for stratified charge combustion. They note that it is the piston wall that guides the stratified charge towards forming a rich mixture near the spark plug. There is a finite optimized value for the cavity depth to obtain balanced homogenous and stratified combustion. A shallow cavity leads to more homogenous 
combustion enabling higher torque at Wide Open Throttle (WOT) while deeper cavity enables stratified combustion which leads to less fuel consumption.

The piston cavity shape was further analyzed using CFD[5] at different speeds at cold start which lead to specific redesigns to the bowl shape to enable better fuel containment in the bowl. It was noted that deeper bowl causes reduced turbulence intensity at full load and the bowl was redesigned as a wider bowl with more shallow depth to balance fuel containment and turbulence intensity. This also led to less piston surface wetting.

Further a swirl sustaining piston crown surface [4] allows turbulence to persist further into the compression stroke allowing better mixing and burning of the mixture; shown in Figure 8, with turbulence intensity plotted vs. crank angle. Thus they obtained higher turbulence even at piston top dead center (TDC) and beyond. This piston had its surface modified to remove features that dissipated swirl energy.

Compound injection strategies (DI+PFI)[29] or multiple injections have also been tried with piston modifications to generate an overall homogenous charge with stratification near the spark plug.

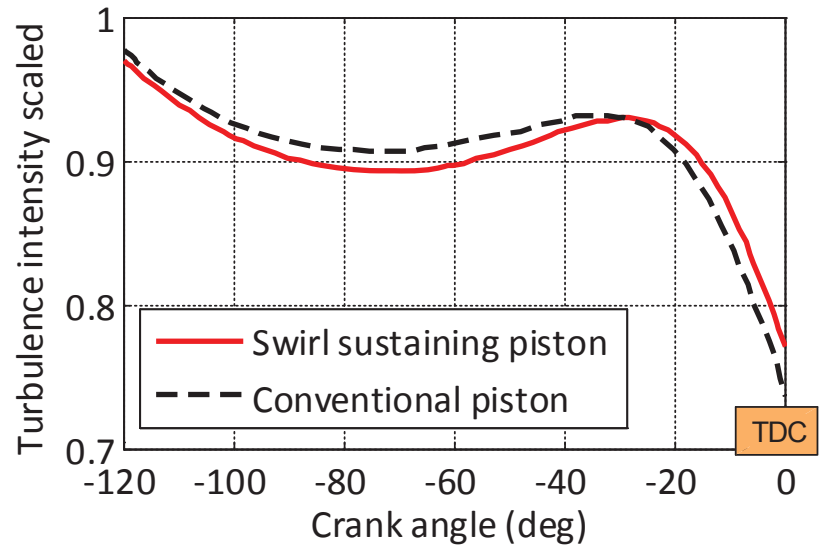

Figure 8: Swirl sustaining piston comparison with normal piston; generated based on data in[4]

\subsubsection{Piston Coatings}

The exhaust $\mathrm{HC}^{\prime}$ s during cold start are to a large extent from piston crevices in the combustion chamber; it is possible to reduce these $\mathrm{HC}^{\prime} \mathrm{s}$ by increasing the piston surface temperature near the crevices by means of ceramic coatings. Using CFD for analysis, the authors[30] used ring shaped coating at the crevice end of the piston surface. This lead to higher surface temperature in the coated areas, reducing the flame quenching area and promoting more fuel oxidation. They note coated pistons suffer from some knock at full load conditions, hence selection of these coatings needs careful consideration. The results showed that using Y-PSZ coating instead of Mg-PSZ makes knock free operation possible. Overall the piston end temperature was increased by $18 \%$ to $48 \%$ over baseline by using this strategy. In experimental verification work[31] performed later, maximum HC emissions decreased by $43 \%$ compared to a standard engine, while the piston surface temperature increase was estimated to be $100^{\circ} \mathrm{C}$. They also noted that the approximate contribution of piston crevices to total engine out $\mathrm{HC}^{\prime}$ s was found to be around $50 \%$. 


\subsubsection{Heated Injectors/Air/Fuel rail}

Heated port fuel injectors have been proven to reduce startup time and emissions with E100 vehicles, enabled engine starts up to $-5{ }^{\circ} \mathrm{C}$ for E100 fuel, though this does require injector preheat time of 6 seconds [32]. This preheating reduced exhaust HC's by approximately $66 \%$ over unheated injectors. For E22 fuel this benefit was approximately $30 \%$. Other authors[33] also working on heated injectors noted some important strategies for engine startup on ethanol fuel as fuel injection in co-ordination with valve timing, higher fuel pressure, multiple spark ignitions, intake manifold vacuum control, alternator load control, increasing cranking speed and heated fuel rail. The benefit of using both heated air and heated fuel for E100 injections was verified [34], while the authors tried to eliminate the requirement of using gasoline for cold start of E100 vehicles. They found a benefit of 31\% reduction in exhaust $\mathrm{HC}^{\prime} \mathrm{s}$ and $34 \%$ for $\mathrm{CO}$ on a FTP75 cycle. Heating of the fuel rail during cold start while possible, has reduced appeal due to the large amount of warm-up time needed. Further heated air usage options do not benefit the initial few cycles during engine start, these are the cycles that require the highest amount of over fueling to ensure successful engine start. With the over-fueling requirements for ethanol being many times that of gasoline[18], these might have lower benefits for gasoline fueled engines.

\subsubsection{Injectors}

Heated DI injectors have not yet been reported to be developed; hence most of the optimization for DI injectors focuses on spray pattern optimization. Marriott et. al. [35] noted that fuel flow rates for SIDI injectors were approximately $1 / 5$ th that of normal flow at steady states due to low pressure of 3-4 bar available at startup. Further they say that the injector needs to be open for longer duration to allow the same amount of fuel to pass, but the allowable injector open duration for this low pressure fuel is limited due to the relatively higher cylinder pressures encountered towards TDC, due to the limitation from the exhaust end of the stroke and firing TDC. They outfitted higher flow injectors to the engine to do these tests at $-20^{\circ} \mathrm{C}$. High pressure stratified starts (HPSS) have the advantage that injection can also be done in compression stroke, though this means that the fuel rail needs to be pressurized, which can take some time before start is enabled. This delay was found to be $0.7 \mathrm{sec}$ for $4 \mathrm{MPa}$ pressure, in addition to the normal start time of around 1.7 seconds. Here the fuel pump displacement was recognized as a critical parameter for HPSS. HPSS increases atomization of the spray due to increased charge density.

In a study on a Ecoboost engine[32] the authors analyzed various spray patterns for piston, liner and valve wetting by the fuel spray. They noted that the smoke and $\mathrm{HC}^{\prime} \mathrm{s}$ in the exhaust is directly proportional to amount of piston wetting.They were able to reduce the overall enrichment requirements for cold start with spray pattern optimization iterations, while at the same time increasing the local mixture richness near 
the spark plug. They thus improved the ignitability of the air-fuel mixture while reducing the amount of fuel needed. Final testing showed that they were able to reduce the fuel flow rates, increase the start of injection (SOI) window by 15 degrees in which the smoke content of the exhaust could be held to a low value of approximately 0.0625 Filter Smoke Number (FSN)/ $625 \mu \mathrm{g} / \mathrm{m}^{3}$.

Further, the standard solenoid injector's performance depends on the control system being used to drive them, with an alternate possibility of using piezo injectors. These were compared by authors[36] noting that cold start multiple injections require ballistic mode of operation in solenoid injectors in which the injectors show large variance in injected fuel quantity. They concluded that piezo injectors show operation independent of temperature. The drawback of piezo injectors being their increased cost. Solenoid injectors also show small fuel quantity deviation as temperature increases, this can be corrected by means of a new closed loop control strategy the authors implemented which minimized fuel quantity deviations, extended linear operating range to below $1 \mathrm{mg}$ stability as shown in Figure 9, also extending temperature range. Thus it was possible to achieve cold start performance with solenoid injector equivalent to that of a piezo injector using the appropriate control mechanism.

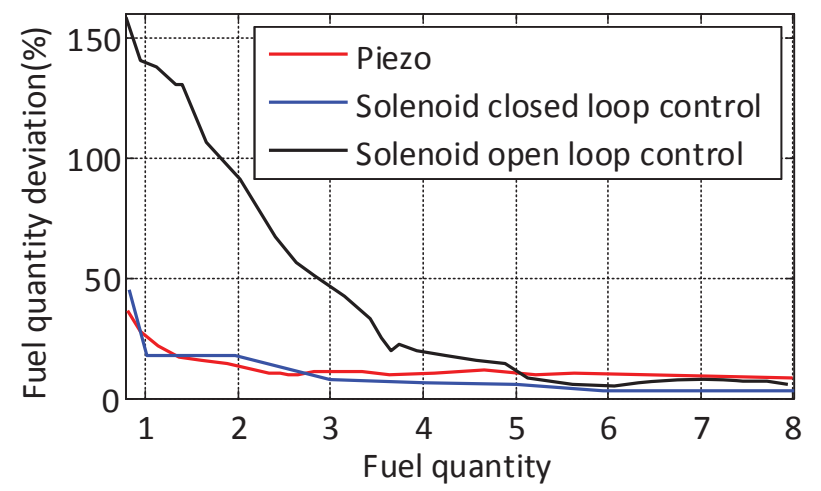

Figure 9: Fuel injected quantity deviation at fuel pressure of 100 bar vs. fuel quantity in $\mathbf{m g}$; generated from data in [36]

\subsubsection{Engine Thermal Inertia}

In general the warm-up time of the engine during startup/the thermal inertia is an issue which means colder cylinder walls; which leads to more fuel wall film, more enrichment requirements and more emissions. Currently there are production vehicles with exhaust gas to coolant heat exchangers[37], aptly called active warm-up systems, but these are hampered by the large thermal inertia of the engine and cooling intent of the engine cooling system. An attempt to address engine warm-up by extracting heat energy from the exhaust and adding it to the engine oil was made[38], which not only led to friction reductions but also $\mathrm{CO}$ emission reductions due to less wall quenching of 
the flame. In an analysis of engine exergy, it was noted that about $30 \%$ of the total heat transfer from the engine was between wall to coolant[39]; they noted that even a perfect thermal device cannot extract more than half the exergy lost in this process. This heat transfer can be minimized by increasing the surface temperature of the wall. An alternate method that could be envisioned for this benefit would be a method to control cooling while raising cylinder wall temperature. A cooling control spacer developed by Honda[27], with the primary aim of reducing friction by increasing cylinder wall temperature has the potentially desirable effect of reducing the wall to coolant heat loss, and might also benefit cold start, with potential for further optimization. Shown in Figure 10 this spacer increases the temperature of the lower part of cylinder wall by up to $10^{\circ} \mathrm{C}$ allowing the cylinder bore to expand by more than $10 \mu \mathrm{m}$ hence reducing the piston rings friction.

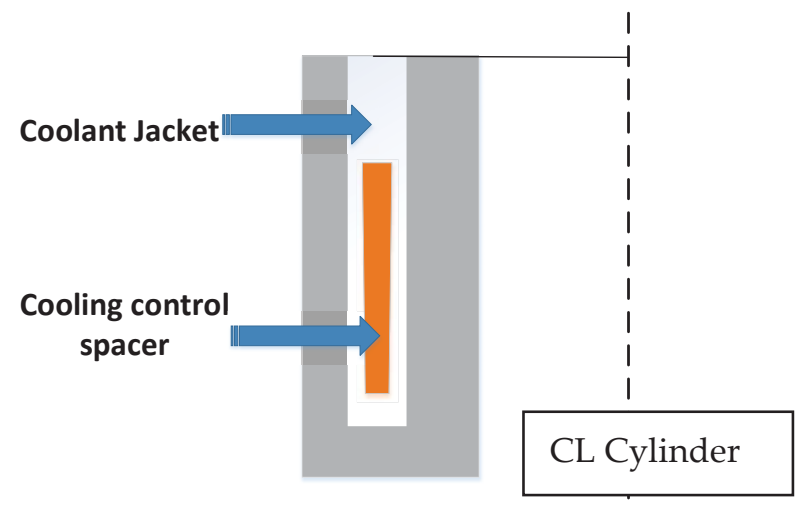

Figure 10 : Coolant control spacer and its effect on wall surface temperature; created based on [27] 


\subsection{Fuel Pressure and Fuel Type ${ }^{1}$}

\subsubsection{Fuel Pressure}

Fuel pressure at cold start is considerably lower than at steady state operation since only the low pressure fuel pump in the fuel tank is active and mechanical fuel pump is yet to boost the fuel pressure.

There is a delay between low pressure fuel pump activation and fuel pressure rise, this was found to be due to two factors by the authors[40]: namely fuel vapor formation and air desorption. They found that the cooling of the fuel rail and lines after shutdown causes vapor to build up due to pressure falling below vapor pressure of the fuel, after which air comes out of the fuel. The authors conclude by saying that air desorbtion slows down pressure build up during cold start as this air takes long time to re-dissolve in the fuel. They found the cooling down of engine to be the dominant factor for the drop in pressure then the leakage of fuel through components. They recommended maintaining rail pressure above fuel vapor pressure so as to avoid air desorbtion by operating the low pressure fuel pump intermittently after engine shutdown.

While this takes care of the slow fuel pressure rise, it does not address the inherent issue due to lower fuel pressure at startup for the initial engine cycles. Direct Injection technology is especially sensitive to fuel injection pressures; a cycle by cycle analysis of the fuel required to successfully get an engine running from cold start at different fuel pressures is shown in Figure 11. As the engine speeds up, reduced fuel injection is required in each successive cycle. It is also seen that the part of fuel that wets the cylinder, is a large portion of the total fuel. The key result being the amount of fuel required for 0.4 MPa DI fueling is seen to be up to approximately $20 \%$ more than $5 \mathrm{MPa}$ DI injections. In direct injection, less time is available for fuel vaporization, hence the proportion of engine out $\mathrm{HC}^{\prime} \mathrm{s}$ to injected fuel is also approximately 50\% higher than for PFI fuel injections which have more time for fuel vaporization. Still DI injection

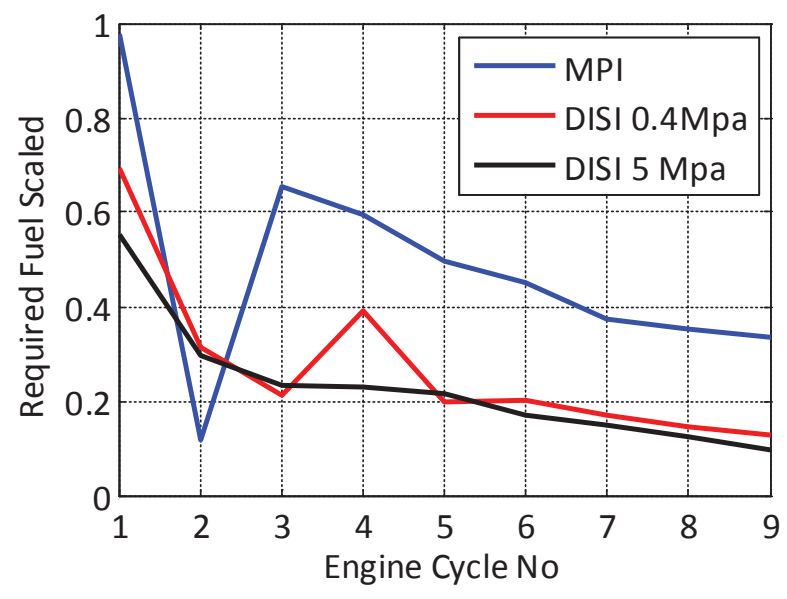

Figure 11: Fuel required for Multi-Port Injection (MPI) and DISI engine at two injection pressures; based on data in[41]

${ }^{1}$ Contains extracts/text from SAE publication on engine startup published as a result of this thesis work[10. Kale, V., et al., Combustion Robustness Characterization of Gasoline and E85 for Startability in a Direct Injection Spark-Ignition Engine. 2012, SAE International. 
is a significant improvement over MPI technology by requiring up to $50 \%$ less fuel on a cycle to cycle basis at startup. In their study, higher starting fuel pressure also helped reduce the engine out $\mathrm{HC}^{\prime}$ s by about $18 \%$.

Further there is a need to control the spray trajectory accurately in GDI applications[42]; as the fuel pressure dropped the authors could see reduced spray velocity, increased wall wetting, larger fuel droplet Sauter Mean Diameter (SMD); thus led to more fuel wall film thickness and fuel charge becoming less homogenous. This leads to higher exhaust HC's and particulate emissions.

Effect of MAP and Fuel Pressure (FP) on spray cone angle and spray penetration length was analyzed by Gandhi et.al[12,43]. They characterized the fuel sprays in three different regimes based on MAP and FP from an engine startup trace. "They concluded that at low fuel pressures MAP did not affect spray cone angle significantly, but the cone angle increases as fuel pressure was increased or MAP was decreased. There was an amplification effect though at very high fuel pressure and low MAP, these effects were found to be counteracting each other with respect to the cone angle increase. Spray penetration length shows a more complex relationship with fuel pressure." [10]

\subsubsection{Fuel Type}

With addition of ethanol into the mix, cold start becomes even more of an challenge due to the high latent heat of vaporization which decreases the compressed gas temperature as well as higher heat absorbed by ethanol combustion products(due to more triatomic molecules), leading to lower combustion and exhaust gas temperature[22]. The authors noted that at ambient temperature and pressure, a stoichiometric mixture of ethanol cannot be obtained below $20^{\circ} \mathrm{C}$. Thus techniques to change the temperature and pressure the fuel encounters in-cylinder during vaporization are required to successfully get a stoichiometric or richer mixture. They concluded that combustion characteristics cannot be explained by latent heat of evaporation/boiling point alone and saturated vapor pressure had to be considered as well.

Models based on properties of fuels can also be used to understand the obstacles to engine startup when using E85 [44]. The authors noted the important barriers in mixture formation with using ethanol in cold starts occurred particularly in DISI engines due to limited time available for in-cylinder vaporization, reduced vapor pressure, higher enthalpy of vaporization and greater increase in viscosity at low temperatures. They further stated that viscosity of ethanol increases much more rapidly than that of gasoline as the temperature decreases. This had a significant impact on the spray characteristics as dictated by the Reynolds number and Ohnesorge number, as the spray became stringier in form and vaporization was much slower.

Reed Vapor Pressure (RVP) is a commonly used indicator of fuel vapor pressure, it is determined at a temperature of $37.8^{\circ} \mathrm{C}$ in a sample chamber. The higher the RVP the better the startability of an engine with the fuel. RVP is measured in a fuel rich condition 
with vapor to liquid fuel in $4: 1$ ratio[2]. While RVP of a gasoline ethanol blend would be expected to decrease with increasing ethanol content, it is noted that the vapor pressure of E10 is higher than baseline gasoline as shown in Figure 13. Overall the trend is increase in RVP with increasing ethanol content up to approximately E10 and then RVP keeps on decreasing with increasing ethanol content, while still higher than computed fuel mixture properties. This is caused due to

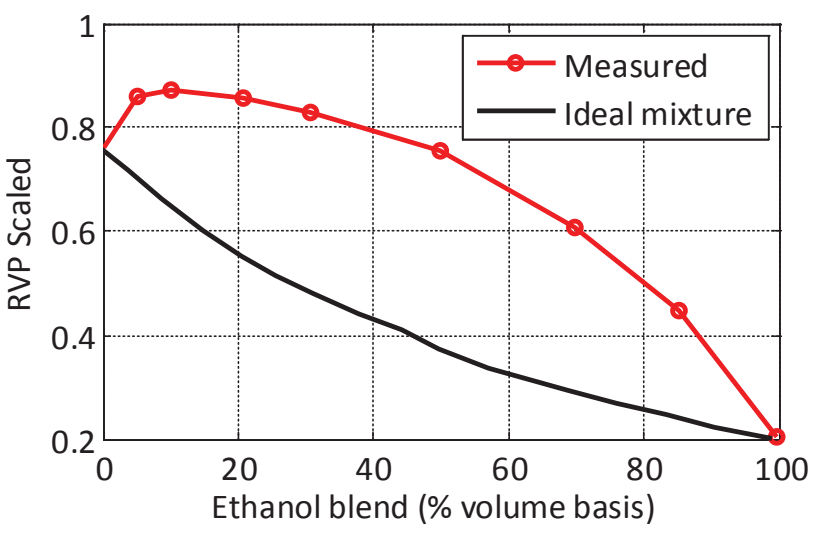
complex interaction of fuel components. This is of significance due to the wider adoption and use of E10 fuel.

Further in a similar study [45] based on experimental testing, the authors found that the ethanol blended fuels with the same RVP, showed different cold start behavior. "The fuel components having lighter carbon chemistry seemed to have higher vapor pressure compared to the other components. Thus butane components were seen to have the highest vapor pressure. Having same RVP, two fuels were expected to show same cold start behavior, but showed radically different behavior with no start for one fuel blend at $-30^{\circ} \mathrm{C}$. They attributed this to the fact that the RVP is measured in a fuel rich condition, while the partial vapor pressure showed a different behavior when fuel quantity is not enough." [10]. We see in Figure 14 that as the fuel injection quantity per liter of air is lowered, the fuel concentration in air-fuel mixture by volume show significant difference even though the fuels had the same RVP. This was further attributed to the lower amount of lighter carbon constituents in E85.

Further they tested

E85 fuel at different temperatures, shown in Figure 12 at temperatures $<0{ }^{\circ} \mathrm{C}$, more than $80 \%$ of the fuel vapor was entirely made up of $\mathrm{C}_{4}$ and $\mathrm{C}_{5}$ components of the fuel.

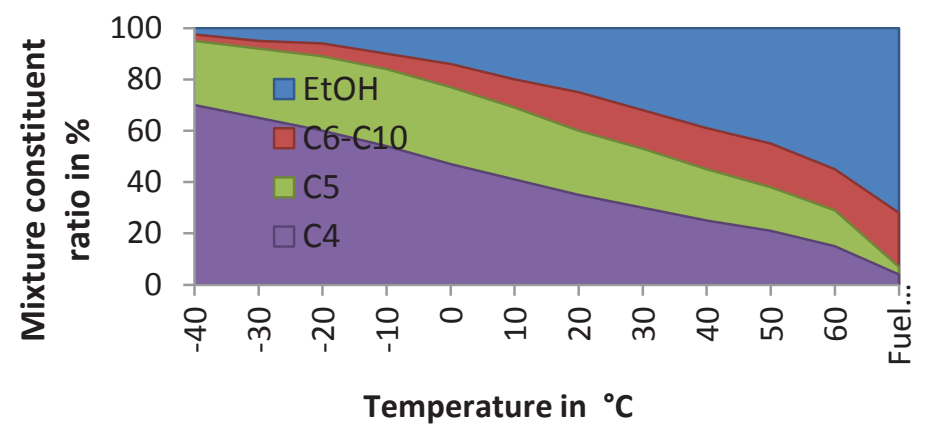

Figure 12 : Mixture constituent's vs. temperature data from [45] 
"Based on the minimum combustible mixture concentration from Le-chatelier principle they found that theoretically they needed greater than $1.6 \%$ fuel vapor concentration with lighter $\mathrm{HC}^{\prime} \mathrm{s}$ in the fuel air mixture. While in practice with the energy the engine needs to turn over for a start, this number increased to $2 \%$ fuel vapor concentration required." [10]

They also studied the effect of

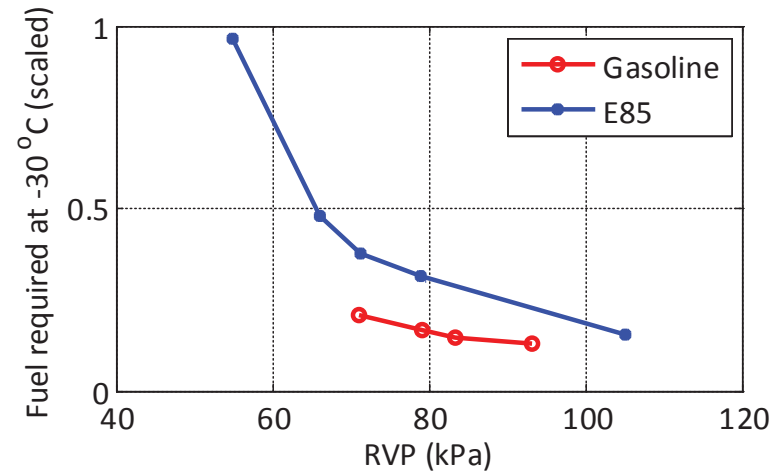

Figure 14: Fuel quantity required vs RVP at $-30 \mathrm{C}$; created based on data in [45]

compression ratio and cranking speed on mixture concentration and found the effects to be minimal. Hypothesizing that the temperature increase due to these were little, as the engine itself absorbed the small increase in energy and there being very small amount of time for the spray to absorb any significant thermal energy. They concluded that some fuels will never be able to form a combustible mixture at $-30^{\circ} \mathrm{C}$. Figure 14 shows that "fuel mixture equivalent to gasoline at $-30^{\circ} \mathrm{C}$ could be obtained by injecting 3 times the fuel or higher RVP of $108 \mathrm{kPa}$ for E85 based on the minimum RVP for the fuel classes. “[10]

An interesting approach to overcome the obstacles for using ethanol as a fuel and at cold start was attempted, in which low temperature reforming of ethanol was done by using engine exhaust heat and a catalyst [46, 47]. They suggested that a reformate $\left(\mathrm{H}_{2} / \mathrm{CH}_{4} / \mathrm{CO}\right.$ mixture) storage device could easily be accommodated on a vehicle. Smooth cold start was obtained due to bypassing the spray mixture formation issues of ethanol and taking it into the gaseous fuel mixture domain.

Further, some of the other issues with ethanol in engines are oil dilution from the fuel spray impingement on the liner[44]; this causes high exhaust $\mathrm{HC}$ when the fuel desorbs from the oil, this has the potential to not only cause issues at cold start but also at high load condition's causing pre-ignition tendencies that are disparate from antiknock properties of ethanol[48].

\subsection{Mixture Formation}

Mixture formation at cold start is a complex phenomenon with surface wetting from fuel sprays being hard to quantify without CFD simulations or extensive experiments. For the first cycle of engine startup, fuel film wetting the combustion chamber walls was found to be the major factor involved in fuel evaporation [49]. Further they noted that at high injection quantities and low temperatures fuel droplets condensed during the compression stroke and condensation appeared to be larger than the evaporation of fuel, 
thus effectively reducing the amount of fuel in the mixture as compression proceeded. Further spark plug wetting was also observed to increase as fueling increased.

\subsubsection{Multiple Injections}

Mixture formation is enhanced by using higher fuel injection pressure as well as multiple injections [51]. Figure 15 shows the effect of multiple ethanol E100 injections on total fuel injection duration; both homogenous charge injection as well as stratification fuel injections are used for the study, with quad homogenous injection found to be the best in terms of fuel required. They also showed that late injections reflect the liquid fuel off the piston, leading to poor combustion, but multiple injections seemed to reduce this problem. A quad injection event showed that there is no fuel wall film formed after the event. They noted that high pressure stratified start alone does not lead to safe ethanol start due to high amount of wall film formed. But rather the start needed to be comprised of homogenous split injections along with stratification charge.

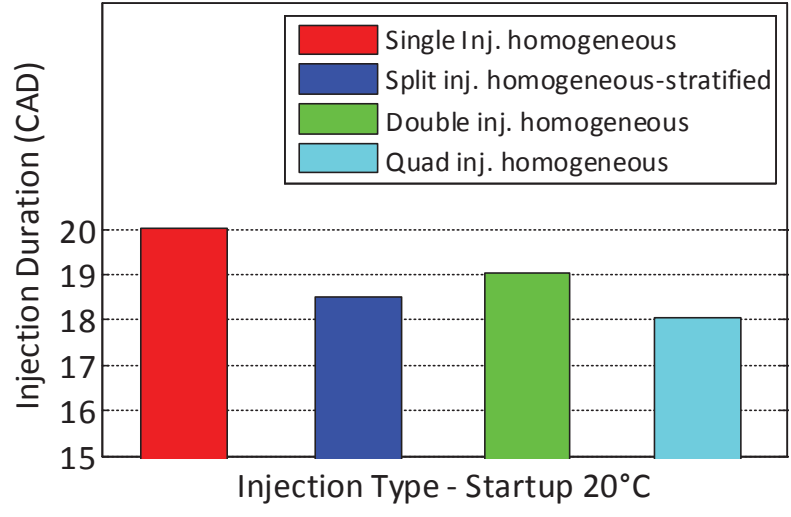

Figure 15: Effect of multiple injections on injection duration with ethanol Hom: Homogenous Ethanol: E100 ; created from data in [50]

Using CFD to guide their analysis, researchers at Ford found out the amount of surface wetting, fuel vapor and AFR ratio at spark timing for cold start with different injection strategies[5], the summary of which is shown in Table 2.

Fixing the fuel pressure at 5bar, they compared single injection and split injection strategies; found that optimum injection strategy changed with engine speed. They also noted that single injections carried over fuel to the exhaust side. With split injection strategy it was possible to reduce piston wetting, reduced exhaust HC emissions by $30 \%$. Further the end of first injection seemed to strongly influence the flow field in the

Table 2: Injection Strategies at 200 RPM created based on data in [5]

\begin{tabular}{|lccccc|}
\hline Strategy for Injection Timing & $\begin{array}{c}\text { Stratified } \\
\text { Single }\end{array}$ & $\begin{array}{c}\text { Intake- } \\
\text { Compression }\end{array}$ & $\begin{array}{c}\text { Compression- } \\
\text { Compression }\end{array}$ & $\begin{array}{c}\text { Homogenous } \\
\text { charge Single }\end{array}$ & $\begin{array}{c}\text { Intake- } \\
\text { Intake }\end{array}$ \\
\hline End of Injection & 40 & 260,30 & 75,30 & 260 & 260,220 \\
\hline Fuel Surface Wetting (\%) & 65.2 & 58.7 & 59 & 60.2 & 50.7 \\
\hline \% Vapor fuel & 34.4 & 36.1 & 40.3 & 32.8 & 39.8 \\
\hline Air-fuel ratio near spark plug & 13.6 & 16.5 & 14.8 & 19.9 & 16.7 \\
\hline Lambda near sprak plug & 0.92 & 1.12 & 1.01 & 1.35 & 1.13 \\
\hline Mixture distribution quality & worst & worse & bad & best & better \\
\hline
\end{tabular}


cylinder and interacts with the second injection to create the fuel cloud near the spark plug. Hence careful optimization of the end of first injection is suggested.

Testing various fuel split ratios for multiple injections is time consuming and the work involved expands quickly as more and more fuel injections are introduced into the experimentation. In a model based approach to understanding the issue of dual injections and their split ratio, the authors[44] noted that intake temperature significantly impacts the optimum split ratio, with higher temperatures preferring lower share of the second injection. Thus injection split ratios found at a given temperature will change at a lower temperature, hence it compounds the work involved in experimentation even more.

\subsubsection{Charge Motion}

The effect of swirl and tumble on mixture preparation has also been studied [53], the authors noted that the Gasoline DI (GDI) engine was more prone to piston wetting and insufficient fuel-air mixing, which required a careful optimization of the injection timing and fuel injection spray pattern. This vaporization and mixing characteristic could be improved by swirl or tumble in the cylinder. Swirl component of the intake air flow is preserved throughout compression stroke, thus is favorable for stratified charge, while tumble component is transformed into turbulence near TDC, giving a more homogenous mixture. Figure 16 shows HC emissions vs. startup cycle number for the three conditions outlined as unmodified baseline, strong swirl and strong tumble, the lowest HC emissions being for the tumble case. They also characterized the effect of swirl and tumble by studying the spray images in terms of average and COV of the pixel intensity representing the vaporization and air-fuel mixing characteristic shown in Figure 17; the greatest advantage to vaporization being provided by strong tumble. They found another advantage swirl and tumble flow provided was that it allowed delayed ignition timing which allowed more time

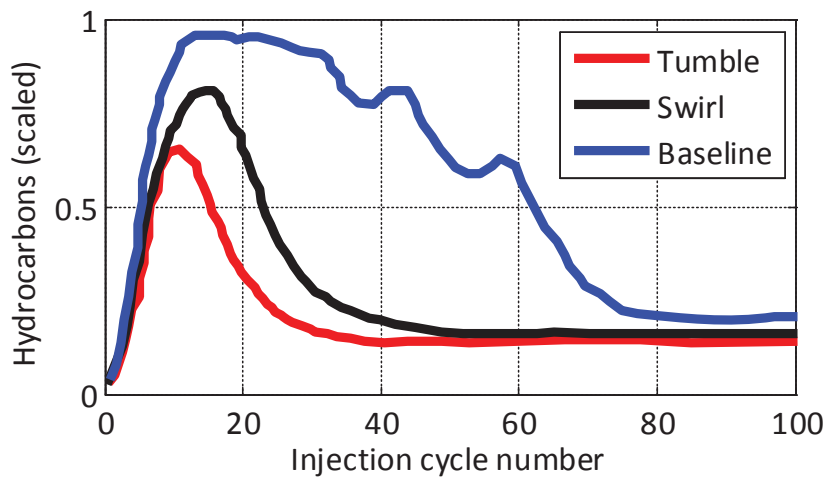

Figure 16 : HC reduction comparison for optimized swirl and tumble only configurations; created based on data in [52] for fuel vaporization and mixing. 
The term Turbulent Kinetic Energy (TKE) is also used to study the impact of factors affecting the airflow in the cylinder. Thus it can be considered that swirl, tumble, squish, etc. are factors that can be used to change the TKE available in-cylinder for use in the fuel-air mixing process. Combustion process is significantly influenced by the TKE at firing TDC; further charge velocity at the spark plug

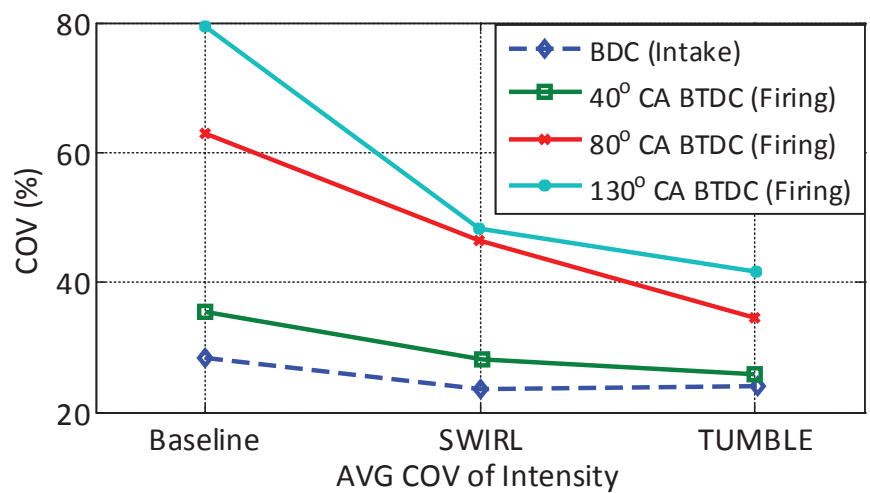

Figure 17 : Comparison of swirl and tumble only configuration for intensity and $\mathrm{COV}$ [52] during ignition process dictates the burn rates for the fuel air mixture; while the overall charge motion also influences the heat transfer to the combustion chamber[54].

Steady state studies give us some representative target values for the in-cylinder TKE and flow velocities. Further, a minimum target value for bulk in-cylinder TKE had been mentioned to be $25 \mathrm{~m}^{2} / \mathrm{s}^{2}$, nominal engine development target was $45 \mathrm{~m}^{2} / \mathrm{s}^{2}$; while the charge airflow velocity at the spark plug had to be less than $10 \mathrm{~m} / \mathrm{s}$ [55]. It is also noted that in general TKE increases as engine speed is increased[56]. Simulations provide a means of estimating the available TKE and ability to study the means to influence it. Further CFD can provide 3D analysis of the flow in-cylinder allowing study of swirl and tumble components; while simulation tools like GT-POWER can give 1-D crank angle resolved analysis of TKE.

A way to generate charge motion on demand is by using charge motion control valves, these valves would be held in an actuated state at cold start. A study[57] found that blocking the intake port up to $75 \%$ using the $\mathrm{CMCV}$ caused the mixture preparation improvements, faster burn rate, causing 50\% mass fraction burn of the fuel (CA50) to occur up to $5^{\circ} \mathrm{CA}$ before baseline and improved combustion stability and fuel efficiency. Fuel mass fraction burn of 0-10 was reduced by up to 8CA during 0-3 seconds of startup using $\mathrm{CMCV}$. Further, they were able to get richer mixture for the same fueling, allowed them to reduce the fueling, increase spark retard due to faster burn rate, resulted in $18 \%$ reduction in engine out HC's for 0-3 seconds of cold start and 7\% during 3-20 seconds.

It has been noted that synchronizing the injection timing with intake valve opening offers benefits for cold start with PFI injectors[58].

It has also been seen that there are vortex like structures in the fuel spray and mixture in the cylinder[59]. The authors found that the spray consists of three distinct periods: initial unsteady, quasi-steady and exponential trailing phase. They conclude that the structures were observed in the decaying phase of sprays. The vortex like patterns had spots of radial velocity close to zero for both Port Fueled Injection (PFI) and DI sprays. Traditionally the parameters considered in sprays are spray penetration 
length, cone angle and droplet distribution. Some other researchers have noted being able to control these vortex pattern formation using injection timing and used it for mixture preparation benefit.

\subsubsection{Exhaust Gas Residuals (EGR) Usage}

There is a limit to the maximum EGR tolerated during combustion; stability decreases as EGR increases, increasing the IMEP COV. This is true both for internal EGR/residuals and external EGR. Higher EGR also enables higher charge temperature for the next cycle at cold start thus improving the spray vaporization characteristics and reducing emissions, which is very desirable at cold start. Higher EGR also results in lower heat loses and increase in gamma of the combustion products, thus also improving thermal efficiency[60].

A different approach to the cold start mixture preparation was executed by using a design to achieve EGR stratification in cylinder along with compound injection (DI+PFI), this achieved better mixture preparation by generating a quasi-homogenous charge and the HC emission during cold-start decreased by up to $50 \%$. Further an radial EGR stratification concept in which specially designed intake system was used achieved EGR tolerance up to $40 \%$ without influence on ignition[61], its hypothesized that this would also benefit cold start significantly. Alger et.al[62] reported a novel continuous discharge ignition system that could allow higher EGR tolerance.

\subsubsection{Mixing at cylinder wall boundary layer}

The spray-wall interaction is very important in influencing the mixture formation and particulate emissions; a model for which was developed[63] enabled determining the influence of SOI and fuel pressure on wall film mass and mixture properties on a crank angle basis. Further it is noted that at the boundary layer, the heat transfer and fuel mixing processes are poorly understood[64]. Heat transfer significantly influences the fuel evaporation at the boundary layer which in turn depends on the velocities in the boundary layer. Normally the log-law is used to predict these velocities, but the actual velocity at the boundary layer is over predicted for 180-260 crank angle ${ }^{\circ}$ aTDC, under predicted for 300-330 crank angle ${ }^{\circ}$ aTDC by the log-law[64]. This will also impact models used to predict the fuel-wall interaction. In another study flame wall interaction and heat flux was compared with experimental, conventional 1-d heat transfer model and simulation data[65]; significant peaks of heat flux were noted as the flame reaches the wall. This peak is not accommodated very well with existing heat transfer models. 


\subsection{Spark Timing at cold start}

Spark advance is a unique control parameter that has a significant impact on cold start. It influences not only the Indicated Mean effective pressure (IMEP) generated but also the emissions. While the effect of spark advance on IMEP is generally well known by means of MBT spark timing, experiments at cold start temperatures can offer

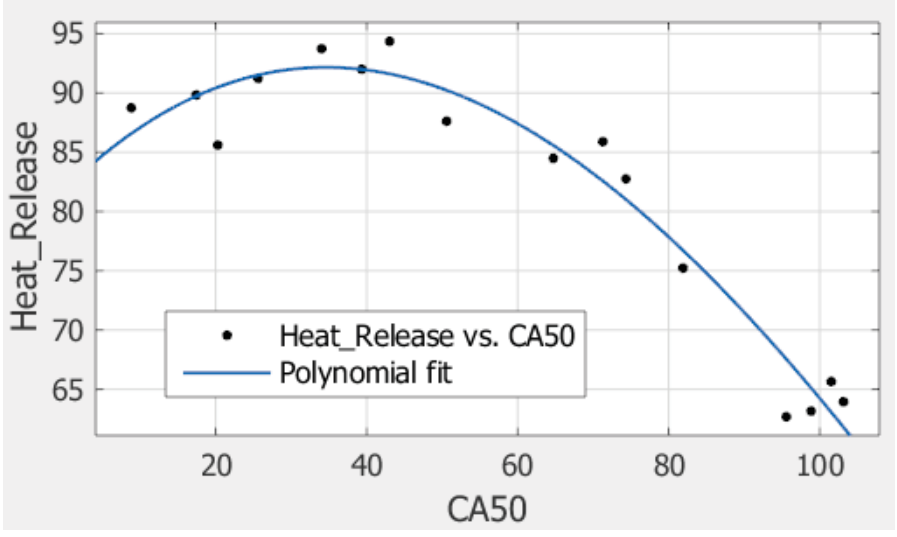

Figure 18: Heat release(\%) vs CA50 at $1200 \mathrm{rpm}, 2.5 \mathrm{bar}$ IMEP, 20C; generated based on data in [3] deeper understanding to know its influence on exhaust HC's. We note that spark advance is directly co-related with 50 percent fuel burn location in crank angle (CA50).

Shown in Figure 18 is the average heat release at cold start temperature plotted vs. CA50 [3]; it shows that beyond a certain value of CA50 where the heat release is maximum, higher CA50 leads to decrease in heat release in-cylinder. To understand impact of spark advance on exhaust HC's, we need an understanding of the HC storage mechanisms, these were highlighted by James A. Eng from General Motors Research [66], where he used premixed, pre-vaporized gasoline in PFI engine. Further the author developed a 0-D ring pack crevice flow model; the mass flow into the crevice are shown in Figure 19 as a blue curve. It was seen that the mass flow into the crevice reverses at

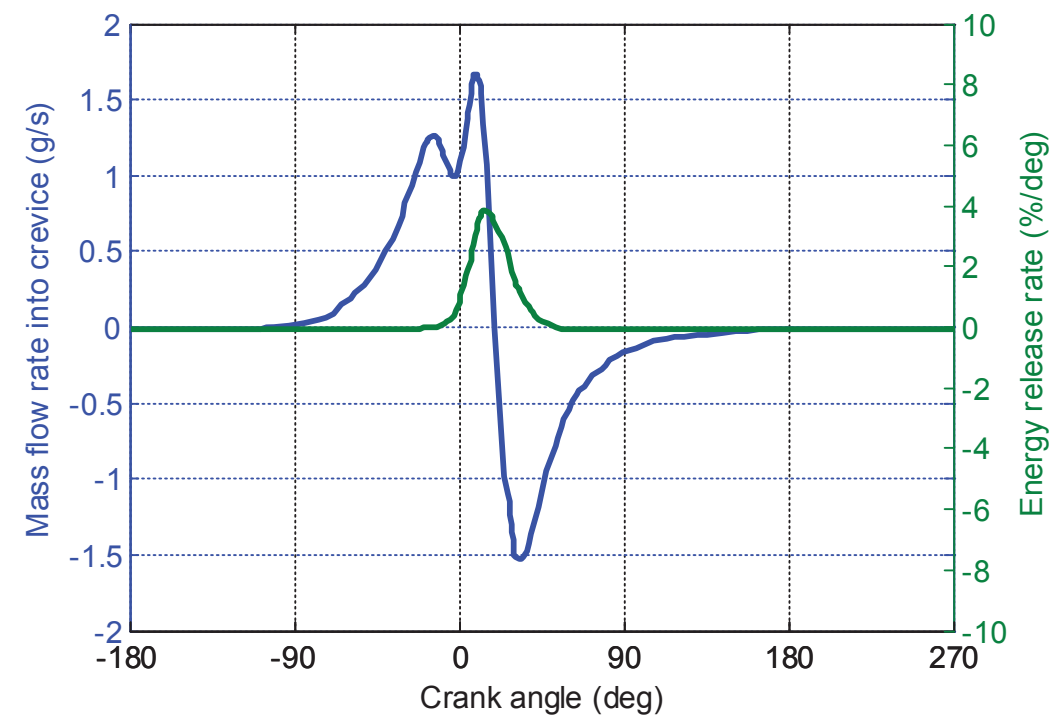

Figure 19: Mass flow into crevices vs engine crank angle; generated based on data in [66] 
approximately $20^{\circ}$ aTDC. From the multiple sources of HC storage in cold start, he noted that with high enough burned gas temperature, the quench layer HC's were rapidly consumed. He also noted from literature that the cut-off temperature for exhaust HC consumption was 1300-1500K. (HC Consumption: Complete conversion of fuel into $\mathrm{CO}, \mathrm{CO}_{2}$ and $\mathrm{H}_{2} \mathrm{O}$. $\mathrm{HC}$ conversion: Partial oxidation of fuel into smaller $\mathrm{HC}$ species.) Thus expansion stroke is completed before opening the exhaust; the exhaust temperature potentially could drop below the $1300 \mathrm{~K}$ needed for exhaust $\mathrm{HC}$ consumption. And thus there might be an increase in $\mathrm{HC}$ and $\mathrm{CO}$ emissions.

While oil layer absorption was found to be approximately $5-10 \%$, the ring pack was estimated to contribute from $30-90 \%$ of all HC storage. The ways the emissions are generated was explained by means of a conceptual model by the authors where the HC's were reintroduced into the cylinder by the gas flow out of the crevices.

Further, internal residuals have a profound effect not only on the combustion process but also on the emissions coming out of the engine. The authors discuss a simplified model to account for the net HC's in the exhaust based on the residuals as shown in Equation 1, where $\mathrm{Xr}$ is the residuals fraction. Even though it is very simplistic, the equation does impress the effect high residuals could have on the HC emissions reduction. Internal residuals being a function of intake and exhaust cam timing are easy to be controlled via cam timing.

$$
H C_{\text {gross }}=\frac{H C_{n e t}}{1-X r}
$$

Equation 1

Since CA50 is a linear function of spark advance used for combustion, and exhaust temperature being a linear function of CA50; the exhaust temperature can be estimated by a linear equation of the form with respect to spark timing. Further as noted in [67] an empirical relationship can be established as shown in Equation 2.

$T_{\text {exh }}=7.5 \Delta S T(C A)$

Equation 2

An attempt to extend this equation based on the temperature offset between lean and rich conditions and generalize it is made, shown in Equation 3.

$T_{\text {exh }}=C_{1} \Delta S T(C A)+C_{2}{ }^{\circ} C+C_{3} \Delta A F R$

Equation 3

This could reasonably accommodate changes in AFR up to reasonable AFR limits from Stoichiometric AFR.

The author[66] also noted that HC emissions from an engine scale inversely with diffusion co-efficient of fuel, thus the oxidation process is mixing limited. (For iso-octane diffusion time was noted as 10-20 ms for a boundary layer of $0.3-0.5 \mathrm{~mm}$.)

As the spark is retarded and CA50 increases beyond $50{ }^{\circ}$ aTDC, for lean burn the exhaust blow down increases the residence time available for the $\mathrm{HC}$ oxidation into the exhaust port with $\mathrm{O}_{2}$ being available. Majority of $\mathrm{HC}$ consumption takes place in- 
cylinder by the flame as shown in Figure 20 by the line for crevice HC after CA90. Further the comparison of lean and rich mixture HC's as shown in Figure 21 allowed them to note the point at which the HC conversion incylinder stopped being the dominant factor, as the high swirl rich case indicated beyond CA30.

They noted that as the spark retard increased, HC emissions reduced due to smaller crevice volume fraction at the end of fuel burn, and increased the oxidation in the exhaust port.

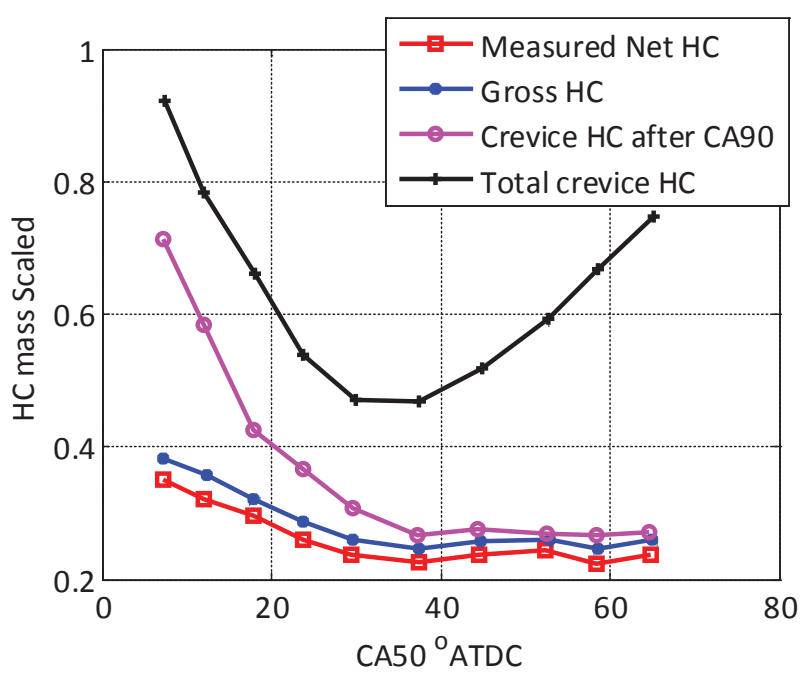

Figure 20: HC accounting vs CA50 in rich, high swirl conditions; created from data in [66]

It was also noted that flame quenching and misfires might not contribute to increase in variation of IMEP as spark is retarded; but rather CA50 variation influences IMEP produced[21].

The speciation of the exhaust HC's is also affected by spark retard. They noted that with more spark retard changes to the exhaust $\mathrm{HC}$ speciation were observed leading to more $\mathrm{C}_{2}-\mathrm{C}_{3}$ and decreasing the $\mathrm{C}_{6+}$ chain $\mathrm{HC}^{\prime}$ s. Also they noted that more spark retard lead to lower $\mathrm{HC}^{\prime}$ s during first 20 seconds.

They adjusted the spark retard for lower emissions by changing it from -17 to -10 ${ }^{\circ} \mathrm{bTDC}$, while increasing the idle speed to compensate for the lowering of the exhaust heat, while lowering the excess fueling toward stoichiometric to lower the $\mathrm{HC}^{\prime} \mathrm{s}$ generated. They were able to achieve 21\% lower FTP75 bag1 NMHC emissions with this strategy.

Further too much Spark retard is known as a possible cause of misfires. The robustness of firing at spark retarded conditions can be largely optimized by using multi-spark ignition, which has been demonstrated to decrease the COV and misfires by adding additional ignition energy into the mixture [68].

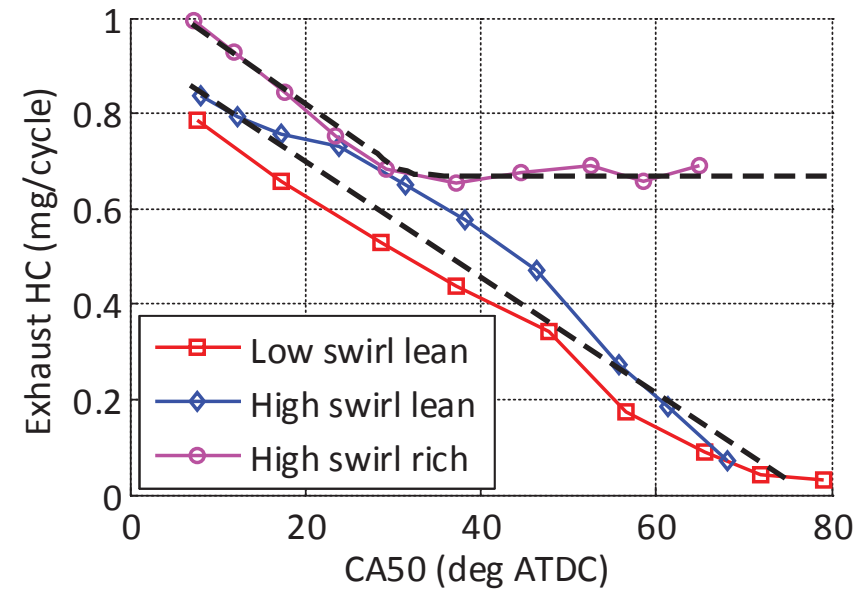

Figure 21: Exhaust $\mathrm{HC}$ vs $\mathrm{CA50}$ at lean and rich conditions; created from data in[66] 
The higher exhaust temperatures at spark retard could also lead to cracking of the larger chain $\mathrm{HC}^{\prime}$ 's into smaller chain $\mathrm{HC}^{\prime}$ s, thus leading to lower HC trap efficiency at higher spark retard. Also noting that at higher exhaust temperatures the adsorbtion and desorbtion phases of the trap overlap especially for weakly adsorbed species like lower chain $\mathrm{HC}^{\prime}$ 's, leading to lower trap efficiency. Further even with faster HC trap heating and sufficient oxygen, some $\mathrm{HC}^{\prime}$ s are desorbed unconverted, thus there seems to be a reaction rate limit which was not affected by heat or $\mathrm{O}_{2}$.

An novel closed loop strategy based on Ion signal sensing was used[69] for cold start misfire detection with GDI engine, reignition or reinjection in expansion stroke and reignition can be attempted based on the feedback signal. If both fails fuel and spark for the next cycle is adjusted. This had the potential to eliminate no fire or misfire condition's which can result in extreme emissions.

\subsection{Literature Survey Summary ${ }^{2}$}

Large portions of the literature available has been focused on piston shape, spray patterns, air flow analysis, fuel-air mixing and understanding effects of spark retard.

Some important parameters that stand out in the literature are the spray characteristics including cone angle, piston/cylinder wetting, SOI, fuel pressure and multiple injections. Some of the hardware based options have tradeoffs with respect to steady-state engine performance, including options such as bowl piston depth and spray cone angle.

While heated injectors and hot air intake are proven to work, they also have startup time and cost implications for engines. Using them as guiding blocks, we can conclude that any technique that raises the in-cylinder gas temperature at injection has potential to reduce the cold start problems. The analysis of a number of hardware options showed using valve timing to be a significant method of raising the in-cylinder gas temperature for mixture preparation benefits with ethanol [22]. While others including partial lift and injection timing just after intake opening also showed potential for better fuel-air mixing.

The practical problems while dealing with low pressure injections were highlighted in[35]. Finally, an important vaporized fuel concentration number $-2 \%$ based on volume that is necessary to get a reliable startup for gasoline was noted[45], is 6\% for E85.

$\mathrm{CMCV}^{\prime}$ 's are proven to work to increase engine startability. Detailing and using the TKE generation options including swirl, tumble require either detailed 3D CFD simulations or extensive optical analysis work.

The control variable SOI is one of the easiest to change via ECU calibration. Due to its large impact on mixture preparation process, it is chosen as one of the important

2 Contains extracts/text from SAE publication on engine startup published as a result of this thesis work[10. Ibid. 
variables that needs studying. Further internal EGR is also of interest due to its impact on mixture temperature, ability to be controlled by cam positions.

"Of these many studies have analyzed ethanol behavior in comparison to gasoline; the analysis of ethanol and gasoline differences by Aikawa et.al [45] would be one of the more comprehensive ones, since they are able to show that RVP as a differentiation factor between fuels is inadequate to portray fuel characteristics. Since RVP is the mandated criteria for fuels today, there is little that can be done with regard to fuel differences within the same RVP. "[10]

Spark advance has been studied in detail in the literature, and its effect on heat release/IMEP, CA50 and exhaust HC emissions are well researched.

Multiple injections seem to solve considerable problems with regards to cylinder/piston wetting. While using multiple injections and finding the optimal injection split ratios is time and resource intensive effort, needs experimentation across temperature range for it to be useful in real world engine implementation.

"These studies have been mostly focused on a very specific portion of cold start, there is a lack of an overall study that combines various control parameters at injection, SOI, fuel pressure, intake and exhaust timing along with compression ratio and piston geometry. There is also a lack of cycle by cycle understanding of engine startup where in each cycle of the cold start is optimized; with the next cycle being optimized based on the previous optimized cycle."[10]

Thus the intent of this research is to determine the equivalent ratio required for fueling that gives robust combustion for engine startup on a cycle by cycle basis, while also reducing emissions. 


\section{Research Setup}

Engine startup testing is unique in terms of the requirements it imposes for accurate results compared to steady state testing. In general since engine startup has steep speed transients, each cylinder fires at a different engine speed, MAP. Due to inherent speed and IMEP variations during the speed run-up, replicating startup cycles on a startup cart is difficult. Further multi-cylinder engine setups also suffer from issues due to cylinder to cylinder variability. Single cylinder engine avoids most of these issues, is deemed to be the most feasible option for this startup testing. Further ability to externally control the engine and coolant/oil temperature to startup conditions brings it thermally very close to actual engine startup event as possible.

\subsection{Single Cylinder Research Engine}

The single cylinder research engine "Hydra" used in this research is based on GM Ecotec LAF engine model and is similar to Ricardo Hydra engine platform. It is a modification of the $88 \mathrm{~mm}$ bore GM LAF design, adapted down to $86 \mathrm{~mm}$ bore for the Hydra engine. Figure 22 shows the engine mounted on the Hydra test stand with the flywheel mounted on the engine crankshaft. Table 3 shows the engine specifications.

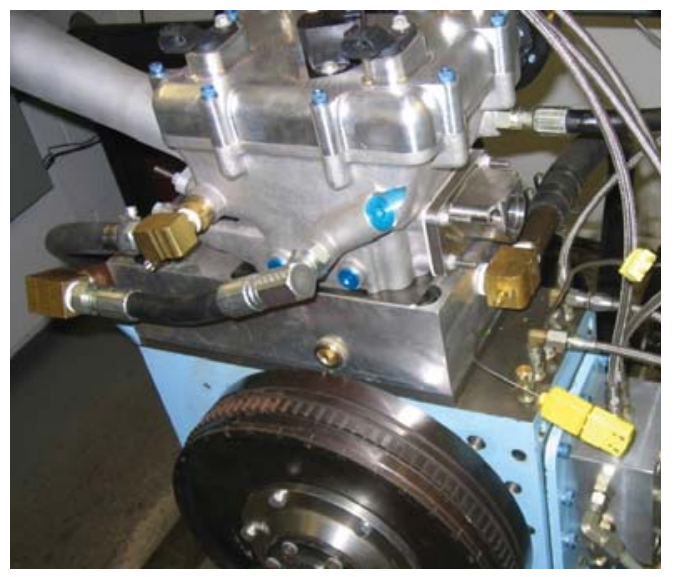

Figure 22: Hydra Single Cylinder Research Engine on a test stand

Table 3: Hydra Single cylinder engine specifications

\begin{tabular}{|l|l|}
\hline Displaced volume & $550 \mathrm{cc}$ \\
\hline Stroke & $94.6 \mathrm{~mm}$ \\
\hline Bore & $86 \mathrm{~mm}$ \\
\hline Connecting Rod & $152.5 \mathrm{~mm}$ \\
\hline Compression ratio & $11-15.5: 1$ \\
\hline Number of Valves & 4 \\
\hline Cam Timing & Dual independent cam phasing \\
\hline Injector & Side injection, Solenoid 6 hole $110^{\circ}$ cone angle \\
\hline
\end{tabular}


Also seen are the engine crankcase, block and coolant and oil connections. The engine head with open cam cover is shown in Figure 23, the intake and exhaust cams with the cam position sensors and the cam phaser's are seen in the top portion of the figure.

\subsubsection{Cylinder Head Design}

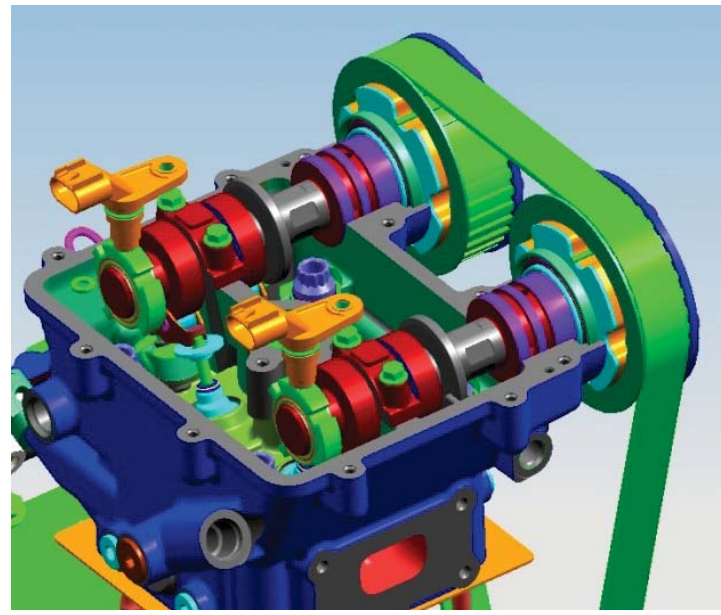

Figure 23 : SCRE cylinder head CAD model

The engine design is based on GM LAF engine family (direct injected 2.4 L), with the combustion chamber scaled down to match the reduced bore design; the spark plug is located in the center. The head has two intake and two exhaust valves with valve geometry based on eco-valve design and with ports for two miniature pressure transducers. Valve-train actuation is roller finger follower mechanism type with hydraulic lash adjusters. The cam phasing is hydraulic dual independent actuation with 64 crank degrees of authority. The fuel injection system consists of high pressure direct

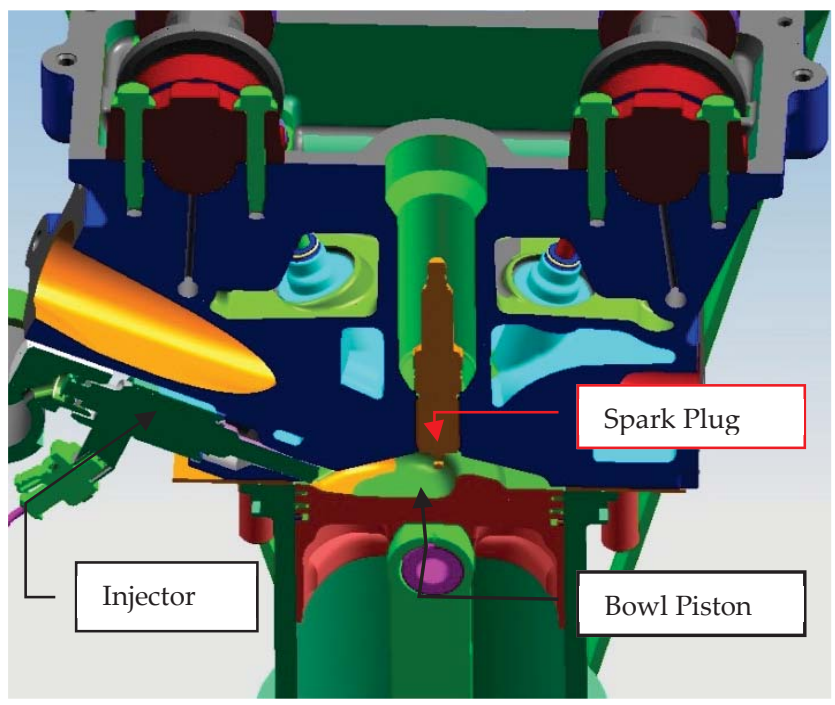

Figure 24 : Section view of cylinder head showing injector, spark plug and piston position 
injection with a Bosch HDEV5 injector at $23^{\circ}$ to deck face. Figure 24 illustrates the geometric configuration between injector, spark plug and piston position; the injector tip provides $22^{\circ}$ of downward angle to give the spray pattern a total of $45^{\circ}$ to the deck face. The spray pattern has a cone angle of $110^{\circ}$ with 6 holes. More details are available in Master's thesis by Brandon Rouse[20], who setup the engine initially.

\subsubsection{Crank-Train}

The shorter throw and the smaller bore of the Hydra engine maintain a nearly constant bore to stroke ratio with respect to the parent LAF engine. Several different pistons were produced for achieving different compression ratios[20]. For the purpose of this testing only one flat top piston: 11 Compression Ratio (CR) and two bowl pistons - 11 \& 15.5 CR were chosen for phase 1 testing, 11 CR flat top piston was used in phase 2 testing; details for each piston are shown in Table 4.

\subsubsection{Piston Design}

Table 4: Piston design details along with compression ratio and type

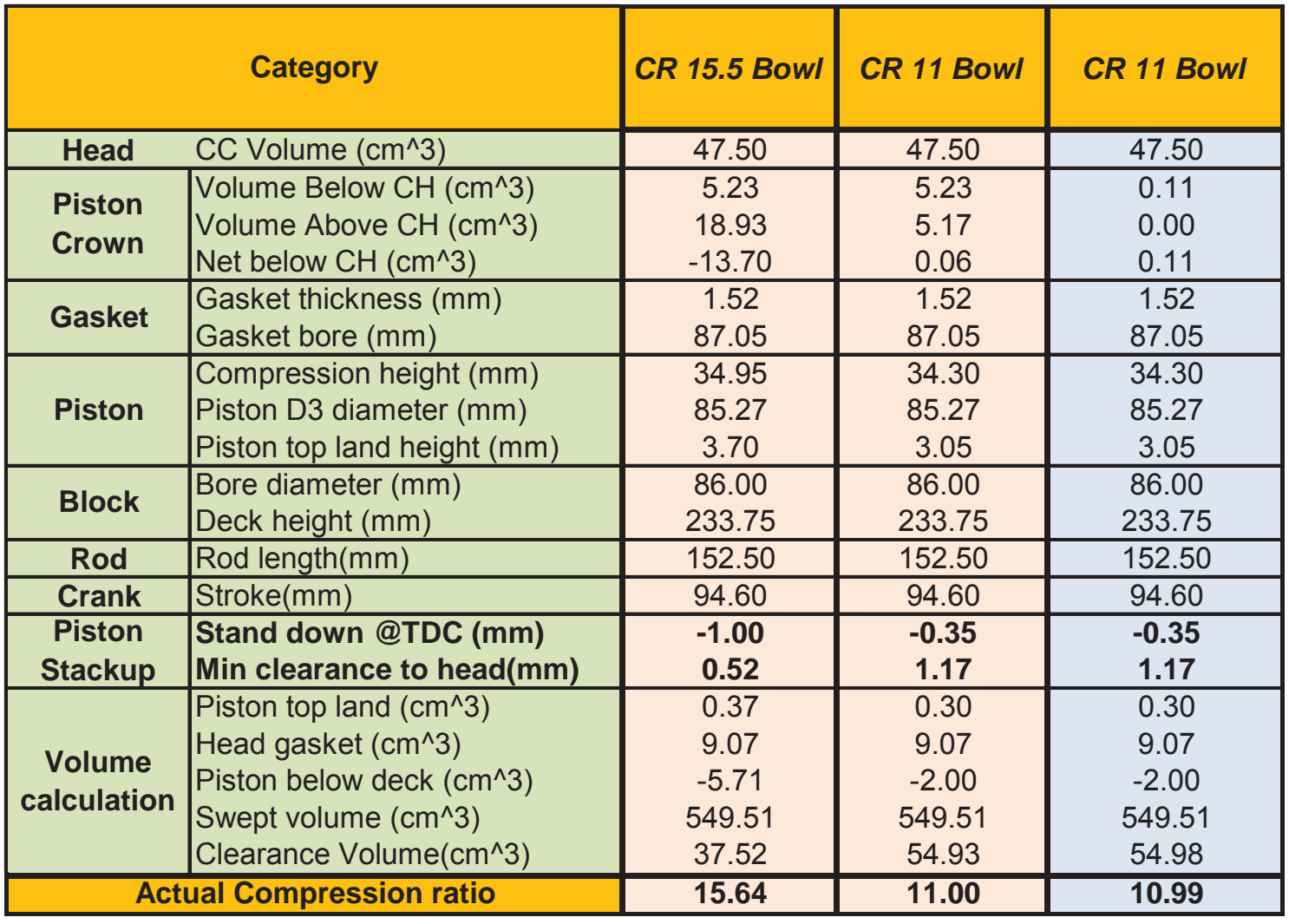

The pistons were designed with consideration for valve clearances from piston surface, thus they have valve cutouts to avoid interference and cutouts are also made for 
the spark plug. Though this meant that the piston surface area for different shapes were considerably different.

\subsubsection{Engine Block}

The engine block has a cast iron base with housings for crankshaft bearings. A single large $68 \mathrm{lb}$. flywheel with inertia of $10.7 \mathrm{lbm}-\mathrm{ft}^{2}$ is used to increase inertia and reduce speed and torque fluctuations. The flywheel has angle markings in degrees and marking is also made for the TDC location, allowing ease of retiming of the engine. The shaft used was custom designed by Raven engineering and has a U-joint, GCV coupling. This shaft design was found to work well for the $180 \mathrm{rpm}$ cold start work, rather than the standard flexible prop-shaft used for steady-state testing, which had too much flex in the couplings. More details are given in setup modifications section on page 43.

\subsection{Laboratory Test Setup}

The engine test lab for the phase 1 testing had a Direct Current (DC) dynamometer mounted on a bedplate along with the Hydra research engine platform. The dynamometer was driven with 430 VDC by a GE DC2000 controller and rated at 141.7 $\mathrm{kW}$ at $10000 \mathrm{rpm}$. The second phase of testing involving 3 cycle testing for emissions was conducted in a different testcell which had an $11.1 \mathrm{~kW}$ DC dynamometer limited upto $3600 \mathrm{rpm}$ speed driven at $250 \mathrm{~V}$ by a Mentor II controller. The engine is mounted on the cushioned platform manufactured by Cussons Technology (Serial number: SN P8803/116) along with the chosen prop shaft. According to Cussons the test stand was designed by Ricardo.

\subsubsection{Engine Coolant System}

The coolant system is closed loop driven by external impeller pump, the schematic of which is shown in Figure 25.

The system for the first phase of testing consisted of an Omega CN77333 temperature controller that switched on and off a zone flow control valve. The controller has a temperature input from a silver slug thermocouple that is plugged into the cylinder pressure transducer port and is flush with cylinder wall. This arrangement allowed coolant flow to the radiator to be switched on and off so as to maintain $25{ }^{\circ} \mathrm{C}$ engine head temperature. A heat exchanger cools the oil down to coolant temperature. 


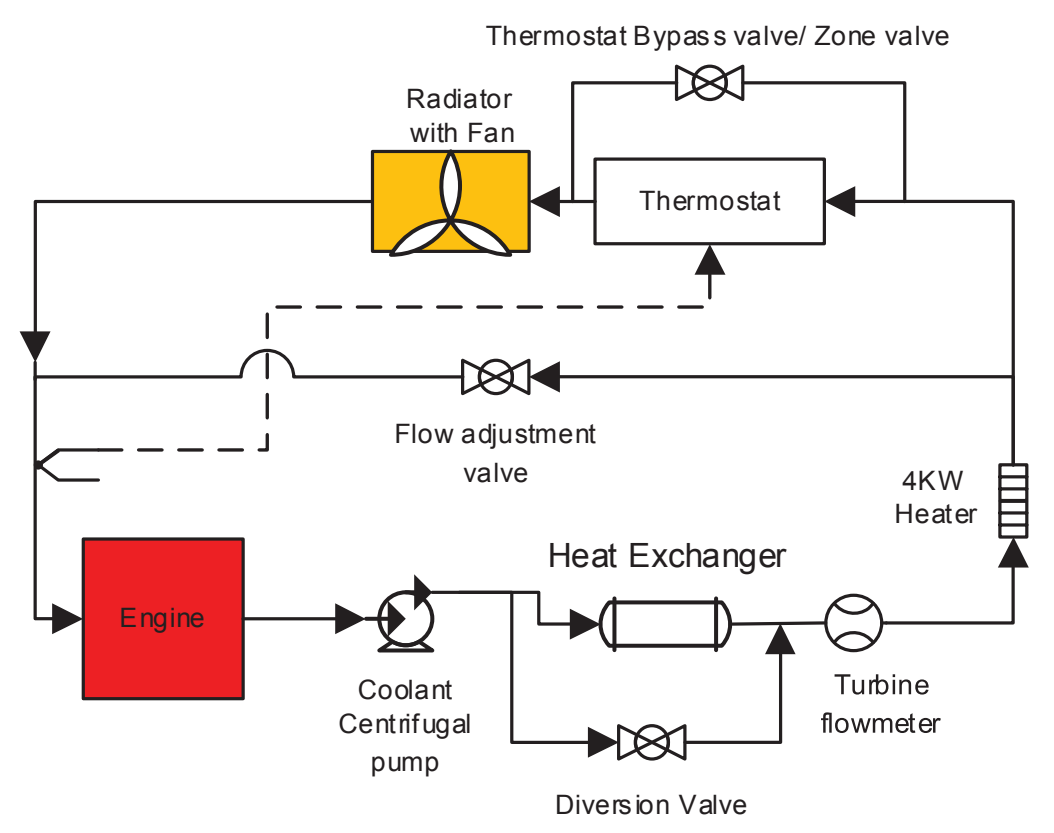

Figure 25: Engine Cooling schematic used in $1^{\text {st }}$ phase testing

The previous cooling system was found to have a long response time to bring the engine back to previous conditions. This was improved in a new setup as shown in Figure 26 involving the second phase of testing when the engine was moved to a different testcell. The cooling method was switched to a water cooled coolant heat exchanger instead of radiator style cooling. Further the coolant heat exchanger temperature is controlled by an Omega CN77333 temperature controller which actuates a solenoid valve that allows water flow through the heat exchanger to keep it within a $2^{\circ} \mathrm{C}$ range of $25^{\circ} \mathrm{C}$. This helps to avoid long temperature oscillations in the system. The water flow control solenoid valve (Mcmaster Carr 7944K242) has maximum pressure of 15.9 bar and temperature range of $-10^{\circ} \mathrm{C}$ to $137.8^{\circ} \mathrm{C}$. Further due to metal and rubber tube corrosion issues found in the previous cooling system, the new one was made mostly of brass fittings and silicone hoses that withstand higher temperatures, corrosion protective zinc anodes were installed at multiple locations in the cooling system. A diesel engine coolant filter was installed to filter out any impurities/materials that might be in the cooling system.

The original coolant stand in the Hydra test stand was used again to fit two new heaters into the coolant and oil system. The coolant heater conditions the coolant entering the engine to an appropriate constant temperature; this heater was fitted with a new temperature controller CAL Controls 9500, that modulates the power available to the heater via phase angle controller SSRMAN-1P-PWM SOFTSTART/random fire relay NWT-40HDA-10 to maintain stable and accurate desired coolant temperature $\left(< \pm 0.5^{\circ} \mathrm{C}\right)$ 


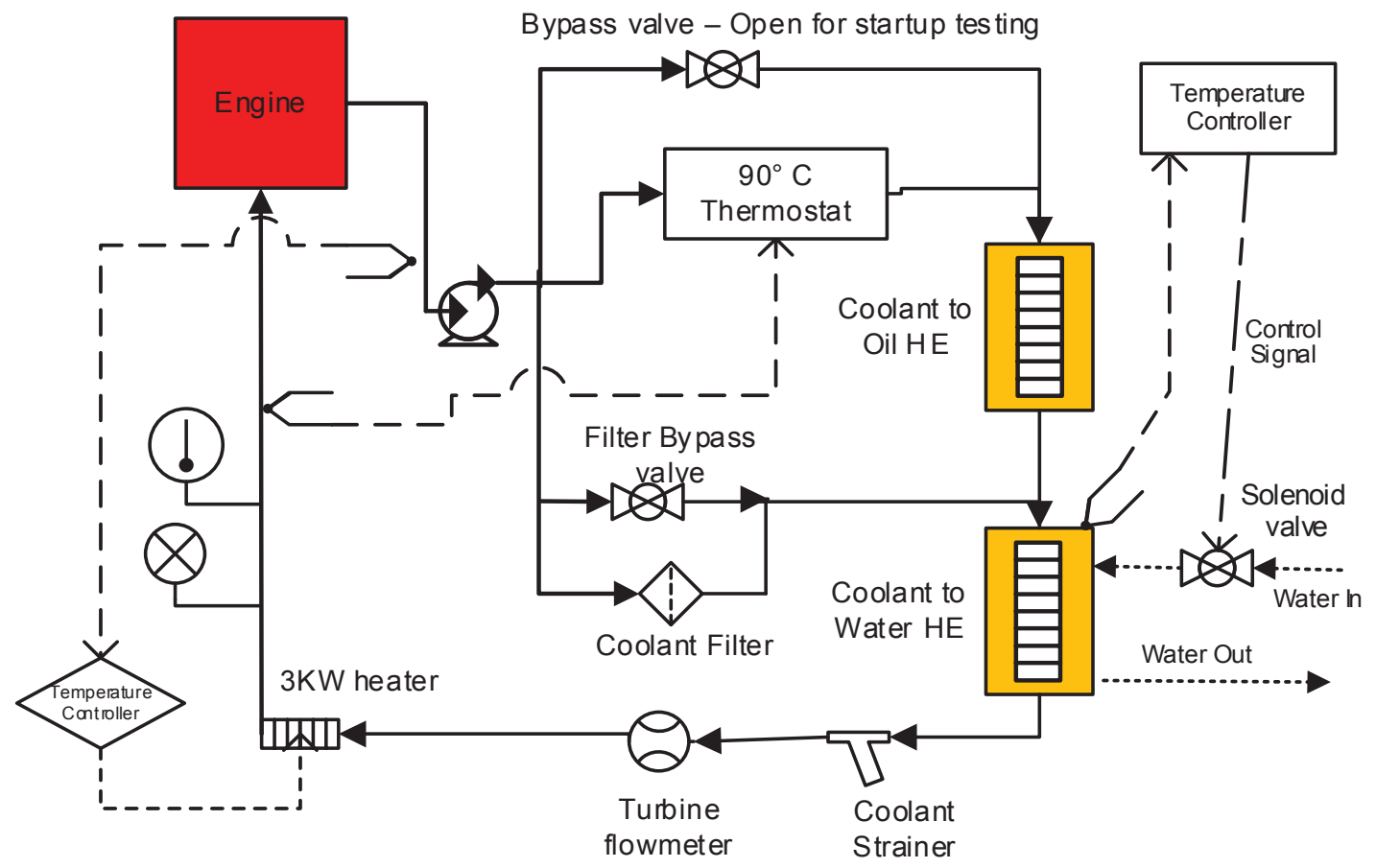

Figure 26: New Engine Cooling schematic

A thermostat bypass valve was also incorporated in the system with the ability to divert all coolant through the coolant-water heat exchanger instead of the thermal flow control valve. This allows the coolant minimum temperature to be brought down close to the water supply temperature. Quick-disconnect couplings with shut off valves were installed on the engine coolant inlet and outlet to make changing engine timing belt or removing the engine head easier; thus eliminating the need to drain the coolant before performing those procedures. Coolant/oil heaters and pump control logic was rewired so that they are all shut-off when dynamometer emergency stop is activated.

\subsubsection{Engine Lubrication System}

The engine oil system is driven by a high voltage gear pump, the schematic of which is shown in Figure 27. The engine block in the SCRE system consists of an oil pan, which is the intake for the oil pump. The oil pressure at the output of the pump is then regulated with a adjustable pressure relief valve (Mcmaster carr - Precision-Adjustable Valve- $1 / 2$ " pipe) and oil pressure is monitored by a pressure transducer. This pressure regulated oil flow goes to the crankshaft, cam phasers and engine valve-train. A turbine style Omega FPR-200 Series flow-meter measures the oil flow rate and sends the signal to the data acquisition. 
The previous lubrication system was found to work adequately for cold start but the performance at steady-state left much to be desired. Hence it was changed when the engine was moved to the new testcell, shown in Figure 28. The turbine style oil flow meter was changed to a KABOLD positive displacement gear wheel type oil flow meter. A new Omega 750W oil heater was added into the system to control the oil entering the engine to a constant temperature. This heater was fitted with a new temperature

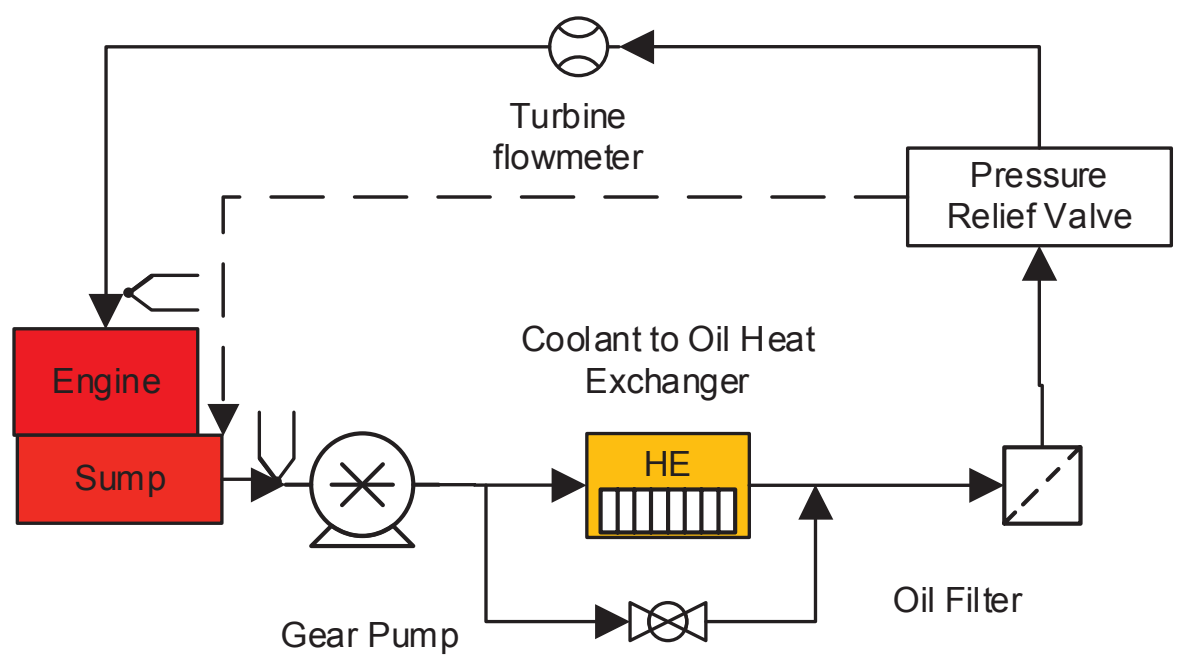

Diversion Valve

Figure 27: Oil system schematic - Phase 1 testing

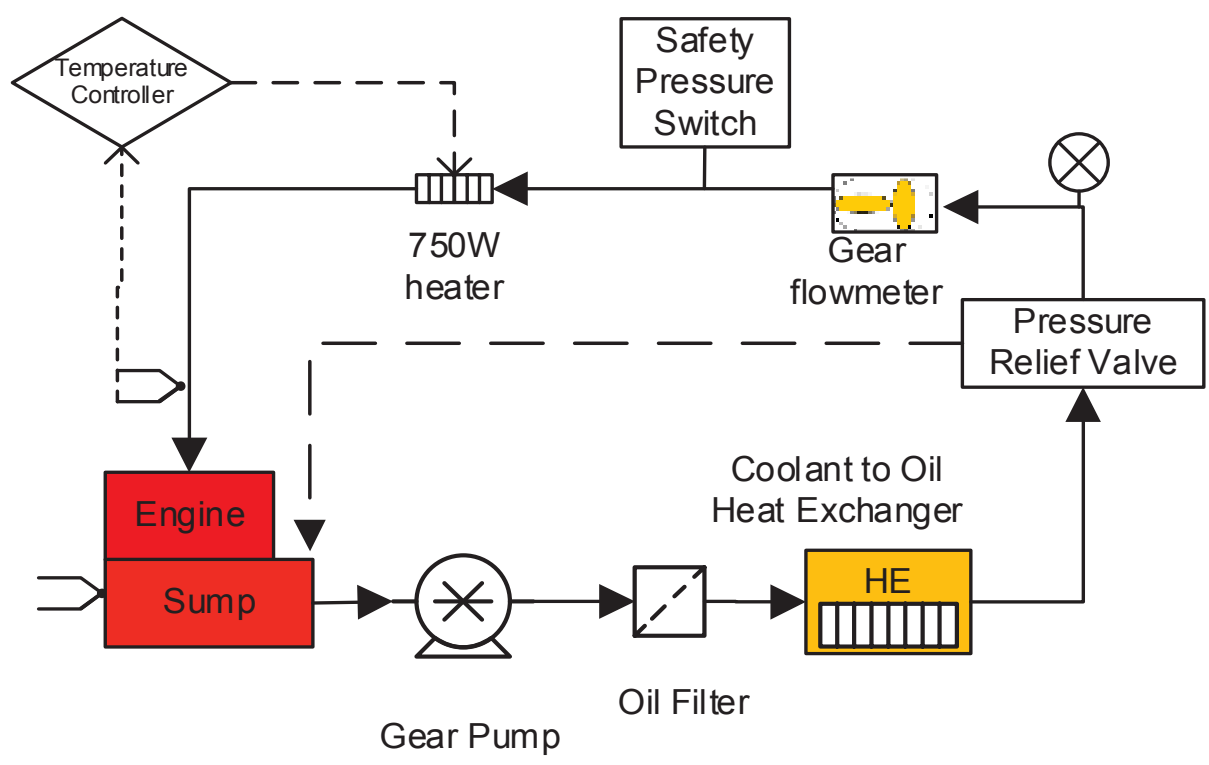

Figure 28: Oil system schematic - Phase 2 
controller CAL Controls 9500, that modulates the power available to the heater via phase angle controller SSRMAN-1P-PWM SOFTSTART/random fire relay NWT40HDA-10 to maintain stable and accurate desired oil temperature $\left(< \pm 0.5^{\circ} \mathrm{C}\right)$. Further an Omega pressure switch was incorporated into the lubrication system, which is wired to sound an alarm when oil pressure is lower than $\sim 125 \mathrm{kPa}$. Further the coolant and oil heaters are shut off when this happens as this might also indicate lack of oil flow.

\subsubsection{Engine Fueling System}

The fuel system schematic is shown in Figure 29; it is externally driven by two stages, a Low Pressure (LP) system using fuel tanks pressurized by helium and a High Pressure (HP) stage mechanically driven. The HP pump is of a wobble plate design made by Siemens Automotive, is return-less type. Pump is controlled by the Engine Control Unit (ECU) proportional-integral-derivative PID control via Pulse Width Modulated (PWM) signal. Further the pump is driven by an electric motor which allows motor speed change via an on device controller. This allows large flexibility for rail fuel pressure adjustment independent of engine speed, up to $12 \mathrm{MPa}$. A large high pressure stainless steel Swagelok sampling cylinder is used as accumulator to dampen the fuel pressure pulsations caused due to single fuel injection events. The return-less nature of fuel pressurization system allows continuous operation without causing fuel heating thus there is no need for a fuel chiller. A Micromotion CFM010 coriolis meter measures the fuel flow from the tanks into the high pressure pump. The entire fuel system is ethanol compatible, allowing problem free operation on gasoline-ethanol blends. 


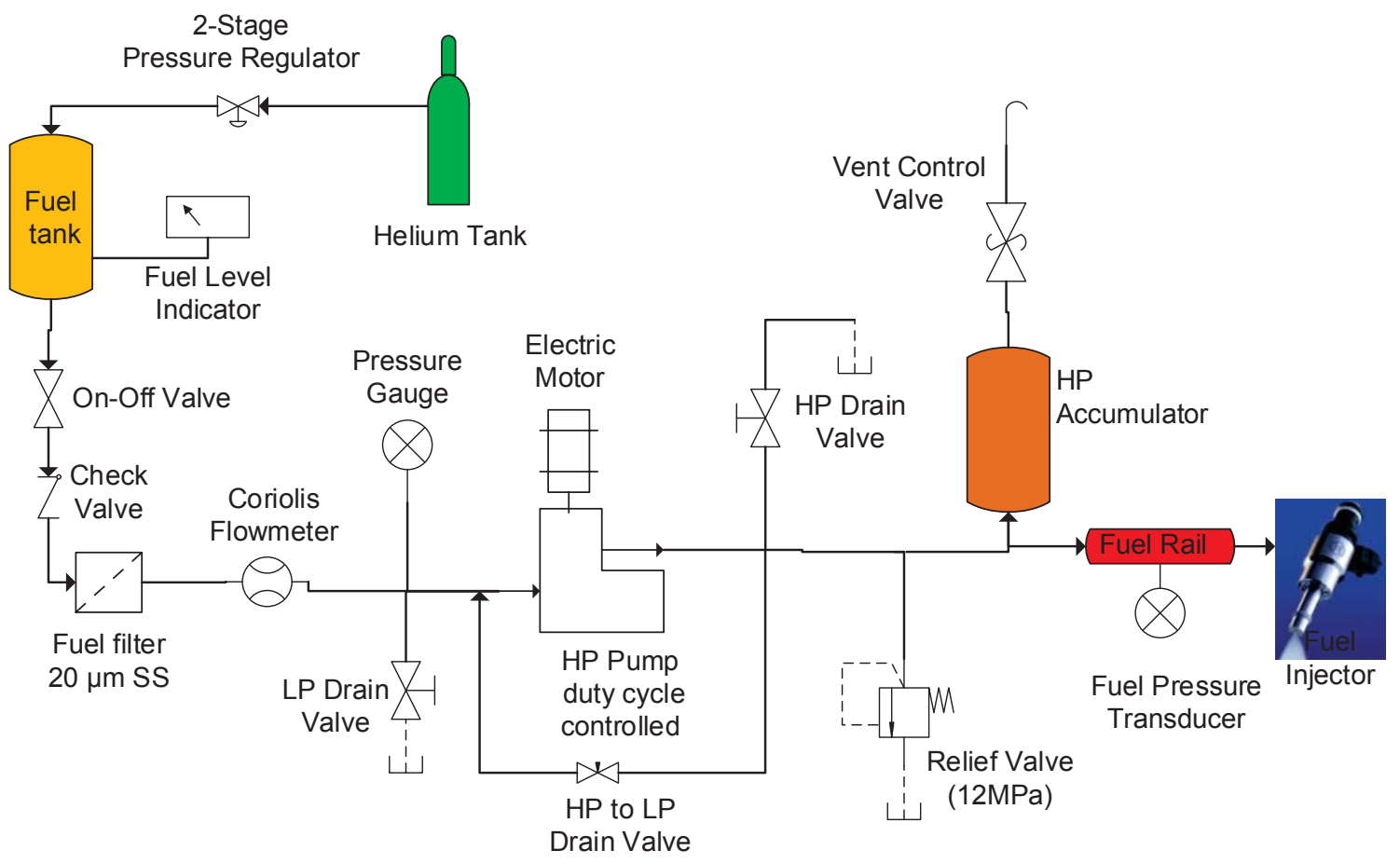

Figure 29: Fuel system schematic 


\subsubsection{Engine Control Unit (ECU)}

A Mototron programmable ECU (ECM-0565-128-0503-F) was used with the engine. This ECU uses a Motorola MPC 565 chip, with a wide range of input and output options, more details are in the datasheet given in Appendix ECU2. The connections of sensors and actuator's for the ECU are also listed in Table 8. The accompanying Motohawk software allows programs to be generated through Matlab \& Simulink interface, a cycle counter subsystem from the program is shown in Figure 30. PID controllers can be used to control various parameters including as fuel pump output, intake and exhaust cam positions, etc. Real-time control via Mototune software is available over the parameters for engine operation related to spark, fuel injection etc. The injector is driven by BOSCH ES - HDEV1 injector power stage and is connected to the ECU injector control channel. This module is capable of driving upto 6 injectors and multiple successive injections on the same injector require only a gap of 3.3 milliseconds duration between them.

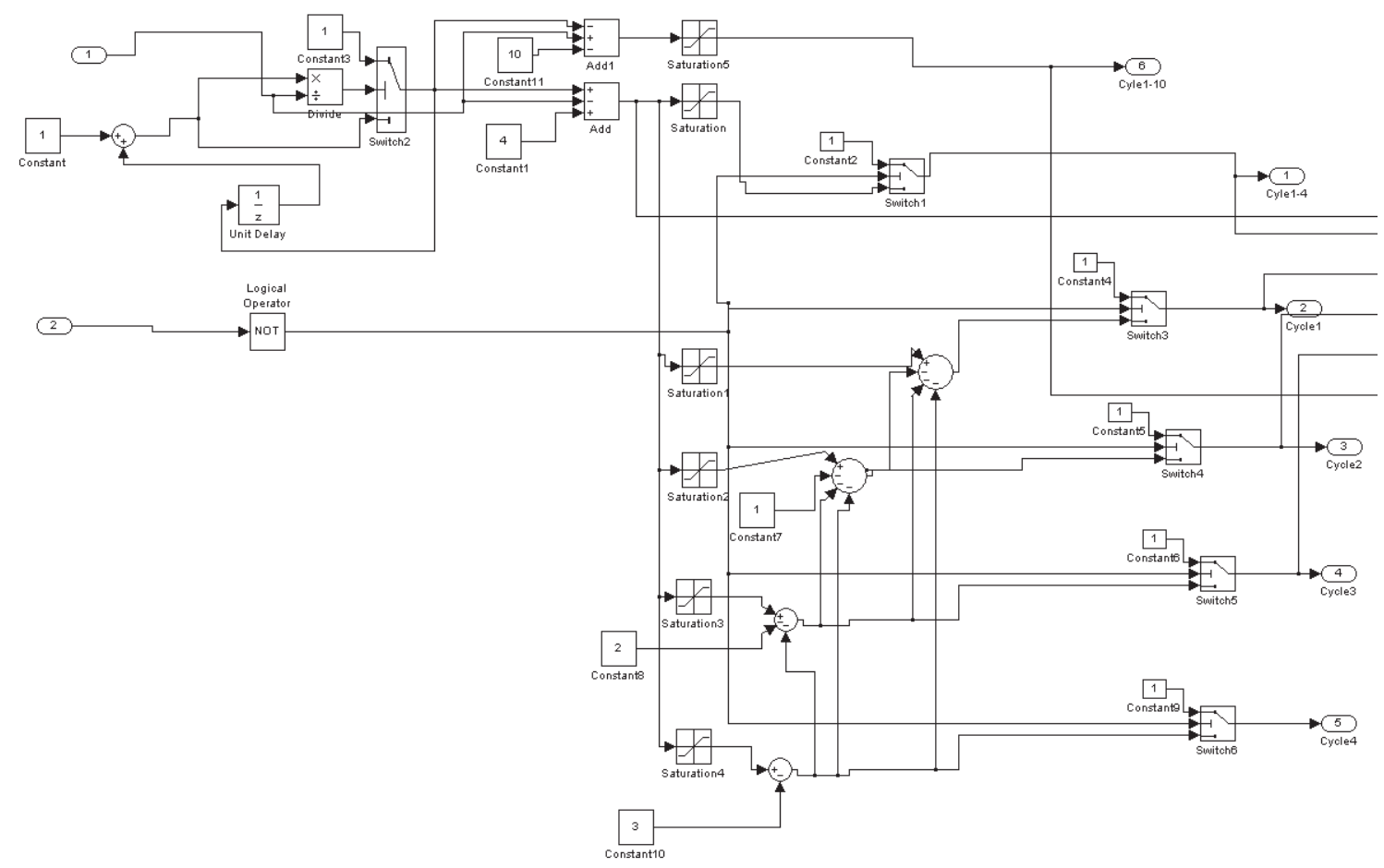

Figure 30: Cycle counter used in Motohawk/Simulink

\subsubsection{Engine Sensors and Actuators}

The main engine sensors and actuators are listed in Table 5. Pressure sensors for fuel pressure, MAP are the GM production sensor versions. The main throttle is $32 \mathrm{~mm}$ Bosch electronic throttle body DV-E5 series, which allowed a full throttle MAP of about $95 \mathrm{KPa}$ at $180 \mathrm{rpm}$ during the $1^{\text {st }}$ phase of testing. 
Table 5: Engine sensors/actuators

\begin{tabular}{|c|c|c|c|}
\hline Sensor Type & Model No & Position in setup & Used for \\
\hline $\begin{array}{l}\text { Crank position } \\
\text { optical encoder }\end{array}$ & $\begin{array}{l}\text { BEI H20 Rugged } \\
\text { Incremental Encoder } \\
\text { ( } 360 \text { PPR) }\end{array}$ & Engine crankshaft & $\begin{array}{l}\text { Cam phase control, } \\
\text { data acquisition }\end{array}$ \\
\hline $\begin{array}{l}\text { Crank-wheel } \\
\text { encoder, crank } \\
\text { position sensor }\end{array}$ & $\begin{array}{l}\text { GM 12578661, } \\
12588992\end{array}$ & Engine crankshaft & $\begin{array}{l}\text { ECU crank position } \\
\text { sensing }\end{array}$ \\
\hline Camshaft sensors & GM 12577245 & $\begin{array}{l}\text { Above intake and } \\
\text { exhaust camshafts }\end{array}$ & $\begin{array}{l}\text { Intake and exhaust } \\
\text { cam position sensing }\end{array}$ \\
\hline MAP sensor & GM 12591290 & Intake manifold & $\begin{array}{l}\text { Manifold pressure } \\
\text { sensing }\end{array}$ \\
\hline $\begin{array}{l}\text { Fuel pressure } \\
\text { sensor }\end{array}$ & GM 12613350 & Fuel rail & Fuel pressure sensing \\
\hline Cam phaser's & $\begin{array}{l}\text { INA F-347195.14 } \\
\text { (GM XX016211AA) }\end{array}$ & $\begin{array}{l}\text { Intake and exhaust } \\
\text { camshaft }\end{array}$ & Cam phasing \\
\hline Throttle & BOSCH DV-E5 32mm & $\begin{array}{l}\text { Before intake } \\
\text { manifold }\end{array}$ & MAP control \\
\hline
\end{tabular}

\subsection{Lab Instrumentation and DAQ}

\subsubsection{Sensors}

Fuel flow is measured by a Micromotion CFM010 coriolis meter, while airflow is measured by a Merriam 5 CFM Laminar Flow Element (LFE). A large surge tank appropriately sized (> 200 times the engine displacement) for a single cylinder is used before the LFE to dampen out the intake flow surges generated by the single cylinder engine. An ETAS LA4 UEGO controller is used with a Bosch LSU $4.7 \mathrm{O}_{2}$ sensor to measure the afr in exhaust. The UEGO lambda measurements are only used for determining the lambda under continuous firing conditions.

\subsubsection{Emissions Instrumentation}

A Horiba MEXA-1600D five gas emissions analyzer was used to monitor the engine background HC levels for first phase: $1^{\text {st }}$ cycle testing. It had a heated sample line, with data being available at $2 \mathrm{~Hz}$ sample rate. Cem-Zero grade Air and Nitrogen were used for the analyzer. A listing of the gases required for operation is listed in Table 6. The emissions bench was spanned and zero calibration checked each day before data was logged. Data transfer out of the analyzer was done by means of floppy disks. Being a standalone system, the analyzer display and inputs (keyboard/mouse) was multiplexed 
by means of a switch (KVM) into the main control room, allowing centralized control of the entire test cell through the control room.

Table 6: Gases and Regulators needed for Horiba emissions bench

\begin{tabular}{|c|c|c|c|}
\hline Instrument & Gas & Spec & Regulator \\
\hline \multirow{2}{*}{ Common } & Zero Air & No HC, Cem-zero & CGA 590 \\
& Zero N2 & Cem-zero & CGA 580 \\
\hline & CO2 & $14 \%$, rest N2 UHP & CGA580 \\
$\begin{array}{c}\text { HORIBA } \\
\text { MEXA-1600D }\end{array}$ & NOx & 4300 ppm & \\
& OC & $22.50 \%$ & CGA 350 \\
& CO & $0.27 \%$, rest N2 UHP & CGA 350 \\
& CO & $9 \%$, rest N2 UHP & CGA 350 \\
\hline
\end{tabular}

A Cambustion Non-Dispersive Infra-Red detector (NDIR) 500 for fast CO/CO2 measurement and a fast flame ionization detector (FFID) HFR400 is used to monitor real-time HC levels in exhaust. It is noted that the FID response differs between oxygenated and non-oxygenated fuels. Hence HC readings are not compared across fuels. The FFID and NDIR give instantaneous readings with some sample delay. This delay is computed based on the high speed sampling readings, and the peak reading location for each cycle is noted individually for $\mathrm{HC}, \mathrm{CO}$ and $\mathrm{CO} 2$ channels. This information is used in the data analysis program to ensure accurate readings are extracted from the data for each channel. The gases needed to operate the analyzers are given Table 7. The Cem-Zero Air and Nitrogen gas tanks are shared between the analyzers and are consumed rapidly when both the analyzers are operated simultaneously. Hence it is recommended that spare tanks be ordered when emissions testing that needs more than a week of continuous runtime is being done, in order to reduce testing downtime. The FFID being of an older design required frequent cleaning, with a need to periodically clean the FFID head pitot tube, which requires disassembly of the head. NDIR had relatively trouble-free operation at engine starts due to its ability to use a sample filter on the sample line. 
Table 7: Gases and Regulators needed for FFID and NDIR emissions instruments

\begin{tabular}{|c|c|c|c|}
\hline Instrument & Gas & Spec & Regulator \\
\hline \multirow{2}{*}{ FFID } & H2 & 99.999 purity & CGA 350 \\
& Propane(span) & 3000ppm C3,rest N2 UHP & CGA 350 \\
\cline { 2 - 4 } & Propane(span) & $1.8 \%$ propane, rest N2 UHP & CGA 350 \\
\hline \multirow{2}{*}{ Common } & Zero Air & No HC, Cem-zero & CGA 590 \\
& Zero N2 & Cem-zero & CGA 580 \\
\hline \multirow{3}{*}{ NDIR } & CO2 & $4 \%$, rest N2 UHP & CGA580 \\
& $\mathrm{CO} 2$ & $16 \%$, rest N2 UHP & CGA580 \\
& $\mathrm{CO}$ & $1 \%$, rest N2 UHP & CGA 350 \\
& $\mathrm{CO}$ & $9 \%$, rest N2 UHP & CGA 350 \\
\hline
\end{tabular}

\subsubsection{Data Acquisition Systems}

The ECU uses 60-2 teeth crank wheel with crank position sensor for crank position information, while a half moon cam position sensor is used to determine the position in the engine cycle, the ECU connections are listed in Table 8.

A slower speed NI cDAQ chassis is used to log low speed measurements. This chassis has modules that measure voltage, current and temperature measurements which are cold junction compensated. A listing of the channels, modules are given Table 9. A NI counter timer module (PCI-6602) is used with cam position sensor signals and optical encoder signal to provide the ECU with real-time cam position information. The ECU then uses PID to control the cam phaser position by means of actuation of the oil control valves. The cam position information is logged through the ECU. Signal lists for the same are shown in Table 10.

An AVL GH12D cylinder pressure transducer is used with DSP ACAP system for measuring cylinder pressure. ACAP system provides simultaneous (non-multiplexed) sampling of channels based on optical encoder triggering. An industrial BEL 360 PPM optical encoder is recommended for cold start testing due to its observed reliable working at large speed transient conditions (Part no: XH20DB-37-SS-360-ABZC-28V/VSM18) triggers the ACAP system, which in turn provides real-time combustion metrics including IMEP, burn durations, CA50, etc. A number of other signals including the emissions instrumentation channels are also logged in the ACAP system. The HC, CO, $\mathrm{CO} 2$ measurements from the emissions instruments are read by ACAP system as analog voltages. A listing of the channels is provided in Table 11. 
Table 8: ECU channel and connections list

\begin{tabular}{|c|c|c|c|c|c|}
\hline Name & Device & Signal Description & Signal Details & ECU Pin & Resource \\
\hline \multirow[t]{3}{*}{ MAP } & automotive sensor & V_supply (+) & $5 v \mathrm{DC}$ & & \\
\hline & & V_supply (-) & & & \\
\hline & & Signal $(+)$ & $0-5 \mathrm{~V}$ DC & J1-A29 & \\
\hline \multirow[t]{3}{*}{ Crank Pos } & Hall effect sensor (60-2) & V_supply (+) & $12 \mathrm{~V} \mathrm{DC}$ & & \\
\hline & & V_supply (-) & & & \\
\hline & & Signal $(+)$ & & J1-A13 & CNK \\
\hline \multirow[t]{6}{*}{$\begin{array}{l}\text { Oxygen sensor (wide } \\
\text { band) }\end{array}$} & Bosch LSU4.2 & Heater (+) & $\begin{array}{c}\text { voltage ramp up } \\
\text { req }\end{array}$ & & \\
\hline & & Heater (-) & LS PWM & J1-B19 & LSO1 \\
\hline & & LSU Signal & UN & J1-B21 & \\
\hline & & non inverting input of pump & $\mathrm{IA}$ & J1-B15 & \\
\hline & & inverting input of pump control & $\mathrm{IP}$ & J1-B14 & \\
\hline & & Virtual ground of pump & VM & J1-B1 & \\
\hline \multirow[t]{6}{*}{ ETB $(32 \mathrm{~mm})$} & Bosch DV-E5 & H-Bridge $(+)$ & & J2-A9 & $\mathrm{H} 1+$ \\
\hline & & H-Bridge (-) & & J2-A17 & $\mathrm{H} 1-$ \\
\hline & & Pot. GND & & & \\
\hline & & Pot. Referance (5V) & & & \\
\hline & & Pot. Signal \# 1 & & J1-A10 & AN13M \\
\hline & & Pot. Signal \# 2 & & & \\
\hline \multirow{5}{*}{$\begin{array}{l}\text { Low-Flow Throttle } \\
\text { (EGR valve) }\end{array}$} & GM P/N 12576918 & $128 \mathrm{~Hz}$ LS PWM & & J2-B17 & LSO7 \\
\hline & & PPS Ground & & & \\
\hline & & PPS Output (signal) & & J1-A16 & AN10M \\
\hline & & V_supply (+) & 5v DC & & \\
\hline & & V_supply (+) & $13.5 \mathrm{~V} \mathrm{DC}$ & & \\
\hline $\begin{array}{c}\text { Camshaft phasing } \\
\text { (input) }\end{array}$ & $\begin{array}{c}\text { From } \mathrm{Nl} \text { signal processing } \\
\text { to Mototron }\end{array}$ & Encoded PWM and duty cycle & & J1-B7 & DG1 \\
\hline \multirow{4}{*}{$\begin{array}{l}\text { Camshaft phasing } \\
\text { (output) }\end{array}$} & Intake Cam Solonoid & V_supply (+) & & & \\
\hline & & LS PWM & & J2-B12 & LSO5 \\
\hline & Solonoid & V_supply (+) & & & \\
\hline & & LS PWM & & J2-B15 & LSO6 \\
\hline \multirow[t]{4}{*}{ Spark } & GM coil on plug & V_supply (+) & & & \\
\hline & & V_supply (-) & & & \\
\hline & & EST1 & & $\mathrm{J} 2-\mathrm{A} 12$ & EST1 \\
\hline & & EST Return & Digital Ground & & \\
\hline \multirow[t]{5}{*}{ Injector Driver } & Bosch Injector driver & V_supply(+) & & & \\
\hline & & V_supply (-) & & & \\
\hline & $\begin{array}{c}\text { Injection Trigger (MV_A- } \\
\text { MV_F) }\end{array}$ & Open Drain Output & & J2-A1 & INJ01 \\
\hline & Enable \# & low-active & Grounded & & \\
\hline & Enable & high-active & 5V Supply & & \\
\hline \multirow[t]{5}{*}{ Fuel Pump Pressure } & Siemens HP Pump & LS PWM duty cycle & $\sim 200 \mathrm{~Hz}, 2.5 \mathrm{Amp}$ & J1-B19 & LSO2 \\
\hline & & V_supply (+) & & & \\
\hline & Fuel Pressure transducer & V_supply (+) & & & \\
\hline & & V_supply (-) & & & \\
\hline & & Signal (+) & & J1-A30 & AN5 \\
\hline
\end{tabular}


Table 9: Slow speed DAQ channel list

\begin{tabular}{|c|c|c|c|c|}
\hline Channel Type & Channel Name & Type & Module No & Channel \\
\hline \multirow{8}{*}{ Temperature } & Oilpan Temp & K-Type Thermocouple & Mod1 & ai0 \\
\hline & Coolant Out Temp & K-Type Thermocouple & Mod1 & ai1 \\
\hline & Coolant In Temp & K-Type Thermocouple & Mod1 & ai2 \\
\hline & Oil In Temp & K-Type Thermocouple & Mod1 & ai3 \\
\hline & Manifold Air Temp C & K-Type Thermocouple & Mod1 & ai11 \\
\hline & Exhuast Temp C & K-Type Thermocouple & Mod1 & ai5 \\
\hline & Oil Return Temp C & K-Type Thermocouple & Mod1 & ai5 \\
\hline & Cyl Head Temp & J-Type Thermocouple & Mod1 & ai3 \\
\hline \multirow[b]{3}{*}{ LFE parameters } & LFE abs pressure & 4-20mA Barometric Sensor & Mod3 & ai22 \\
\hline & LFE Relative Humidity & 4-20mA Temp/RH sensor & Mod5 & ai3 \\
\hline & LFE Temp C & 4-20mA Temp/RH sensor & Mod6 & ai4 \\
\hline \multirow[b]{2}{*}{ Dyno } & Dyno RPM & Not Used & Mod8 & ai2 \\
\hline & Dyno Torque $(\mathrm{N}-\mathrm{m})$ & Load cell $0-5 \mathrm{~V}$ & Mod8 & ai0 \\
\hline & Fuel Flow & 4-20mA Coriolis Meter & Mod6 & aio \\
\hline Flow & LFE CFM & $\begin{array}{l}\text { 4-20mA Diff.Pressure } \\
\text { Transducer }\end{array}$ & Mod6 & ai1 \\
\hline \multirow{4}{*}{ Temperature } & Coolant In RTD & RTD & Mod7 & ai0 \\
\hline & Coolant Out RTD & RTD & Mod7 & ai1 \\
\hline & Oil In RTD & RTD & Mod7 & ai2 \\
\hline & Oil Out RTD & RTD & Mod7 & ai3 \\
\hline \multirow[b]{4}{*}{ Pressure } & MAP & Pressure $0-5 \mathrm{~V}$ & Mod5 & ai1 \\
\hline & Exhaust Presure & Pressure $0-5 \mathrm{~V}$ & Mod5 & ai2 \\
\hline & Crankcase Pressure & Pressure $0-5 \mathrm{~V}$ & Mod5 & ai3 \\
\hline & Oil Pressure & Pressure 0-5V & Mod5 & ai4 \\
\hline
\end{tabular}

Table 10: NI PCI- 6602 Counter Timer Channel listing

\begin{tabular}{|r|l|l|l|l|}
\hline \multirow{2}{*}{ Channel Type } & Name & Module & Resource & PIN \\
\hline Optical Encoder & A & 6602 & CTR 0 & PFI 11 \\
\cline { 2 - 5 } & B & 6602 & CTR 1 & PFI 17 \\
\cline { 2 - 5 } & Z & 6602 & CTR 0 & PFI 10 \\
\hline Exhaust Cam & Cam 4x wheel & 6602 & CTR 0 & PFI 18 \\
\hline Intake Cam & Cam 4x wheel & 6602 & CTR 0 & PFI 30 \\
\hline $\begin{array}{r}\text { Encoded PWM } \\
\text { out }\end{array}$ & Cam position Signal to & 6602 & CTR 0 & PFI 12 \\
\hline
\end{tabular}


Table 11: High Speed DAQ Channel List, all channels are 0-5V

\begin{tabular}{|c|c|c|c|c|}
\hline Channel Type & Channel Name & ADC Module No & ACAP Channel No & Module \\
\hline Pressure- In-Cylinder & cyl1 & 1 & 1 & 2812 \\
\hline Emissions & $\mathrm{CO} 2$ & 1 & 2 & 2812 \\
\hline Emissions & $\mathrm{CO} 2$ & 1 & 3 & 2812 \\
\hline Knock & KNKS & 1 & 4 & 2812 \\
\hline Knock- Intensity & knki & 1 & 5 & 2812 \\
\hline Knock-Peak & knkp & 1 & 6 & 2812 \\
\hline Pressure- Exhaust & expr & 1 & 7 & 2812 \\
\hline Injector Current & Inj1 & 1 & 8 & 2812 \\
\hline Not Used & lamb & 2 & 9 & 2812 \\
\hline Pressure- Fuel & Fuel pressure & 2 & 10 & 2812 \\
\hline Pressure- Manifold & Map & 2 & 11 & 2812 \\
\hline Emissions & $\mathrm{HC}$ & 2 & 12 & 2812 \\
\hline UEGO-Lambda & cLAM & 2 & 13 & 2812 \\
\hline Dyno- Torque & DYNT & 2 & 14 & 2812 \\
\hline Not Used & ENCZ & 2 & 15 & 2812 \\
\hline Not Used & ENCA & 2 & 16 & 2812 \\
\hline Not Used & C17 & 3 & 17 & 2812 \\
\hline Not Used & C18 & 3 & 18 & 2812 \\
\hline Not Used & C19 & 3 & 19 & 2812 \\
\hline Not Used & C20 & 3 & 20 & 2812 \\
\hline Not Used & $\mathrm{C} 21$ & 3 & 21 & 2812 \\
\hline Spark & SPRK & 3 & 22 & 2812 \\
\hline Not Used & DPWR & 3 & 23 & 2812 \\
\hline Not Used & DYEA & 3 & 24 & 2812 \\
\hline Default ACAP & ENCD & & & \\
\hline Default ACAP & TIME & & & \\
\hline
\end{tabular}




\subsection{Setup Modifications}

Cycle 1 analysis was deemed as a starting point for testing. The setup for cold start testing required many modifications to the steady state setup. A brief listing of the steps taken is given below.

- Identification of engine and bedplate resonance through NVH testing at 180 rpm speed.

- The engine teststand manufacturer Cussons Technology, UK and Ricardo were contacted for advice to enable low speed testing at 180 RPM. They noted that the teststand was designed for a lowest engine speed of 900 RPM. Frequency Response Function (FRF) data was taken using accelerometers on the engine block (noted as Block 1,2,3,4) and bedplate (noted as bedplate 1,2,3,4) as shown in Figure 31; the first resonance peak is to the first marker of $3 \mathrm{~Hz}$ or $180 \mathrm{rpm}$. Hence change were done to engine test stand mounting to stiffen it, move resonance points from $3.3 \mathrm{~Hz}(198 \mathrm{RPM})$ to above $10 \mathrm{~Hz}$ (600 RPM).

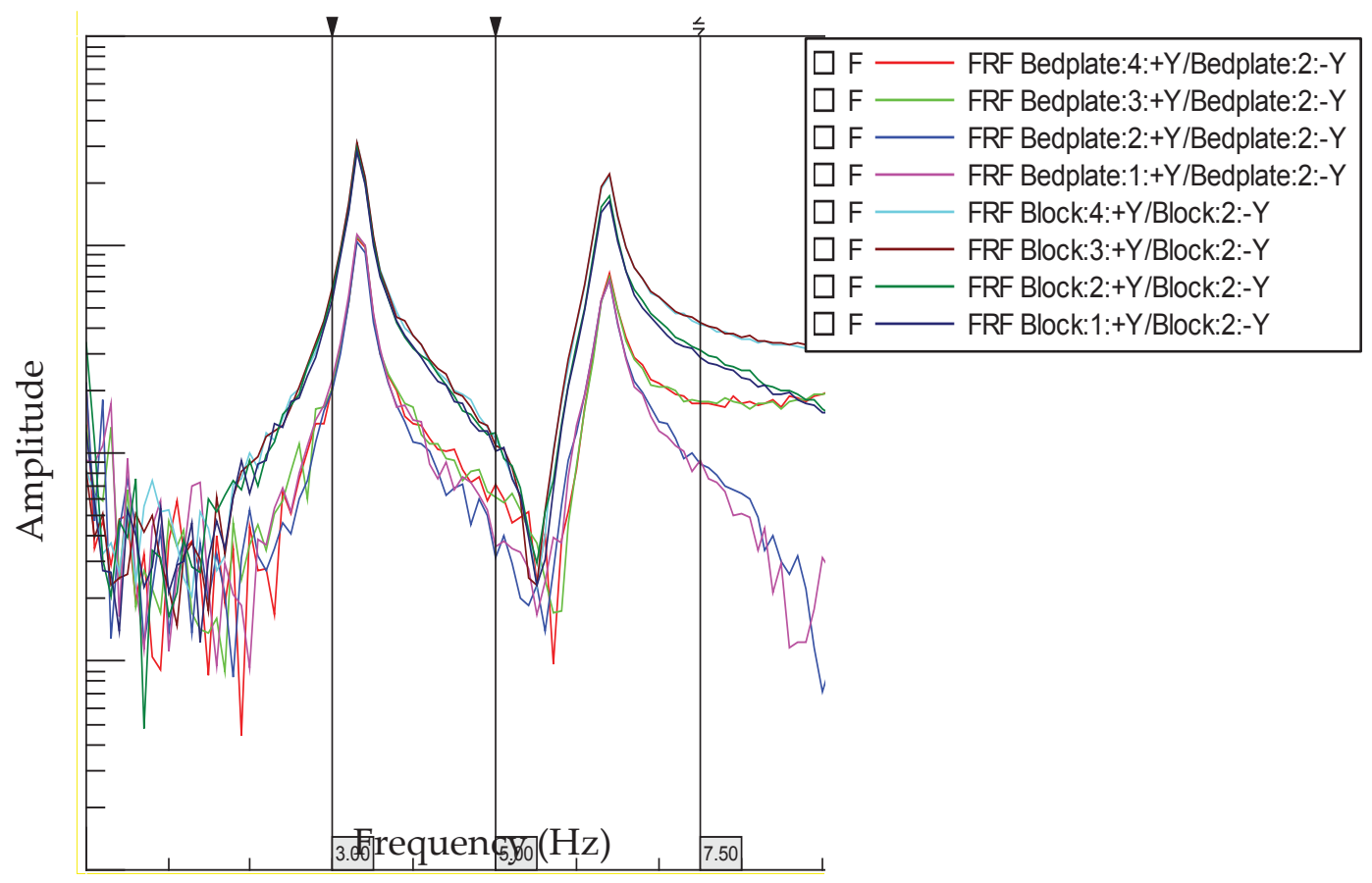

Figure 31: FRF data for resonance identification lies close to marked 3Hz/180 rpm 1st line

- Addition of a novel silver slug surface thermocouple (Type J) in the cylinder pressure transducer port that allowed to measure the engine head temperature 
close to real-time. This was used in phase 1 testing only. The inability to locate a high speed cold junction compensated amplifier at reasonable prices limited it's utility at the higher speed of $1000 \mathrm{rpm}$ in phase 2 of testing.

- Modification of coolant circuit to allow radiator flow on/off control by a temperature controller, tuning of the same for best possible temperature control window of the engine head temperature.

- Two cooling fans were added to the cooling circuit at the radiator to achieve closer to ambient temperatures. The engine head could be maintained at ambient $+1.5^{\circ} \mathrm{C}$ temperature for the first phase of testing.

- Addition of air heater with a phase angle temperature controller in the intake air heater circuit for phase 1 testing. After calibration the intake air temperature was controlled precisely at $25^{\circ} \mathrm{C}\left[ \pm 1^{\circ} \mathrm{C}\right]$ to maintain data consistency and reduce temperature swings. Phase 2 testing was conducted in summer in a testcell held within $25^{\circ} \mathrm{C}\left[ \pm 2^{\circ} \mathrm{C}\right]$ by the building ventilation system, adding fans during night time; hence air heater operation was not required.

- Addition of half-moon cam sensor to compensate for ECU engine cycle position location loss due to RPM variation caused due to single firing and compression events and aid the ECU in getting a consistent position for the engine cycle.

- Addition of a crankcase oil heater, to periodically heat the oil to $90^{\circ} \mathrm{C}$ to purge it of fuel and moisture condensate buildup due to $25^{\circ} \mathrm{C}$ testing.

- Change of oil to synthetic oil to compensate for the extreme carbon, fuel and moisture buildup in oil and better lubrication at cold start, synthetic oil was observed to have more capacity to absorb impurities.

- Custom ECU program to control injection duration / injection timing/ spark timing on a cycle to cycle basis and to follow a pattern of this firing and skipped cycles on a repeated basis.

- Analysis and selection of a suitable shaft for running the single cylinder engine at $180 \mathrm{rpm}$ speed.

- Shown in Figure 32 is the dynamometer shaft finally selected for cold start testing setup. Note the $\mathrm{CV}$ joint at the engine end attached to the engine flywheel and the SGF GAV 26 coupling at the dynamometer end. The GCV coupling shown in Figure 33 has nominal torque carrying capacity of $416 \mathrm{Nm}$ and maximum dynamic angle of deflection of $2^{\circ}$. The breaking torque of the coupling is 10 times the nominal torque capacity. The static stiffness of torsional rate is $370 \mathrm{Nm} /$ degree. 


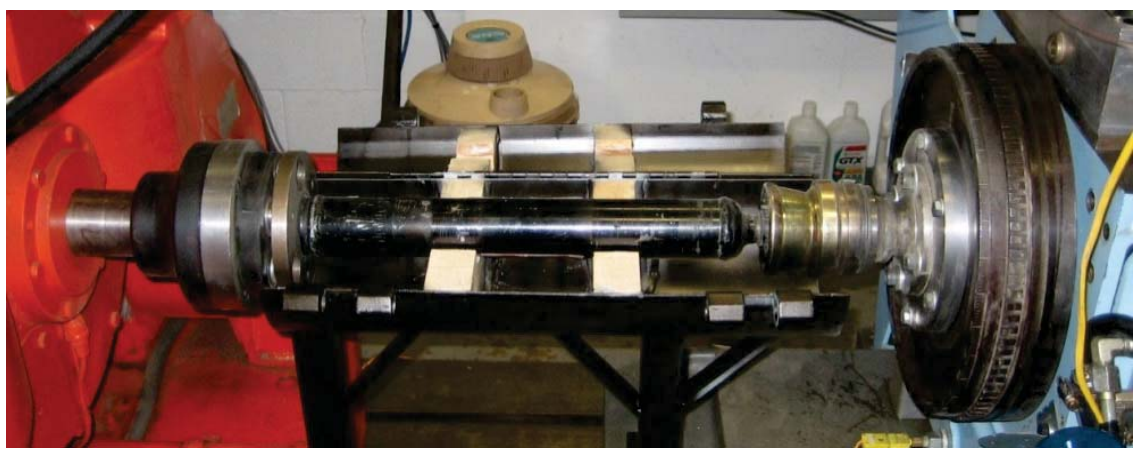

Figure 32: Dyno shaft attached to the engine and the dyno.

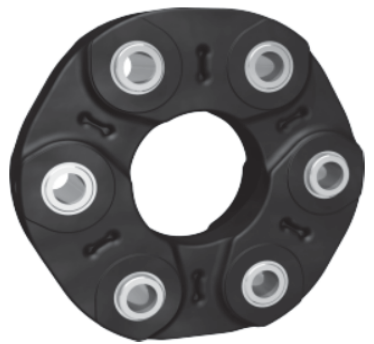

Figure 33: SGF GAV coupling 


\section{Results and Discussions}

\subsection{Overall Test Plan}

The testing was divided into two phases based on the engine startup cycle under consideration:

1) Phase 1 - Cycle 1 testing / Startability focused testing

2) Phase 2 - Cycle 2, 3 testing / Emissions focused testing

The basis of this testing was to analyze engine start on a cycle to cycle basis. In phase 1 the focus was on finding the lowest possible $\varnothing$ which shows has $100 \%$ reliability of firing i.e. there are no misfires. A startup trace from a 4-cylinder GM engine is shown in Figure 34, the engine starts its first fired cycle at $180 \mathrm{rpm}$ and $0.4 \mathrm{MPa}$ fuel pressure and engine speed rises as each cylinder fires. By the time the same cylinder fires a second time the engine speed is on an average $1000 \mathrm{rpm}$ and fuel pressure is $6 \mathrm{MPa}$.

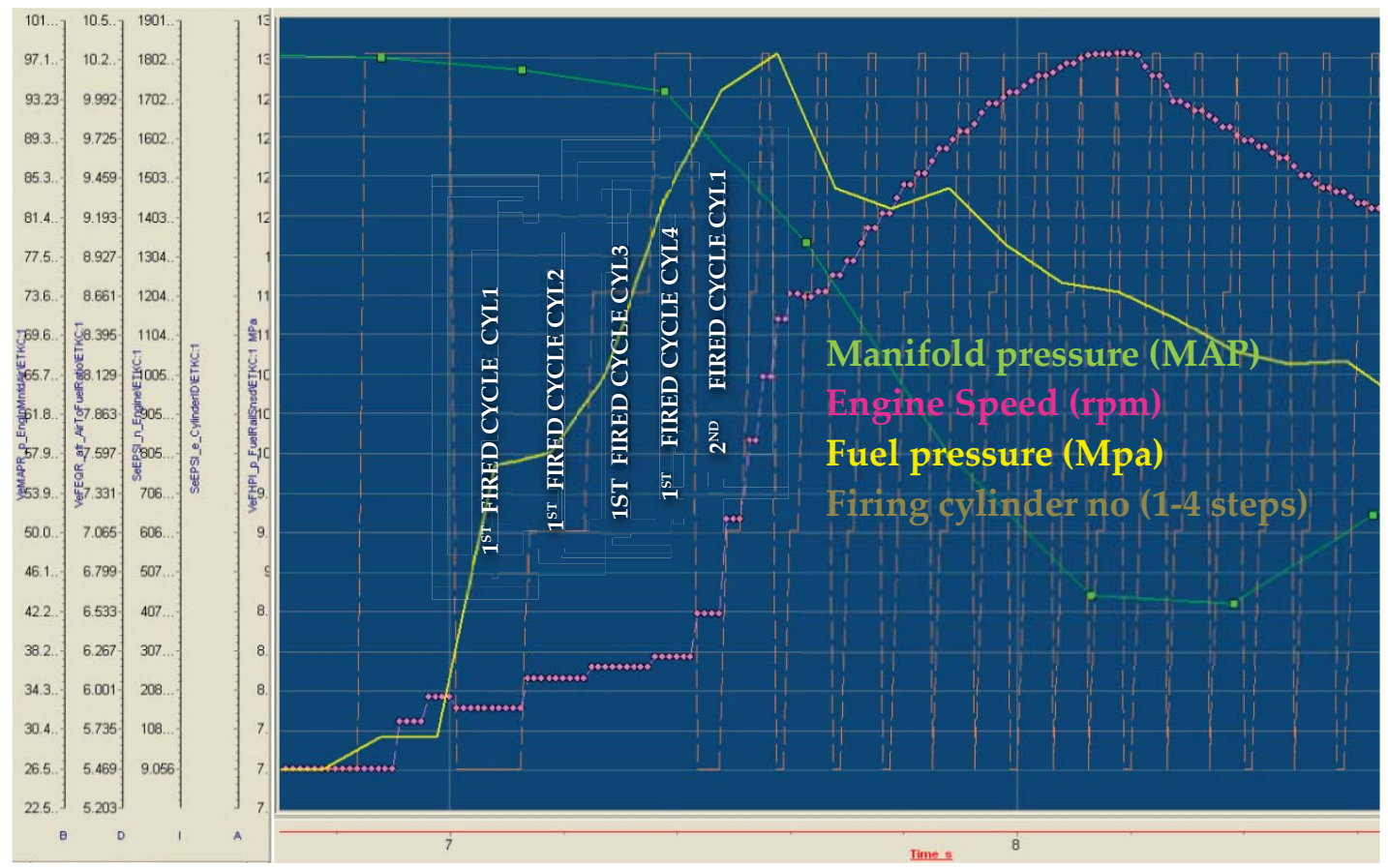

Figure 34 : Startup trace from a GM vehicle showing engine speed, fuel pressure, firing cylinder number, MAP (data from GM)

The phase 2 - cycle $2 \& 3$ testing focused on reliable firing with lowest possible emissions. The engine temperature for both phases was set at $25^{\circ} \mathrm{C}$ which is the same as the Federal Test Procedure (FTP) test cycle. The concept being, replicate the chosen optimum $1^{\text {st }}$ cycle conditions at $1000 \mathrm{rpm}$, and then following that cycle with the testing 
for $2^{\text {nd }}$ and $3^{\text {rd }}$ cycle parameters. This was necessary to replicate the effect of $1^{\text {st }}$ cycle residuals on the $2^{\text {nd }}$ cycle and to enable repeatable tests. To define the test plan, series of baselines were created; these are basically a single combination of the test parameters that are constant for a given test run and are explained in detail later in this chapter.

\subsection{Testing Overview}

The process used in realizing the objectives outlined in the introduction chapter are as follows: The engine and laboratory setup was modified to enable cold start testing. Then variables selected for investigation including CR, piston type, spark, SOI were constrained to a range of values based on known trends from the literature, inputs from experts at GM. Based on these constraints, experimental testing matrices were designed.

The test bed, control systems and instrumentation were tuned for testing the $1^{\text {st }}$ cycle of engine cold start. The engine and intake air temperature were held to $25 \pm 1^{\circ} \mathrm{C}$. Results were analyzed and the best first cycle parameters were determined.

\subsubsection{Strategies}

Using the strategies discussed in the literature review to construct a Design of Experiments (DOE) matrix that isolates effects of variables is a simple process, but completing them in a time feasible manner is equally important. Doing full factorial DOE analysis in engine startup experimentation would be time and cost prohibitive. Hence the need for reducing the number of variables/their ranges based on known relationships or limits. For this research, for the $1^{\text {st }}$ cycle testing the variables that were selected for further analysis at startup are:

- Bowl and flat top piston configurations

- Two compression ratios $(11,15.5)$

- E85 (ethanol blend with $85 \%$ ethanol and gasoline), UTG91/E10 (gasoline test fuel with octane rating of 91)

- Low and high startup Fuel Pressure(FP) : 0.4, $3 \mathrm{MPa}$

- 3 Intake Maximum Opening Position (IMOP): 95,110,125 aTDC

- Start of Injection (SOI) sweep for optimum SOI

- Equivalence ratio (Ø) sweep for lowest enrichment

Since the influence of spark advance (more spark retard leads to more exhaust heat and less HC until combustion stability limit) is well understood, it was fixed at a $-5^{\circ}$ aTDC. Similarly Exhaust Maximum Opening Position (EMOP) was also fixed at $-126^{\circ}$ aTDC, in order to be able to find the influence of other variables while keeping the testing time practical (Advance EMOP positions lower IMEP, lower valve overlap leading to lower residuals). Similarly introducing split injections greatly increases the testing time, as it introduces two additional variables: split ratio and injection timing of each injection into the testing and thus is not investigated. Since only single injection is 
considered, the minimum $\varnothing$ found from this experimental testing work could be improved upon if split injections were introduced.

\subsubsection{Phase 1 - Startability Test Plan}

Using well understood relationships (from the literature) that exist between test variables, a feasible test matrix can be designed. The relationships between variables used as a guide in this research are shown in Figure 35.

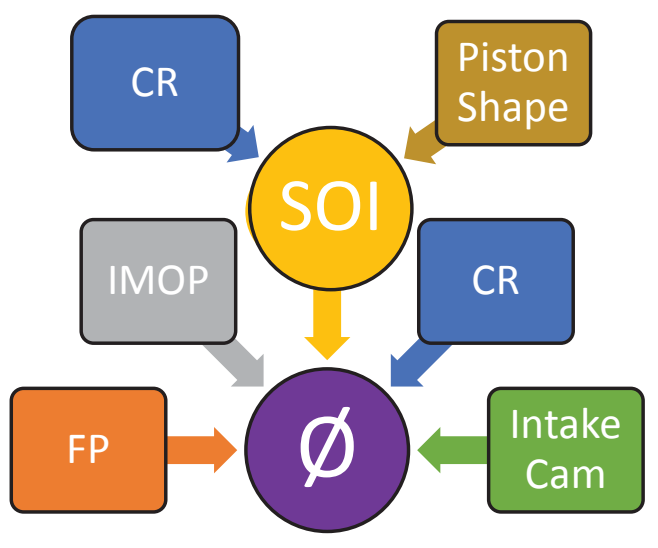

Figure 35: Relationships between variables for finding the minimum starting $\varnothing$

Piston shape and CR influence the optimum SOI for a given piston, as these have a direct impact on the fuel air mixture formation and stratification. Further the SOI position in the engine cycle directly impacts the minimum $\varnothing$ requirements at engine start. Similarly fuel pressure, IMOP, compression ratio and intake cam lift profile directly impacts the fueling $\varnothing$. Based on these SOI is deemed an important variable.

In case of startability testing baselines were defined by means of variables that are set as constant for a group of tests; these variables are piston type, $C R$, valve lift's, fuel type and fuel pressure. Thus the variables that would change for a given baseline are defined as SOI, IMOP and $\varnothing$. The ranges for variables that change in a baseline are shown in Table 12. These values were based on inputs from research sponsor GM and represent adequate starting points.

Shown in Table 13 are the 12 startability baselines based on the above discussion. 
Table 12: Variables and their range

\begin{tabular}{ll}
\hline Variable & Value \\
\hline SOI & $\begin{array}{l}270^{\circ} \mathrm{bTDC} \text { for low FP testing } \\
30-90^{\circ} \mathrm{bTDC} \text { for high FP testing in increments of } 30^{\circ}\end{array}$ \\
IMOP & 3 positions $95,110,125^{\circ}$ aTDC \\
$\varnothing$ & 4 to lean limit for low FP \\
& 2 to lean limit for high FP \\
\hline
\end{tabular}

The testing process for a given baseline for startability is shown as a flowchart in Figure 36 . Since we need to simulate the $1^{\text {st }}$ cycle firing, we need to fire a cycle and then return to original pre-firing conditions. It was observed from the Horiba emissions measurement bench that the background level of HC's dropped to below 1000ppm approximately 9 cycles after the firing cycle for gasoline low pressure tests and hence this value was used in a set of fired cycle \& skipped cycles. For this testing 1 in 10 firing

Table 13 : Startability testing baselines for test matrix 1

\begin{tabular}{|c|c|c|c|c|c|c|c|c|c|c|c|}
\hline & Physical & Paramet & & & Control & Parameter & & & & & \\
\hline $\begin{array}{l}\text { Name } \\
\text { Units }\end{array}$ & $\begin{array}{c}\text { Piston } \\
\text { Type }\end{array}$ & $C R$ & $\begin{array}{c}\text { Intake } \\
\text { cam lift } \\
\text { mm }\end{array}$ & $\begin{array}{l}\text { Fuel } \\
\text { Type }\end{array}$ & MAP & $\begin{array}{c}\text { Fuel } \\
\text { Pressure } \\
\text { Mpa }\end{array}$ & $\begin{array}{l}\text { EMOP } \\
\text { aTDC }^{\circ}\end{array}$ & $\begin{array}{l}\text { IMOP } \\
\text { aTDC }^{\circ}\end{array}$ & $\begin{array}{c}\text { Spark } \\
\text { Advance } \\
\text { bTDC }^{\circ}\end{array}$ & $\begin{array}{c}\text { SOI } \\
\text { bTDC }^{\circ}\end{array}$ & $\varnothing$ \\
\hline Range & $\begin{array}{c}\text { Bowl(B)/ } \\
\text { Flat } \\
\text { Top(F) }\end{array}$ & $11,15.5$ & Default & $\begin{array}{c}\text { E85/ } \\
\text { UTG91 }\end{array}$ & $98 \mathrm{kpa}$ & & -126 & $95 ; 125$ & 5 & & \\
\hline LP & & & & & & 0.4 & & & & 270 & $\begin{array}{c}\text { 4;lean } \\
\text { limit }\end{array}$ \\
\hline HP & & & & & & 3 & & & & $\begin{array}{l}\text { 30-90; } \\
\text { fixed }\end{array}$ & $\begin{array}{c}\text { 2; lean } \\
\text { limit }\end{array}$ \\
\hline $\begin{array}{l}\text { Increment/ } \\
\text { Switch(S) }\end{array}$ & S & S & S & S & S & S & & 15 & & 20 & $1,0.3$ \\
\hline 1 & $B$ & 11 & Default & E85 & 98 & 0.4 & -126 & 95 & 0 & 270 & 4 \\
\hline 2 & B & 11 & Default & E85 & 98 & 3 & -126 & 95 & 5 & $30-90$ & 2 \\
\hline 3 & B & 11 & Default & UTG91 & 98 & 0.4 & -126 & 95 & 5 & 270 & 4 \\
\hline 4 & B & 11 & Default & UTG91 & 98 & 3 & -126 & 95 & 0 & $30-90$ & 2 \\
\hline 5 & $\mathrm{~F}$ & 11 & Default & E85 & 98 & 0.4 & -126 & 95 & 0 & 270 & 4 \\
\hline 6 & $\mathrm{~F}$ & 11 & Default & E85 & 98 & 3 & -126 & 95 & 5 & $30-90$ & 2 \\
\hline 7 & $\mathrm{~F}$ & 11 & Default & UTG91 & 98 & 0.4 & -126 & 95 & 5 & 270 & 4 \\
\hline 8 & $\mathrm{~F}$ & 11 & Default & UTG91 & 98 & 3 & -126 & 95 & 0 & $30-90$ & 2 \\
\hline 9 & B & 15.5 & Default & E85 & 98 & 0.4 & -126 & 95 & 0 & $30-90$ & 4 \\
\hline 10 & B & 15.5 & Default & E85 & 98 & 3 & -126 & 95 & 5 & $30-90$ & 2 \\
\hline 11 & B & 15.5 & Default & UTG91 & 98 & 0.4 & -126 & 95 & 5 & 270 & 4 \\
\hline 12 & B & 15.5 & Default & UTG91 & 98 & 3 & -126 & 95 & 0 & $30-90$ & 2 \\
\hline
\end{tabular}


means firing 1st cycle, 9 skipped cycles and this is repeated 55 times, thus giving us 55 fired cycles worth of data.

We start with a baseline, and use a predefined $\varnothing$ and 1 in 10 firing with the skip firing process. We continue decreasing the fueling $\varnothing$ according to the defined decrement until the engine starts to misfire (termed as scanning for lowest $\varnothing$ ). $\varnothing$ is determined by continuously firing the engine until a stable reading it obtained on the lambda meter. Thus the fuel injection duration required for stoichiometric fueling/ $\varnothing=1$ is determined by this method.

\begin{tabular}{c} 
Constant Parameters: EMOP/MAP \\
Constant for a given run: Piston/CR/Cam lift/Fuel/FuelPr \\
Variables: SOI / IMOP, $\varnothing$ \\
\hline
\end{tabular}

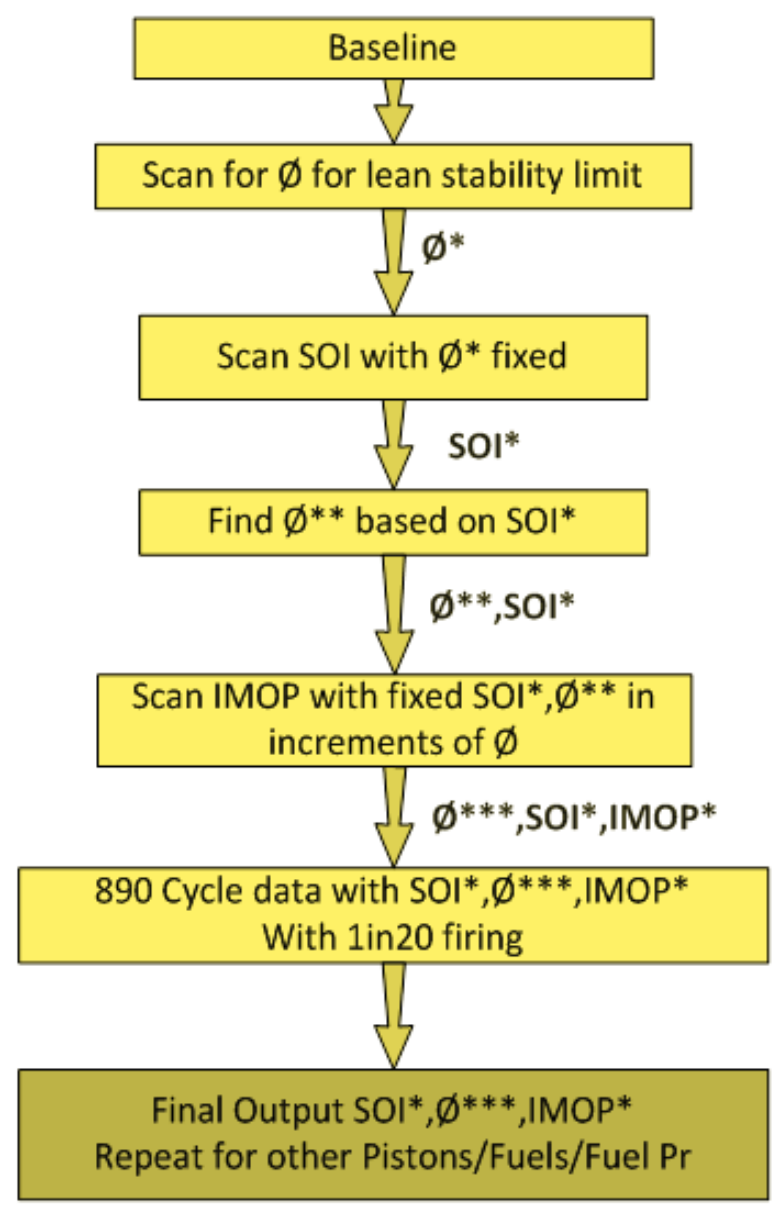

Figure 36 : Startability testing process for a baseline for test matrix $1,{ }^{*}$ indicates optimal value for the variable at that stage. 
We note that this process of determining stoichiometric fuel requirement at a particular cam position is impacted by the residuals; an attempt is made to remove this factor from the results by scaling the fueling $\varnothing$ by the amount of residuals obtained by simulations. The process by which this was done will be discussed in detail in the

Table 14 : Demonstration of testing a baseline using the process flowchart

\begin{tabular}{|c|c|c|c|c|c|c|c|c|c|c|c|}
\hline \multirow[b]{3}{*}{$\begin{array}{l}\text { Nam } \\
\text { Unit }\end{array}$} & \multicolumn{11}{|c|}{ Constant Parameters: Coolant Temp: 25C, RPM:180 } \\
\hline & \multicolumn{4}{|c|}{ Physical Parameters } & \multicolumn{7}{|c|}{ Control Parameters } \\
\hline & $\begin{array}{l}\text { Piston } \\
\text { Type }\end{array}$ & $\mathrm{CR}$ & $\begin{array}{c}\text { Intake } \\
\text { cam lift } \\
\mathrm{mm}\end{array}$ & $\begin{array}{l}\text { Fuel } \\
\text { Type }\end{array}$ & MAP & $\begin{array}{c}\text { Fuel } \\
\text { Pressure } \\
\text { Mpa }\end{array}$ & $\begin{array}{c}\text { EMOP } \\
\circ \text { aTDC }\end{array}$ & $\begin{array}{l}\text { IMOP } \\
\text { aTDC }^{\circ}\end{array}$ & $\begin{array}{c}\text { Spark } \\
\text { Advance } \\
\text { bTDC }^{\circ}\end{array}$ & $\begin{array}{c}\text { SOI } \\
\circ \text { bTDC }\end{array}$ & $\varnothing$ \\
\hline $\begin{array}{c}\text { Range } \\
\text { LP } \\
\text { HP } \\
\text { Increment/ } \\
\text { Switch(S) }\end{array}$ & $\begin{array}{l}\text { Bowl(B) } \\
\text { / Flat(F) }\end{array}$ & $\begin{array}{c}11 \\
15.5\end{array}$ & $\begin{array}{c}\text { Default/ } \\
\text { new }\end{array}$ & $\begin{array}{l}\text { E85/ } \\
\text { UTG91 }\end{array}$ & $\begin{array}{c}95 \\
\text { kpa }\end{array}$ & $\begin{array}{c}0.4 \\
3\end{array}$ & -126 & $95 ; 125$ & 5 & $\begin{array}{c}270 \\
30-90 ; \text { fixed } \\
20\end{array}$ & $\begin{array}{c}\text { 4; lean limit } \\
\text { 2; lean limit } \\
\\
1 / 0.3\end{array}$ \\
\hline Test No & & & & & & & & & & & optimum \\
\hline 1 & $\mathrm{~B}$ & 11 & Default & E85 & 95 & 0.4 & -126 & 95 & 5 & 270 & \\
\hline 2 & $\mathrm{~B}$ & 11 & Default & E85 & 95 & 0.4 & -126 & 95 & 5 & 270 & 3 \\
\hline 3 & B & 11 & Default & E85 & 95 & 0.4 & -126 & 95 & 5 & 270 & \\
\hline 4 & $B$ & 11 & Default & E85 & 95 & 0.4 & -126 & 110 & 5 & 270 & $\varnothing^{*}=3<$ \\
\hline 5 & B & 11 & Default & E85 & 95 & 0.4 & -126 & 110 & 5 & 270 & 2 \\
\hline 6 & $\mathrm{~B}$ & 11 & Default & E85 & 95 & 0.4 & -126 & 110 & 5 & 270 & 1 \\
\hline 7 & B & 11 & Default & E85 & 95 & 0.4 & -126 & 125 & 5 & 270 & $\varnothing^{*}=3$ \\
\hline 8 & B & 11 & Default & E85 & 95 & 0.4 & -126 & 125 & 5 & 270 & 2 \\
\hline 9 & B & 11 & Default & E85 & 95 & 0.4 & -126 & 125 & 5 & 270 & 1 \\
\hline FINAL & $\mathrm{Ba}$ & seline & & & & & & $\begin{array}{l}\mathrm{IMOP}^{*} \\
=125\end{array}$ & & 270 & $\varnothing^{* *}=1$ \\
\hline 1 & $B$ & 11 & Default & E85 & 95 & 3 & -126 & 95 & 5 & 30 & 2 \\
\hline 2 & B & 11 & Default & E85 & 95 & 3 & -126 & 95 & 5 & 30 & 1.7 \\
\hline 3 & B & 11 & Default & E85 & 95 & 3 & -126 & 95 & 5 & 30 & 1.4 \\
\hline 4 & B & 11 & Default & E85 & 95 & 3 & -126 & 95 & 5 & 30 & 1.2 \\
\hline 5 & B & 11 & Default & E85 & 95 & 3 & -126 & 95 & 5 & 50 & $\varnothing^{*}=1.7$ \\
\hline 6 & B & 11 & Default & E85 & 95 & 3 & -126 & 95 & 5 & 70 & $\varnothing^{*}=1.7$ \\
\hline 7 & B & 11 & Default & E85 & 95 & 3 & -126 & 95 & 5 & 90 & $\varnothing^{*}=1.7$ \\
\hline 8 & B & 11 & Default & E85 & 95 & 3 & -126 & 95 & 5 & $\mathrm{SOI}^{*}=70$ & 1.7 \\
\hline 9 & B & 11 & Default & E85 & 95 & 3 & -126 & 95 & 5 & 70 & 1.4 \\
\hline 10 & B & 11 & Default & E85 & 95 & 3 & -126 & 95 & 5 & 70 & 1.2 \\
\hline 11 & $\mathrm{~B}$ & 11 & Default & E85 & 95 & 3 & -126 & 95 & 5 & 70 & 1.1 \\
\hline 12 & B & 11 & Default & E85 & 95 & 3 & -126 & 110 & 5 & $\mathrm{SOI}^{*}=70$ & $\varnothing^{* *}=1.4$ \\
\hline 13 & B & 11 & Default & E85 & 95 & 3 & -126 & 110 & 5 & 70 & 1.2 \\
\hline 14 & B & 11 & Default & E85 & 95 & 3 & -126 & 110 & 5 & 70 & 1.1 \\
\hline 15 & $\mathrm{~B}$ & 11 & Default & E85 & 95 & 3 & -126 & 110 & 5 & 70 & 1 \\
\hline 16 & $B$ & 11 & Default & E85 & 95 & 3 & -126 & 125 & 5 & $\mathrm{SOI}^{*}=70$ & $\varnothing^{* *}$ \\
\hline 17 & B & 11 & Default & E85 & 95 & 3 & -126 & 125 & 5 & 70 & 1.2 \\
\hline 18 & B & 11 & Default & E85 & 95 & 3 & -126 & 125 & 5 & 70 & 1.1 \\
\hline 19 & B & 11 & Default & E85 & 95 & 3 & -126 & 125 & 5 & 70 & 1 \\
\hline FINAL & $\mathrm{Ba}$ & seline & & & & & & $\begin{array}{l}\mathrm{IMOP}^{*} \\
=110\end{array}$ & & $\mathrm{SOI}^{*}=70$ & $\varnothing^{* * *}=1.1$ \\
\hline
\end{tabular}


simulation work section 4.5.

$\varnothing^{*}$ is the leanest $\varnothing$ which is misfire free. This $\varnothing^{*}$ is used while sweeping for optimal SOI which starts at $30{ }^{\circ}$ aTDC to $90{ }^{\circ}$ aTDC in the increments of $20^{\circ}$. SOI* is the optimal SOI which has maximum IMEP and is misfire free. Using these $\varnothing^{*}$ and SOI* we try to decrement $\varnothing^{*}$ further to the lowest possible $\varnothing$ that is misfire free, and note this as $\varnothing^{* *}$. Then testing is done at three IMOP positions 95,110,125 starting with the $\varnothing^{* *}$ and $\mathrm{SOI}^{*}$ to find the lowest $\varnothing$ at each IMOP position. The best IMOP denoted as IMOP* is chosen based on IMEP and no misfires and lowest $\varnothing$ (denoted as $\varnothing^{* * *}$ ).

Data for combustion and test cell is then acquired for 890 engine cycles with 1 in 20 firing. This data is essentially replication of the earlier test condition in which 1 in 10 firing was used, and serves as confirmation of the stability and repeatability of the test condition and results. This complete process of testing shown in the flowchart is demonstrated in a table format in Table 14 for baselines $1 \& 2$. Values shown with $\mathrm{a}^{\text {(*) }}$ in the table indicate optimal value for a sweep.

\subsection{Detailed Startability Testing Results}

The data was loaded and analyzed in Matlab, a script was developed to extract cycle by cycle data from the continuous dataset logged by ACAP software. Results of the testing were divided into 2 parts based on fuel as detailed below, optimum points were chosen within the constraints range set in the test matrix.

1. Gasoline (UTG91) Tests

a. Low fuel pressure testing (0.4 MPa)

b. SOI sweep for high fuel pressure testing ( $3 \mathrm{MPa}$ )

c. High fuel pressure testing with chosen optimum SOI.

2. Ethanol (E85) Tests

a. Low fuel pressure testing (0.4 MPa)

b. SOI sweep for high fuel pressure testing ( $3 \mathrm{MPa}$ )

c. High fuel pressure testing with chosen optimum SOI.

The comparison of the results from low and high fuel pressure tests is shown later in section 4.4. A comparison of all the data across all CR's is also done at the end of that section.

As noted in the previous section the experimental results $\varnothing$ values are updated to estimate the actual $\varnothing$ from the fueling. This was done after the experimental results were published without these modifications in a SAE paper [10], which noted that the results had ignored the effect of residuals. The original results are presented in this section, the updated results are presented in conjunction with the simulation work in section 4.5. 


\subsubsection{Gasoline Testing}

\subsubsection{Gasoline Low pressure testing}

Shown in Figure 37 are the gasoline low pressure testing results; these were broken down into 3 parts based on piston used.

- CR 11 flat top piston (CR11F), shown on left

- CR 11 bowl piston (CR11B), shown in middle

- CR 15 flat top piston (CR15B), shown on right

The EMOP and SOI positions used for testing are $-126^{\circ}$ aTDC and $270^{\circ}$ bTDC respectively. For each piston following metrics are plotted; mean IMEP $(\mathrm{kPa})$ of fired cycles and IMEP STD $(\mathrm{kPa})$ in the error bar vs. $\varnothing$ in the top graph; percent misfires among the fired cycles vs. $\varnothing$ in the middle graph; mean CA50 (CAD) vs. $\varnothing$ in bottom graph. The series plotted in the graphs are based on IMOP positions, thus we have 3 series IMOP 95(blue), IMOP 110(green), IMOP 125(red).

Analyzing the results:

- CR11F: Starting the testing at $\varnothing 4$ for IMOP 95, continuing until $\varnothing 2.5$ there were
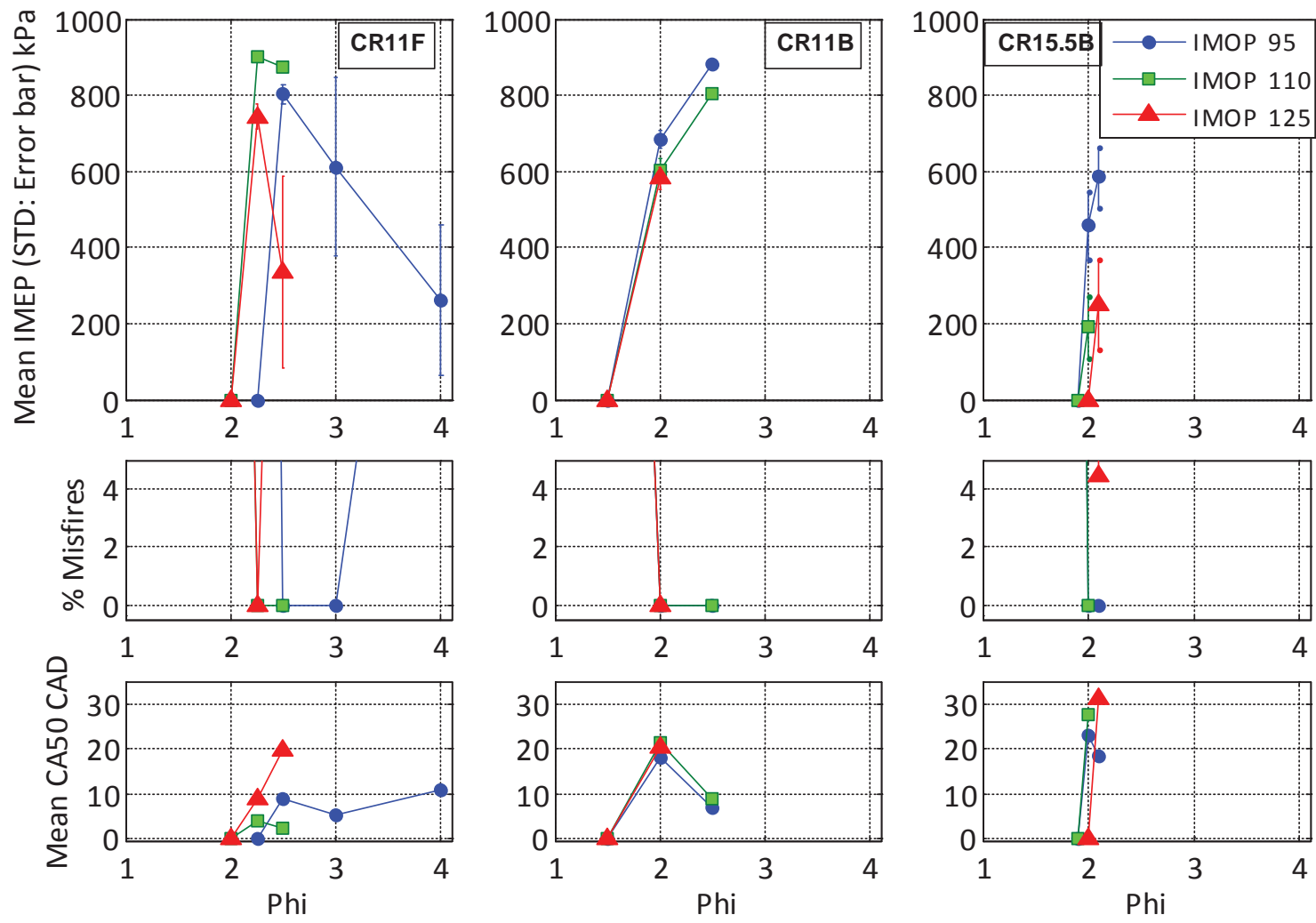

Figure 37: Gasoline 0.4MPa tests 
no misfires, at $\varnothing 2.25$ there were more than $10 \%$ misfires. Taking $\varnothing 2.5$ as starting point for IMOP 110, 125 testing, we were able to run without misfires at $\varnothing$ of 2.25 while any lower $\varnothing^{\prime}$ s again showed considerable misfiring. Test points with lower $\varnothing^{\prime}$ s that did not misfire had lower IMEP STD values. CA50 of test points without misfires were between $5^{\circ}$ to $12^{\circ}$. Overall IMOP 110 has significantly higher IMEP for the same $\varnothing$ levels compared to IMOP 95,125.

- CR11B: All the IMOP positions were very close together in terms of IMEP, most of them close to 600 IMEP, which is a good target value for turning over the engine. IMEP STD were low and comparable to the CR11F piston results.CA50 values were significantly higher than CR11F results. IMOP 95 was still the optimal IMOP with higher IMEP's for same $\varnothing$ levels, with minimum $\varnothing$ at robust firing being $\varnothing 2$.

- CR15B: At $\varnothing$ value of 2, IMEP was lower than CR11B. Preference for IMOP 95 seemed to be a characteristic of both the bowl pistons. While IMEP STD was significantly higher than $\mathrm{CR} 11 \mathrm{~F} / \mathrm{B}$. Higher CR increased the CA50 of the combustion.

\subsubsection{Gasoline high pressure testing SOI sweep}

Shown in Figure 38 are the results for gasoline 3MPa SOI sweep, the results are broken down into 3 parts based on piston used.

- CR11F results, shown on left.

- CR11B results, shown in middle.

- $\quad$ CR 15B results, shown on right.

The EMOP and IMOP positions used for the testing for each piston were are $126^{\circ}$ aTDC and $95^{\circ}$ aTDC. The metrics plotted in each are; Mean IMEP $(\mathrm{kPa})$ of fired cycles and IMEP STD (kPa) in the error bar vs. $\varnothing$ (blue) and \% misfires (green).
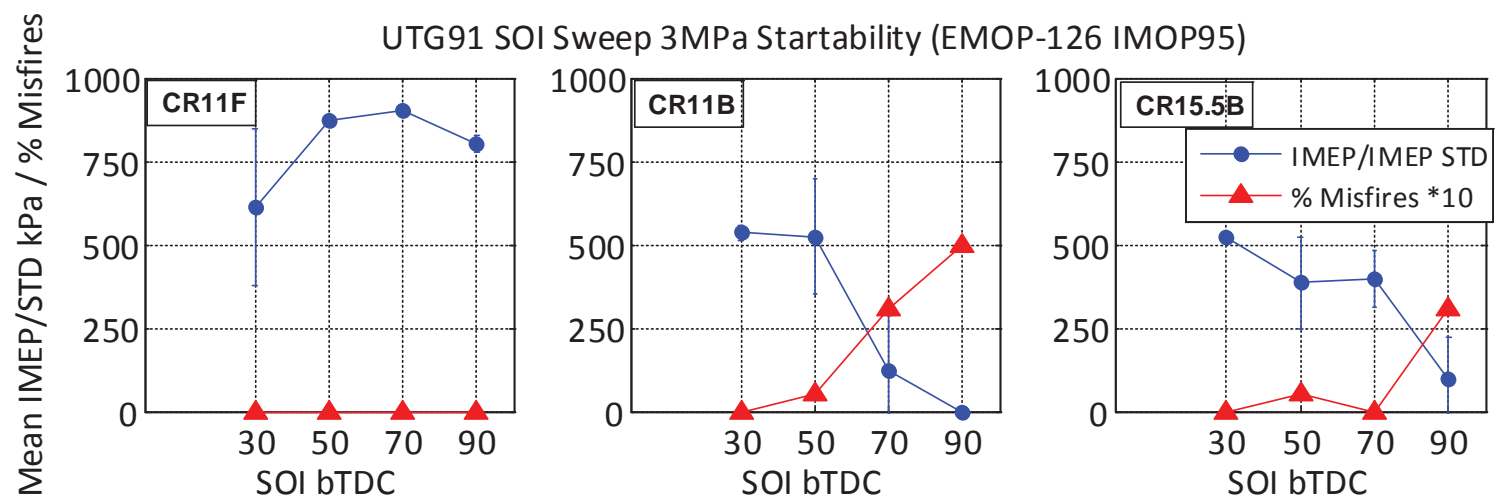

Figure 38: Gasoline 3MPa SOI sweep 
Analyzing the results:

- CR11F: IMEP increased as SOI increased up to $70^{\circ}$, after which the IMEP declined. There were no misfires at any SOI, thus $70^{\circ}$ was chosen as optimum SOI for the piston.

- CR11B: IMEP decreased as SOI increased. Misfires also increased as SOI increased beyond $30^{\circ}$. Thus $30^{\circ}$ was chosen as optimum SOI.

- CR15B: IMEP decreased as SOI increased. Misfires also increased as SOI increased beyond $30^{\circ}$ but went back to zero at SOI $70^{\circ}$ and increased sharply after that. Thus $30^{\circ}$ was chosen as optimum SOI.

- Both bowl pistons preferred the same SOI.

\subsubsection{Gasoline high pressure testing}

Shown in Figure 39 are the gasoline high pressures testing results. The results were analyzed similar to the low pressure testing.

Analyzing the results:

- CR11F: Testing started at $\varnothing 1.7$ for IMOP 95, there were no misfires up to $\varnothing 1.4$, at $\varnothing$ 1.2 there were more than 10\% misfires. For IMOP 110 and IMOP 125 testing there were no misfires up to $\varnothing 1.2$ only at IMOP110. Test points with lower $\varnothing$ 's that were
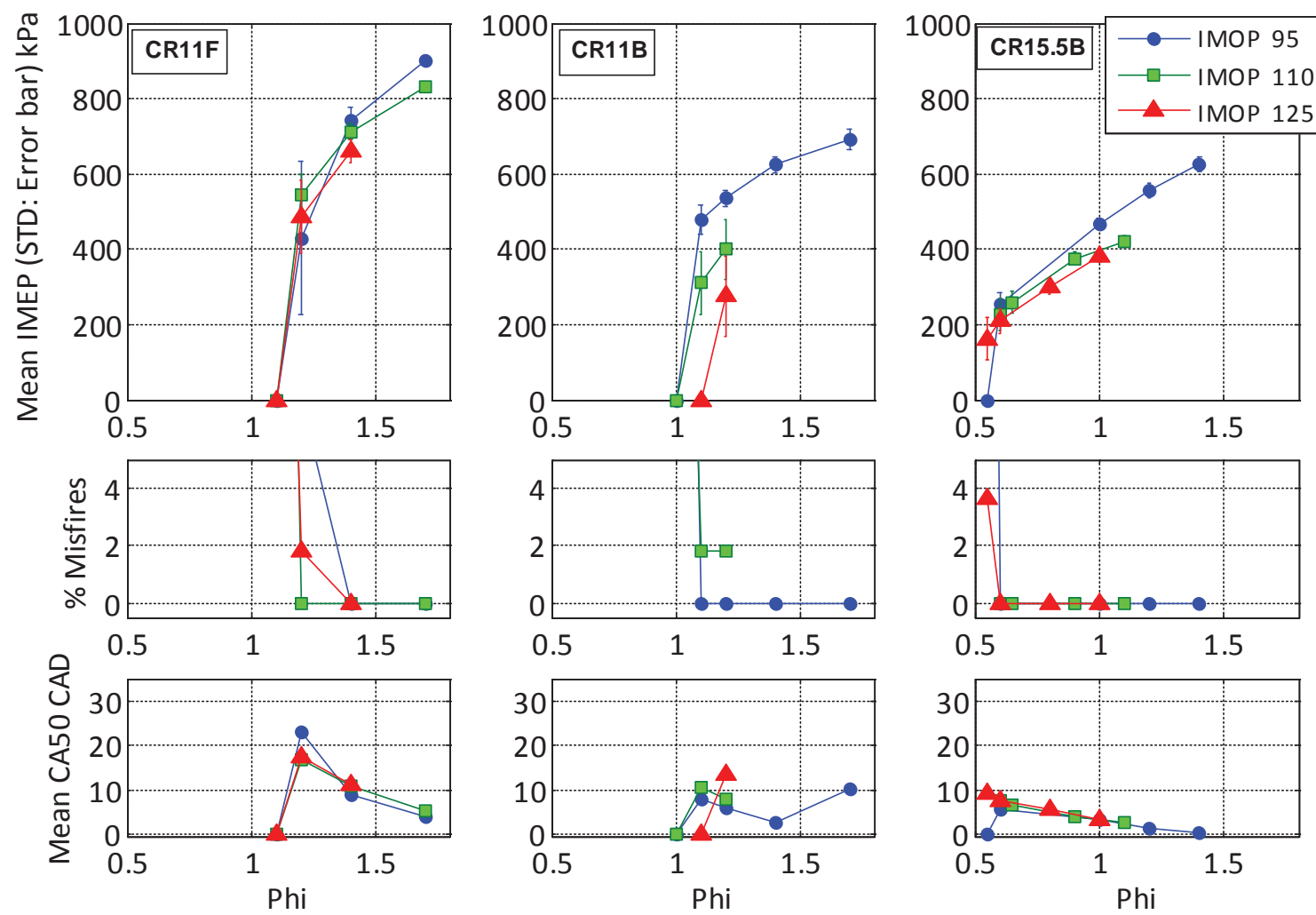

Figure 39 : Gasoline 3MPa tests 
misfire free had higher IMEP STD values. The $1.2 \varnothing$ test point for 110 IMOP position had CA50 of approximately $18^{\circ}$.

- CR11B: All IMOP positions were significantly apart in terms of IMEP. Only IMOP 95 showed no misfires, while IMOP 110 and IMOP 125 showed lower IMEPs and misfires. IMEP STD's for stable test points was lower than CR11F piston results. CA50 values were significantly lower than CR11F results, with IMOP 95 IMEP STD lying between $4-10^{\circ}$.

- CR15B: For $\varnothing$ of 1.4, approximately the same IMEP as CR11B was noted. Preference for IMOP 95 is noted as a characteristic of both the bowl pistons, while IMEP STD was smaller than CR11F/B. Higher CR seemed to have decreased CA50 of the combustion. The stability of CR15B combustion was significantly higher as there were no misfires for any IMOP position up to a very lean $\varnothing$ of 0.6 .

\subsubsection{E85 Testing}

\subsubsection{1. $\quad$ E85 Low pressure testing}

Shown in Figure 40 are the E85 low pressures testing results. The results were broken down into 3 parts based on piston used; same plotting style was used as previously used in gasoline testing results. The EMOP and SOI positions that were used for testing are $-126^{\circ}$ aTDC and $270^{\circ}$ bTDC respectively.

Analyzing the results:

- CR11F: Testing started with $\varnothing 4$ for IMOP 110, at $\varnothing 3.5$ there were more than $50 \%$ misfires hence no further data is taken for that IMOP and IMEP is denoted as zero. Taking $\varnothing 3.5$ as starting point for IMOP 95 and IMOP 125 testing these test points show $5 \%$ misfires, while any lower $\varnothing$ 's again showed more than $50 \%$ misfiring. The test points with no misfires had lowest IMEP STD values. CA50 of the test point without misfires is approximately $17^{\circ}$. 

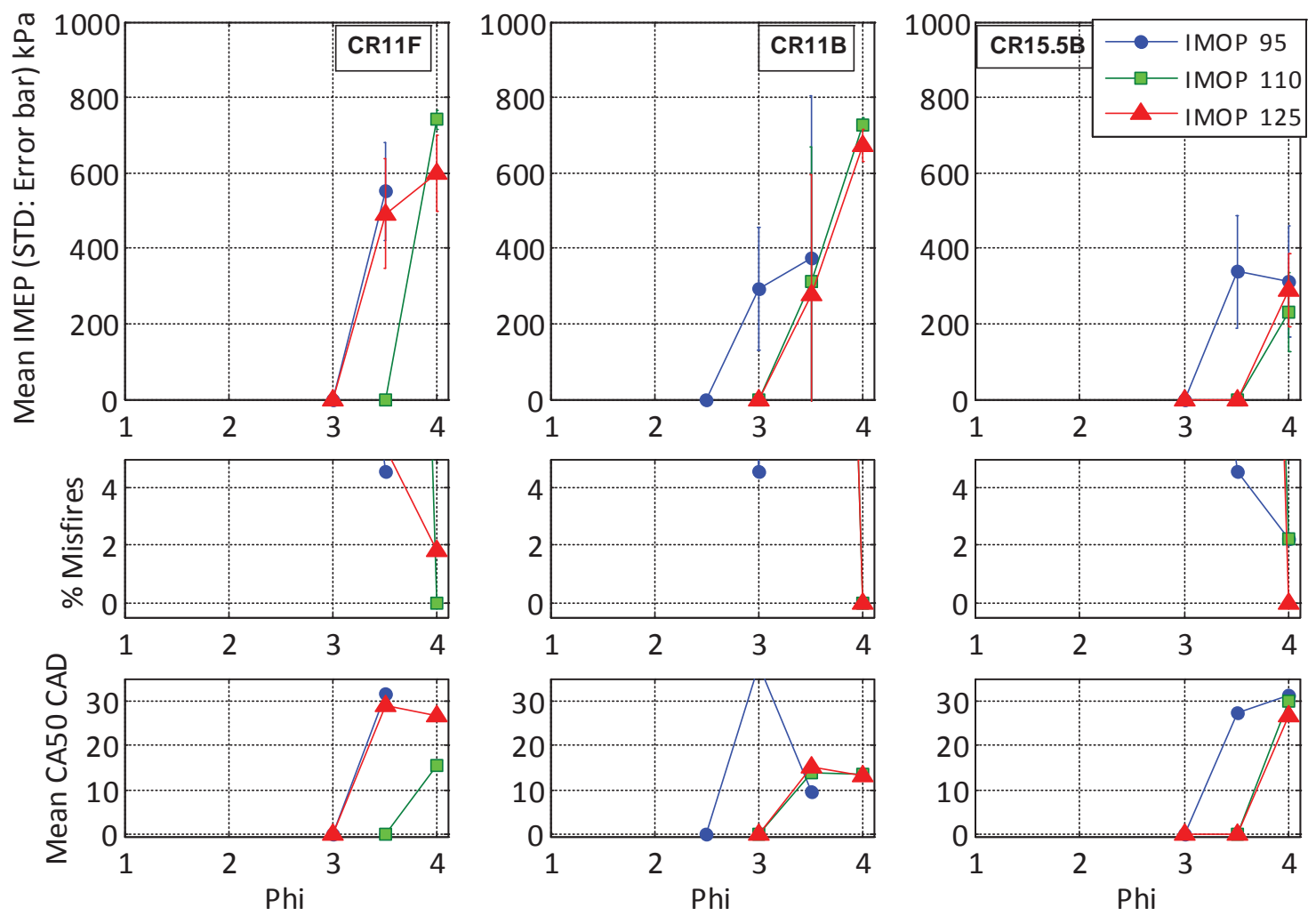

Figure 40: E85 test results

- CR11B: Only $\varnothing$ of 4 and IMOP 110 and 125 yielded stable combustion without misfires. IMOP 95 supported combustion at both $\varnothing 3.5$ and $\varnothing 3$ but had more than $5 \%$ of misfires. IMEP STD was low and comparable to the CR11F piston results. Misfire free test point CA50 values were similar to CR11F results.

- CR15B: For $\varnothing$ of 4, we note lower IMEP than CR11B. Preference for IMOP 95 is noted to be a characteristic of both the bowl pistons which supported lower $\varnothing$ combustion, but had significant misfires. IMOP 125 at $\varnothing 4$ seemed to be the only misfire free test point. While IMEP STD was significantly higher than CR11F/B. Higher CR seemed to have increased the CA50 of the combustion which was more than $27^{\circ}$.

\subsubsection{2. $\quad$ E85 high pressure testing SOI sweep}

Shown in Figure 41 are the E85 high pressure SOI sweep results. The results were broken down into three parts based on piston used; same plotting style was used that was previously used in gasoline testing results. The EMOP and IMOP positions that were used for the testing for each piston were are $-126^{\circ}$ aTDC and $95^{\circ}$ aTDC. 
Analyzing the results:

- CR11F: As SOI increased, the IMEP increased, misfires decreased. There were no misfires at SOI of $90^{\circ}$, thus it was chosen as optimum SOI for CR11F piston.

- CR11B: There were two SOI's at which misfires are zero; $30^{\circ}$ and $70^{\circ}$. Since $70^{\circ}$ had higher IMEP, it was chosen as optimum SOI for CR11B piston.

- CR15B: The IMEP decreased as SOI increased. Misfires also increased as SOI increased beyond $50^{\circ}$. Thus $30^{\circ}$ was chosen as optimum SOI for CR15B piston.

- Bowl pistons preferred different SOI's in case of E85 fuel compared to gasoline.
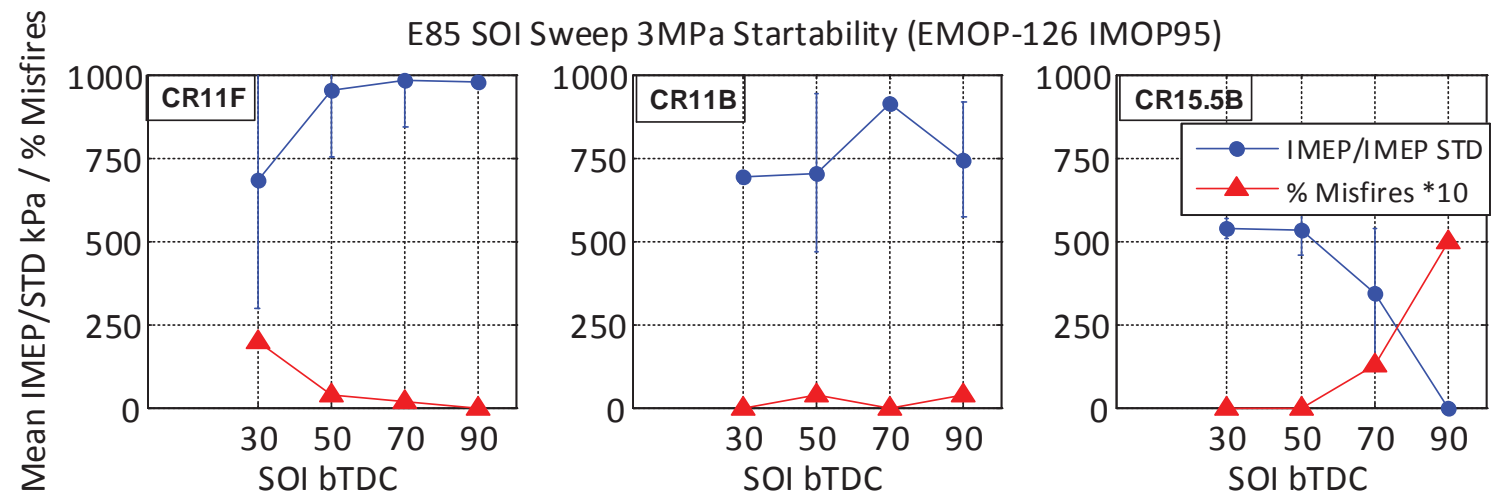

Figure 41: E85 SOI sweep

\subsubsection{3. $\quad$ E85 High pressure testing}

Shown in Figure 42 are the E85 low pressures testing results. The results are broken down into 3 important parts based on piston used; same plotting style was used which was previously used in gasoline testing results.

Analyzing the results:

- CR11F: Testing started at $\varnothing 3$ for IMOP 95, at $\varnothing 2.7$ there were significant misfires, while $\varnothing 2.4$ had more than $50 \%$ misfires. Taking $\varnothing 2.4$ as starting point for IMOP 125 testing, there were $4 \%$ misfires at $\varnothing 1.8$ while any lower $\varnothing^{\prime}$ 's again showed more than $50 \%$ misfiring. Similarly for IMOP 110 there was robust firing at $\varnothing$ of 2.1. The CA50 of the test point without misfires for IMOP 110 is approximately $5-7^{\circ}$.

- CR11B: For $\varnothing$ of 2.1 and IMOP 110 and 125, there was stable combustion with no misfires. Below $\varnothing 2.1$ all IMOP positions misfired. IMEP STD is low and was comparable to the CR11F piston results. Stable test point CA50 values are higher than 10 which was higher that the CR11F results. 
- CR15B: At $\varnothing$ of 2.1 IMEP was lower than CR11B. It had a preference for IMOP 95, at $\varnothing 1.5$ seemed to be the only stable combustion point at that $\varnothing$. While IMEP STD was significantly higher than CR11F/B. CA50 of combustion was comparable to CR11B piston and a bit higher than CR11F piston.
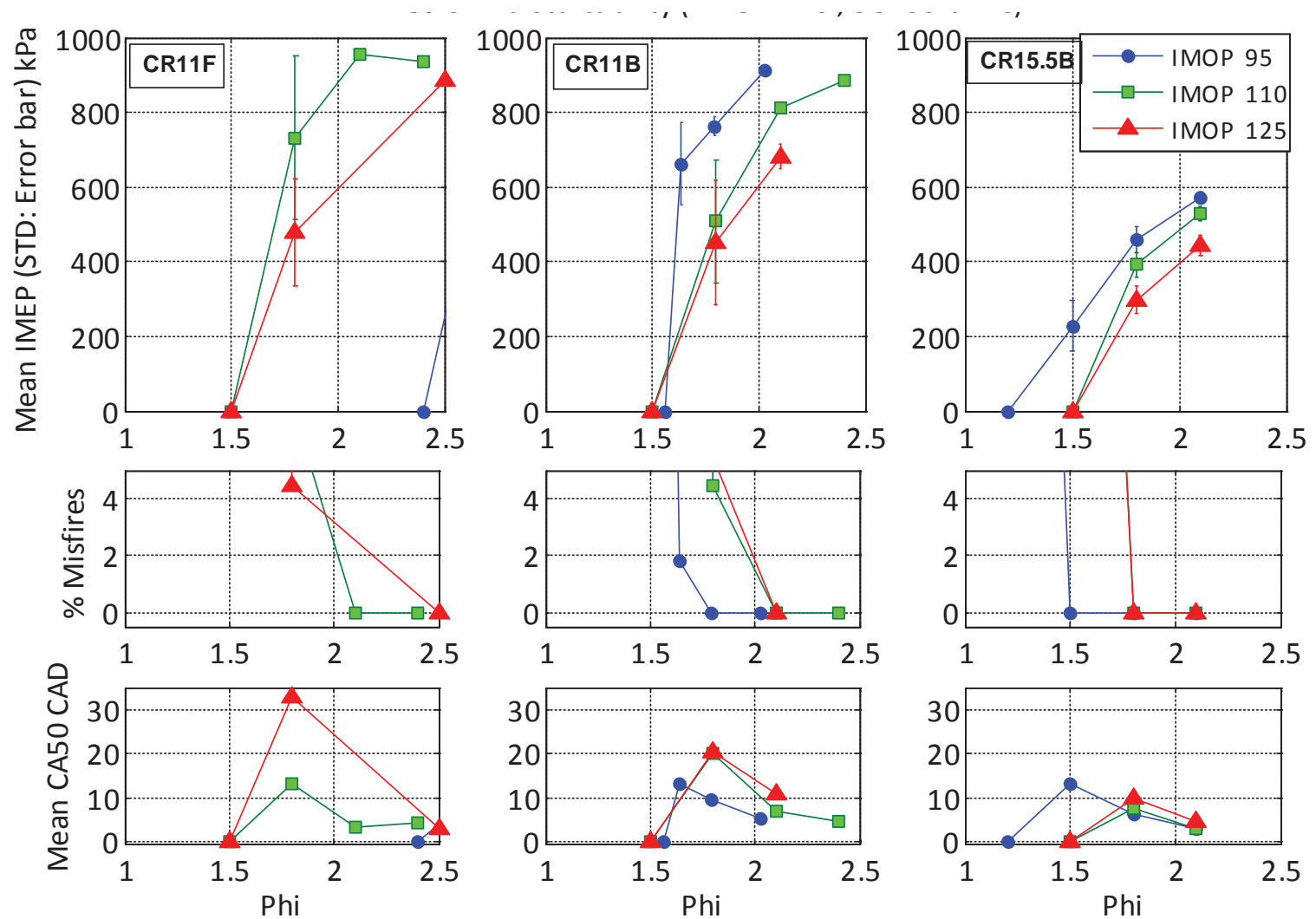

Figure 42 : E85 high pressure testing 


\subsection{Overall Phase 1 - Cycle 1 Testing Results}

The results from the graphs are tabulated below in terms of the lowest starting $\varnothing$ for the $1^{\text {st }}$ cycle, and the IMEP and IMOP position at that $\varnothing$. Table 15 shows the results for low fuel pressure testing, Table 16 shows the optimal SOI for the SOI sweeps at high fuel pressure and Table 17 shows tabulated results for the high fuel pressure testing.

Table 15 : Minimum $\varnothing$ required for $0.4 \mathrm{MPa}$ fuel pressure testing and the corresponding IMOP position for gasoline and E85 for each piston

\begin{tabular}{cc|c|c|c|c|c}
\hline Test type & 0.4 MPa Fuel Pressure & \multicolumn{3}{c}{ E85 } \\
\hline \multicolumn{7}{c|}{ UTG91 } \\
\hline CR & ${\text { IMOP }{ }^{\circ} \text { aTDC }}^{\text {0 }}$ & IMEP kPa & IMOP ${ }^{\circ}$ aTDC & $\varnothing$ & IMEP kPa \\
\hline 11F & 110 & 2.25 & 903 & 110 & 4 & 740 \\
11B & 95 & 2.00 & 684 & 125 & 4 & 728 \\
15.5B & 95 & 2.00 & 459 & 125 & 4 & 310 \\
\hline
\end{tabular}

Table 16: Optimum SOI for $3 \mathrm{MPa}$ fuel pressure testing for gasoline and E85 for each piston

\begin{tabular}{cc|c}
\hline Test type & \multicolumn{2}{c}{ 3MPa Fuel Pressure } \\
\hline \multicolumn{3}{c}{ SOI $^{\circ}$ bTDC } \\
\hline CR & UTG91 & E85 \\
\hline 11F & 70 & 90 \\
11B & 30 & 70 \\
15.5B & 30 & 30 \\
\hline
\end{tabular}

Table 17: Minimum $\varnothing$ required for $3 \mathrm{MPa}$ fuel pressure testing and the corresponding IMOP position for gasoline and E85 for each piston

\begin{tabular}{cc|c|c|c|c|c|}
\hline Test type & \multicolumn{7}{c|}{ 3MPa Fuel Pressure } \\
\hline \multicolumn{3}{c}{ UTG91 } & \multicolumn{3}{c}{ E85 } \\
\hline CR & ${\text { IMOP }{ }^{\circ} \text { aTDC }}^{\text {Ø }}$ & IMEP kPa & IMOP ${ }^{\circ}$ aTDC & $\varnothing$ & IMEP kPa \\
\hline 11F & 110 & 1.2 & 546 & 110 & 2.1 & 955 \\
11B & 95 & 1.1 & 478 & 110 & 2.1 & 681 \\
15.5B & 95 & 0.6 & 253 & 95 & 1.5 & 228 \\
\hline
\end{tabular}

The results are also illustrated as a comparison of the effect a change of a parameter has on minimum starting $\varnothing$, is shown in Figure 43, Figure 44 and Figure 45. These show that high fuel pressure is highly effective in reducing the starting $\varnothing$. Further using bowl piston instead of flattop has benefits only for gasoline fuel. E85 is thought to form fuel puddles leading to large piston wetting and reduced vaporization, thus not 
benefiting from the use of bowl piston. And increasing compression ratio only helps higher fuel pressure starts.

\begin{tabular}{|c|c|}
\hline \multicolumn{1}{|c|}{ CR11 } \\
\hline Flat top piston \\
\hline \begin{tabular}{c} 
Gasoline \\
\hline $\begin{array}{c}\text { Use High fuel pressure } \\
\text { vs low }\end{array}$
\end{tabular} \\
\hline $\begin{array}{c}\text { Use High fuel pressure } \\
\text { vs low }\end{array}$ \\
\hline $46 \%$ reduction in $\varnothing$ & $47 \%$ reduction in $\varnothing$ \\
\hline
\end{tabular}

Figure 43: Effect of increase in fuel pressure from low to high on starting $\varnothing$ for both fuels

\begin{tabular}{|c|c|c|c|}
\hline \multicolumn{4}{|c|}{ CR11 } \\
\hline \multicolumn{4}{|c|}{ Use of Bowl vs Flattop } \\
\hline \multicolumn{2}{|c|}{ Gasoline } & \multicolumn{2}{|c|}{ Ethanol } \\
\hline $\begin{array}{l}\text { Low fuel } \\
\text { pressure }\end{array}$ & $\begin{array}{c}\text { High Fuel } \\
\text { pressure }\end{array}$ & $\begin{array}{l}\text { Low fuel } \\
\text { pressure }\end{array}$ & $\begin{array}{l}\text { High Fuel } \\
\text { pressure }\end{array}$ \\
\hline $\begin{array}{c}12 \% \text { reduction } \\
\text { in } \varnothing\end{array}$ & $\begin{array}{l}10 \% \text { reduction } \\
\text { in } \varnothing\end{array}$ & No effect & No effect \\
\hline
\end{tabular}

Figure 44: Effect of use of bowl piston instead of a flat top piston on starting $\varnothing$ for both fuels

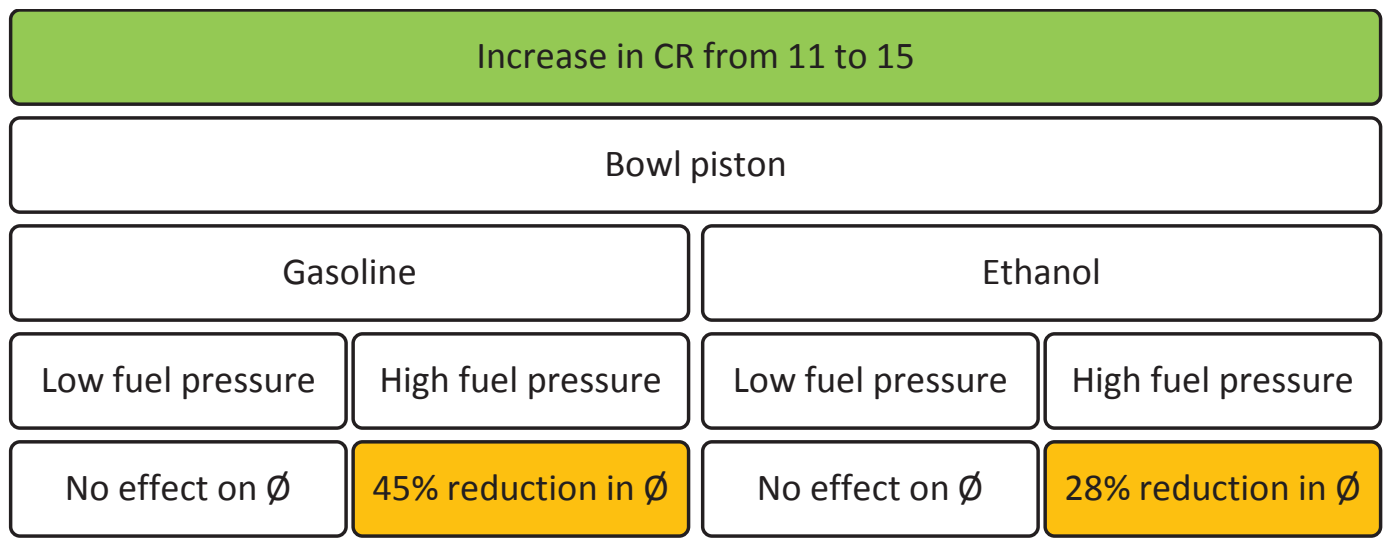

Figure 45: Effect of increase in CR from 11 to 15 on starting $\varnothing$ for both fuels 
Further it's noted that the optimal IMOP position for flat-top piston across fuels is constant. Bowl piston allowed SOI's closer to the TDC compared to the flat-top piston.

An overall analysis of the complete data set was done my means of plotting the IMEP data for all IMOP positions as overlapping datasets. This plot shown in Figure 46 was termed as IMEP envelope plot, shows us an approximate relationship between CR and fueling $\varnothing$ for low and high fuel pressure of gasoline and E85. This enables better comparison across all parameters based on IMEP and minimum starting $\varnothing$. A key observation inferred beyond comparison done earlier is stated as; increase in compression ratio for the bowl piston increased the $\varnothing$ requirement at low fuel pressures.
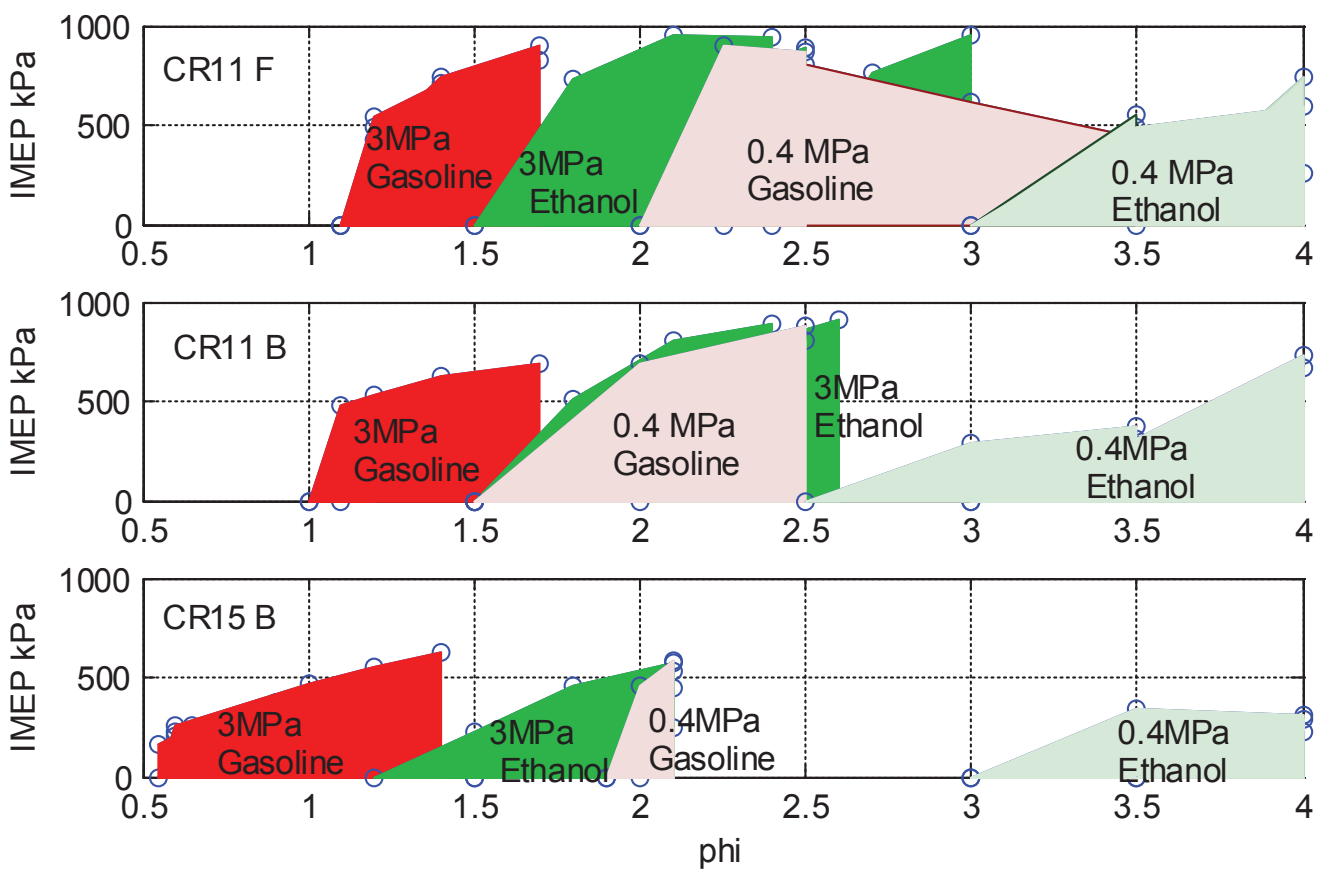

Figure 46: Overall IMEP envelope plot for all datasets 


\subsection{Startup Simulation Model and Startability Simulation}

A simulation model was necessary for theengine startup testing to enable better exploration of the intake and exhaust cam phasing space. This would enable finding a feasible cam phasing region, also allow picking exact testpoints for $2^{\text {nd }}$ and $3^{\text {rd }}$ cycle testing. Thus there was an effort to create a simulation model suitable for engine startup. It was decided to perform simulations based on same speed step approach as followed in the experimental testing in which the engine speed for a particular startup cycle was fixed, thus we conduct cycle 1 simulation at $180 \mathrm{rpm}$ and cycle 2, 3 simulations at 1000 rpm. The overall integration of the simulation work with the experimental testing is shown in Figure 47. The simulation model was created in GT-POWER version 7.0 software. The results of the simulations were used as a guide to advanced startability testing which still focuses on $1^{\text {st }}$ engine startup cycle (discussed in more details in section 4.6) and to generate the test plan for cycle2 \& cycle3 testing. Finally the phase 2 testing was completed.

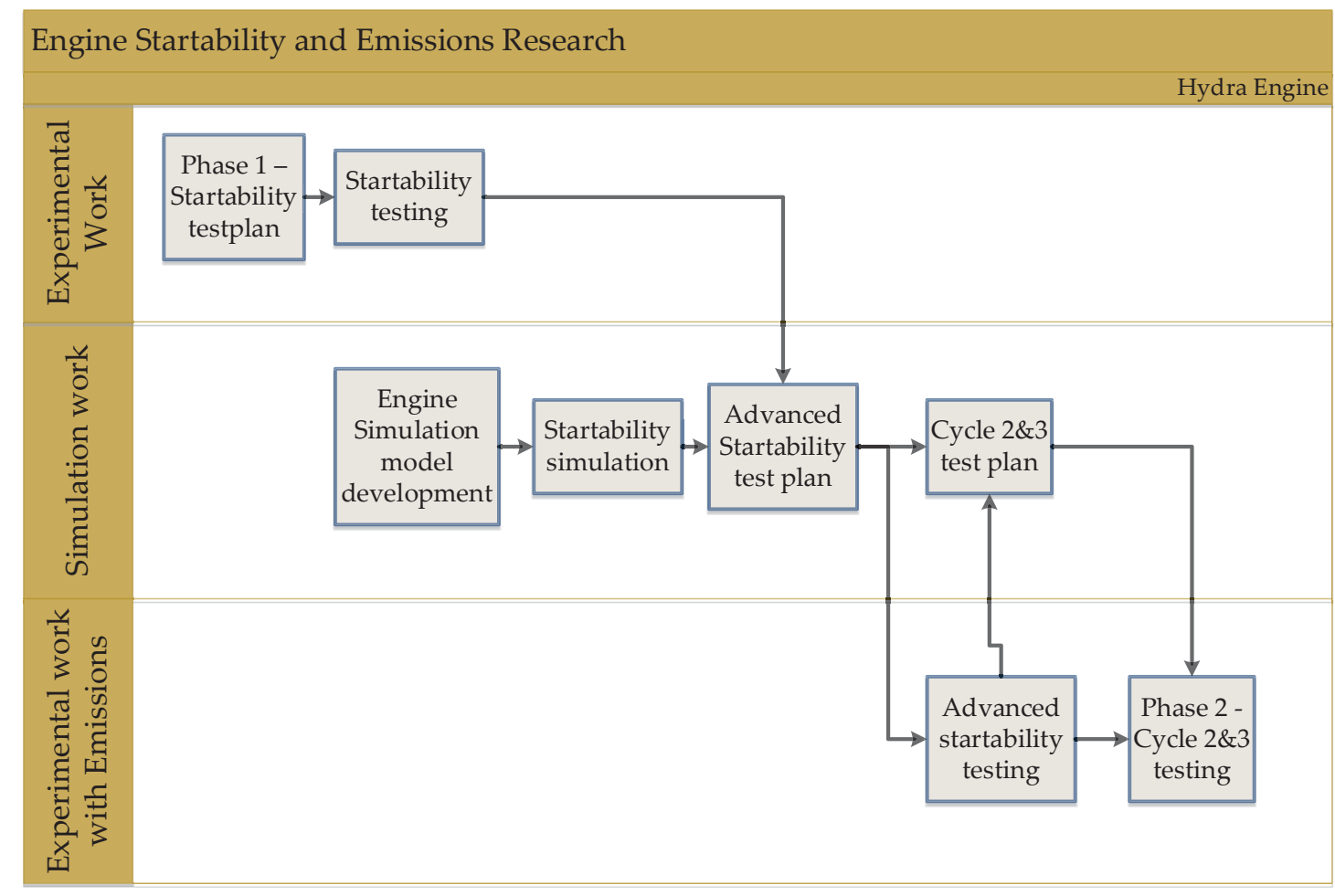

Figure 47: Research work flowchart

\subsubsection{Startability Simulation}

The simulation model created was based on a 4 cylinder GM LAF GT-POWER model. The LAF engine is the parent engine for the single cylinder engine. The geometry for the 
intake and exhaust ports is conserved across the single cylinder and multi-cylinder engine. Since this was a new GT-POWER model being created for the Hydra engine, all other geometric information had to be extracted either from the CAD model for the single cylinder engine or by taking physical measurements on the engine. The valve discharge coefficient information from the base LAF model was retained, while the lift table was updated with information from Hydra intake and exhaust cams. Once the modeling was done it was tuned via a model tuning process outlined in the GT-POWER user manual (including flow and heat transfer co-efficients) and validated to work at steady state $\left(90^{\circ} \mathrm{C}\right.$ engine temperature); by means of comparison with experimental incylinder pressure data and combustion metrics previously collected on the engine at multiple speed \& load conditions.

Using the steady state tuned and validated model, the modification process for the startup simulations was initiated and completed. Figure 48 shows the engine startup simulation model structure; starting at the left with the intake system with the cylinder \& crank system in the middle and the exhaust system on the right. A number of parameters were extracted from the model including engine conditions at valve timing events.

Initially all temperatures for the engine were set to $25^{\circ} \mathrm{C}$ which is the standard FTP testing temperature. GT-POWER default combustion model does not have spark control, but has a fuel burned fraction that can be manually set. While this is useful, fuel burned fraction information is not available at engine startup unless detailed experimental testing is done. Hence we retain the default value and note that the model assumes all fuel is vaporized, burned. Thus the IMEP numbers we obtain from this model will indicate the maximum IMEP available at those engine conditions for stoichiometric fueling.

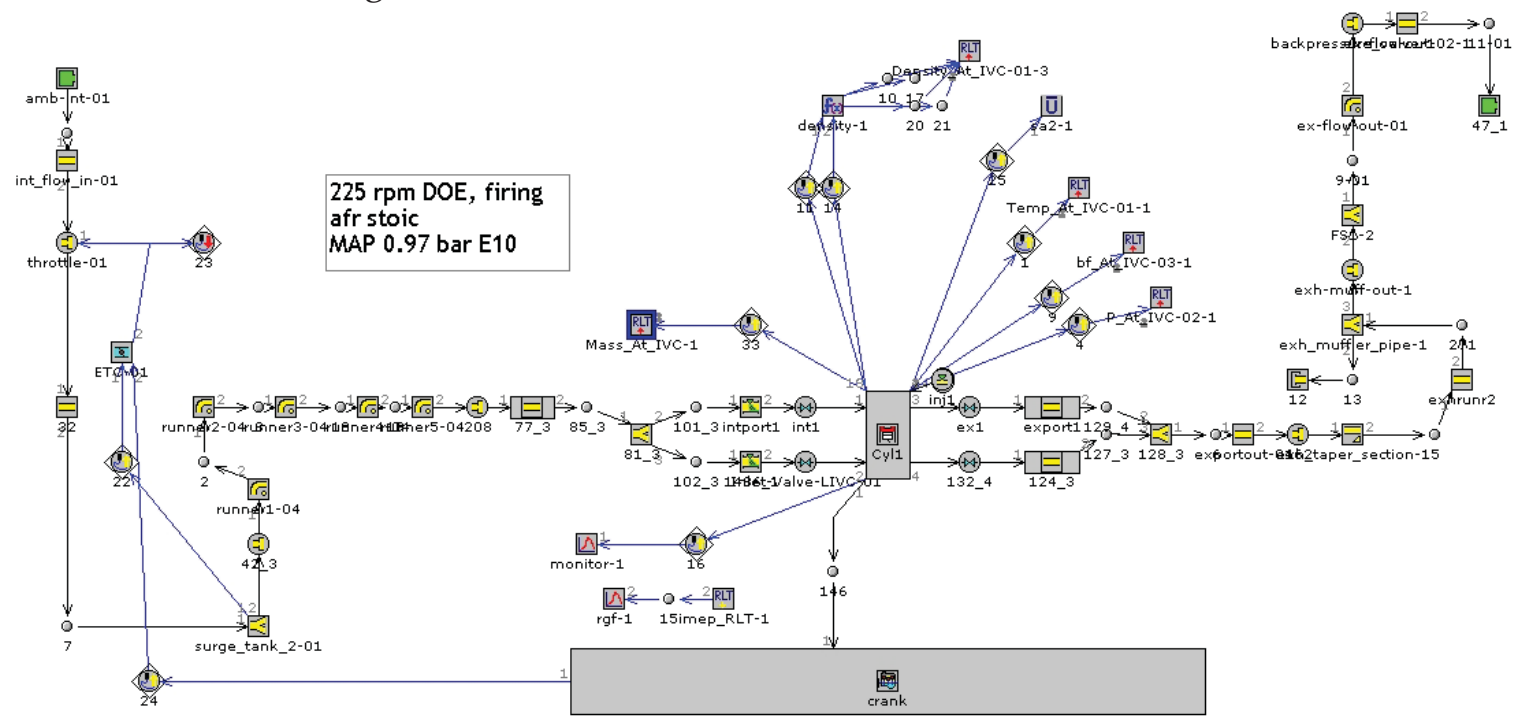

Figure 48: Hydra engine GT-POWER simulation model 
The original GT-POWER Woshni heat transfer model when used in the engine startup model was found to indicate IMEP results close to those seen from the experimental testing, hence it was used as is for the rest of the simulation work. Since our main interest is in capturing the trends for residuals, IMEP, trapped mass maps generated in the cam phasing space, more detailed simulation model was not needed for the purpose of guiding this research. These maps allow us to determine a feasible cam phasing space (IMEP greater than $600 \mathrm{kPa}$ ) in which the engine could be run at startup. Full factorial analysis was done in the cam phasing space with cam timing increments of 10 degrees for both intake and exhaust cam.

The startability simulation replicates the engine testing conditions that were chosen for the experimental phase 1 - cycle testing. All the simulation results are plotted as contour maps with $\mathrm{X}$ axis showing IMOP in ${ }^{\circ} \mathrm{CA}$ and $\mathrm{Y}$ axis being the EMOP in ${ }^{\circ} \mathrm{CA}$. The phase 1 test points are shown as white dots. The LAF engine park position is also noted on the graph. Shown in Figure 49, the in-cylinder residual fractions (Xr) trend showed that the residuals change drastically across the test points selected for the 1st phase of testing. The results of the model for IMEP are shown in Figure 50, it was seen that IMEP reduced as the IMOP was retarded, which is expected as the charge mass was reduced accordingly.

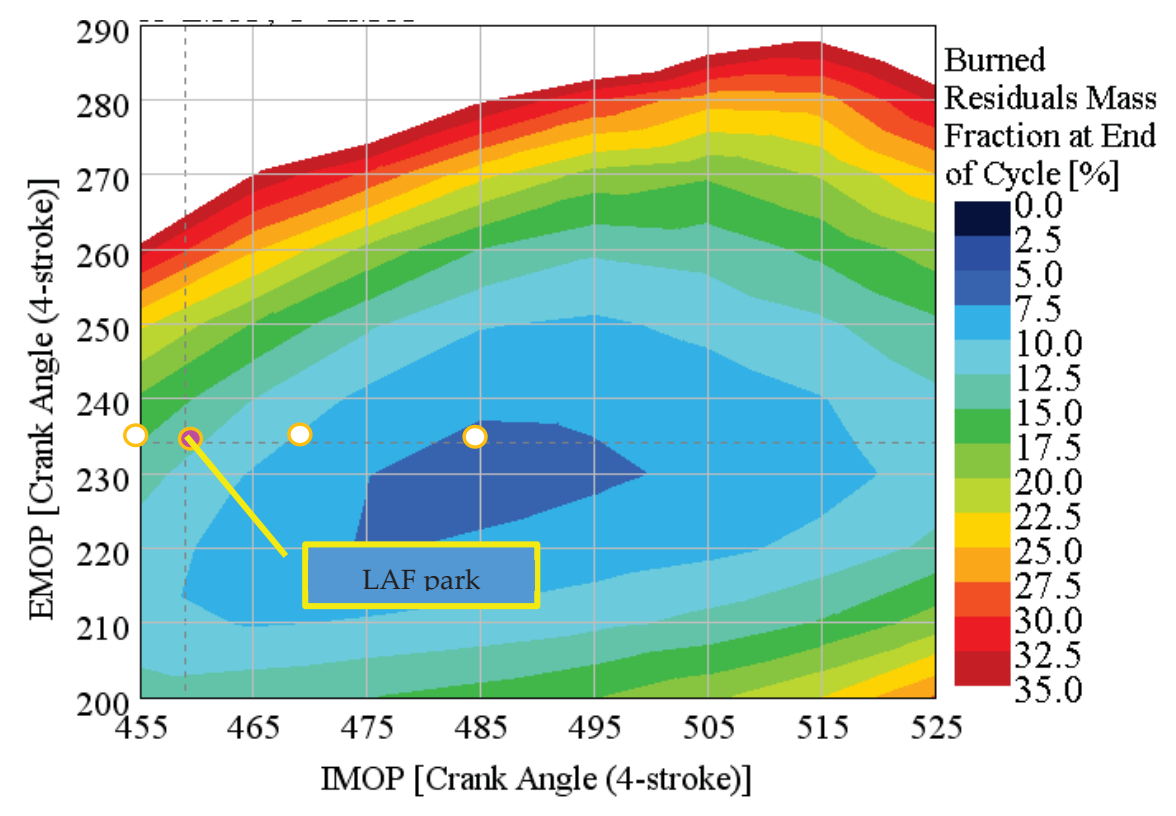

Figure 49: Residuals after 1st cycle firing at 180 RPM 0.95bar MAP

The simulation work was also used to deduce the approximate in-cylinder residual values at the test points used in the $1^{\text {st }}$ phase. These then used to calculate the estimated actual fueling $\varnothing$ values for the test points. This is necessary as the $\varnothing$ value was determined by means of continuous firing at the chosen cam positions, and hence 
the residuals reduced the fuel amount necessary to reach stoichiometric $\varnothing$, as there are no residuals in the aircharge for the $1^{\text {st }}$ cycle. This required simulation results for both CR11 and CR15.5 piston. The formula used to calculate the estimate actual $\varnothing$ was,

Estimated actual $\emptyset=$ Contineous fired $\emptyset(1-X r)$

Equation 4

The estimated $1^{\text {st }}$ cycle maximum IMEP was calculated from steady state GT-POWER computed IMEP by the following formula

Estimated 1 st cycle Max.IMEP = Steady state simulation IMEP / $(1-X r)$

Equation 5

The estimated actual $\varnothing$ for the results of the 1st cycle testing based on the new residuals information was computed. The results of the experimental phase 1 testing were updated based on this new $\varnothing$ value. It was noted that all the initial conclusions stay the same except for the E85 low pressure results and CR11F. The data for E85 low pressure results was insufficient after the new estimated actual $\varnothing^{\prime}$ s were calculated to make any updated conclusions for the optimum IMOP positions. Using the estimated actual $\varnothing$ for 1st cycle testing, the updated results for the experimental phase 1 testing are shown in Table 18 and Table 19.

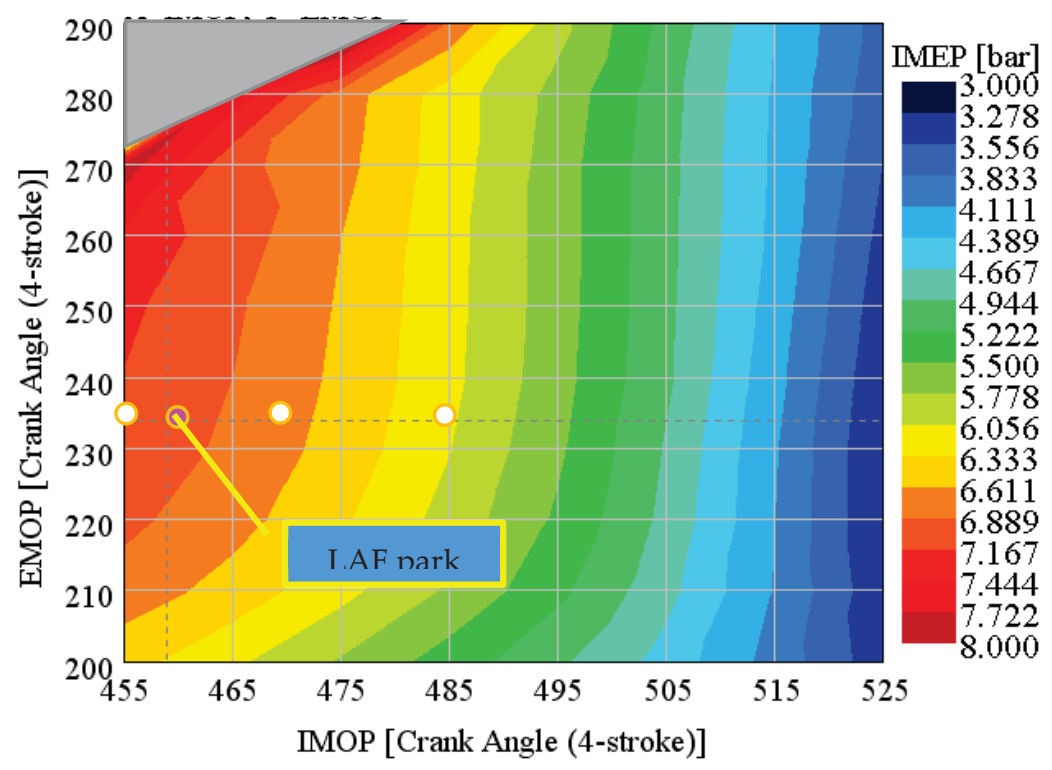

Figure 50: Estimated $1^{\text {st }}$ cycle IMEP without residuals at 180 RPM MAP 0.95 bar 
Table 18: Cycle 1 low pressure testing results - updated with estimated actual $\varnothing$

\begin{tabular}{c|cccc|c|c|c|}
\hline Test type & \multicolumn{6}{c|}{0.4 MPa Fuel Pressure (updated Ø) } \\
\hline \multirow{3}{*}{ CR } & \multicolumn{3}{|c}{ UTG91 } & \multicolumn{3}{c|}{ E85 } \\
\cline { 2 - 8 } & IMOP ${ }^{\circ}$ aTDC & $\varnothing$ & IMEP kPa & IMOP ${ }^{\circ}$ aTDC & $\varnothing$ & IMEP kPa \\
\hline 11F & 110 & 2.04 & 903 & 110 & 3.63 & 740 \\
11B & 95 & 1.71 & 684 & 125 & 3.72 & 728 \\
15.5B & 95 & 1.71 & 459 & 125 & 3.78 & 310 \\
\hline
\end{tabular}

Table 19: Cycle 1 high pressure testing results - updated with estimated actual $\varnothing$

\begin{tabular}{c|ccc|c|c|c|}
\hline Test type & \multicolumn{6}{c|}{3 MPa Fuel Pressure(updated Ø) } \\
\hline \multirow{2}{*}{ CR } & \multicolumn{3}{|c|}{ UTG91 } & \multicolumn{3}{c|}{ E85 } \\
\cline { 2 - 8 } & IMOP ${ }^{\circ}$ aTDC & $\varnothing$ & IMEP kPa & IMOP ${ }^{\circ}$ aTDC & $\varnothing$ & IMEP kPa \\
\hline $11 F$ & 110 & 1.09 & 546 & 110 & 1.91 & 955 \\
$11 B$ & 95 & 0.94 & 478 & 110 & 1.91 & 681 \\
$15.5 B$ & 95 & 0.51 & 253 & 95 & 1.28 & 228 \\
\hline
\end{tabular}


The overall IMEP envelope graph is also updated with the new estimated $\varnothing$ data as shown in Figure 51.
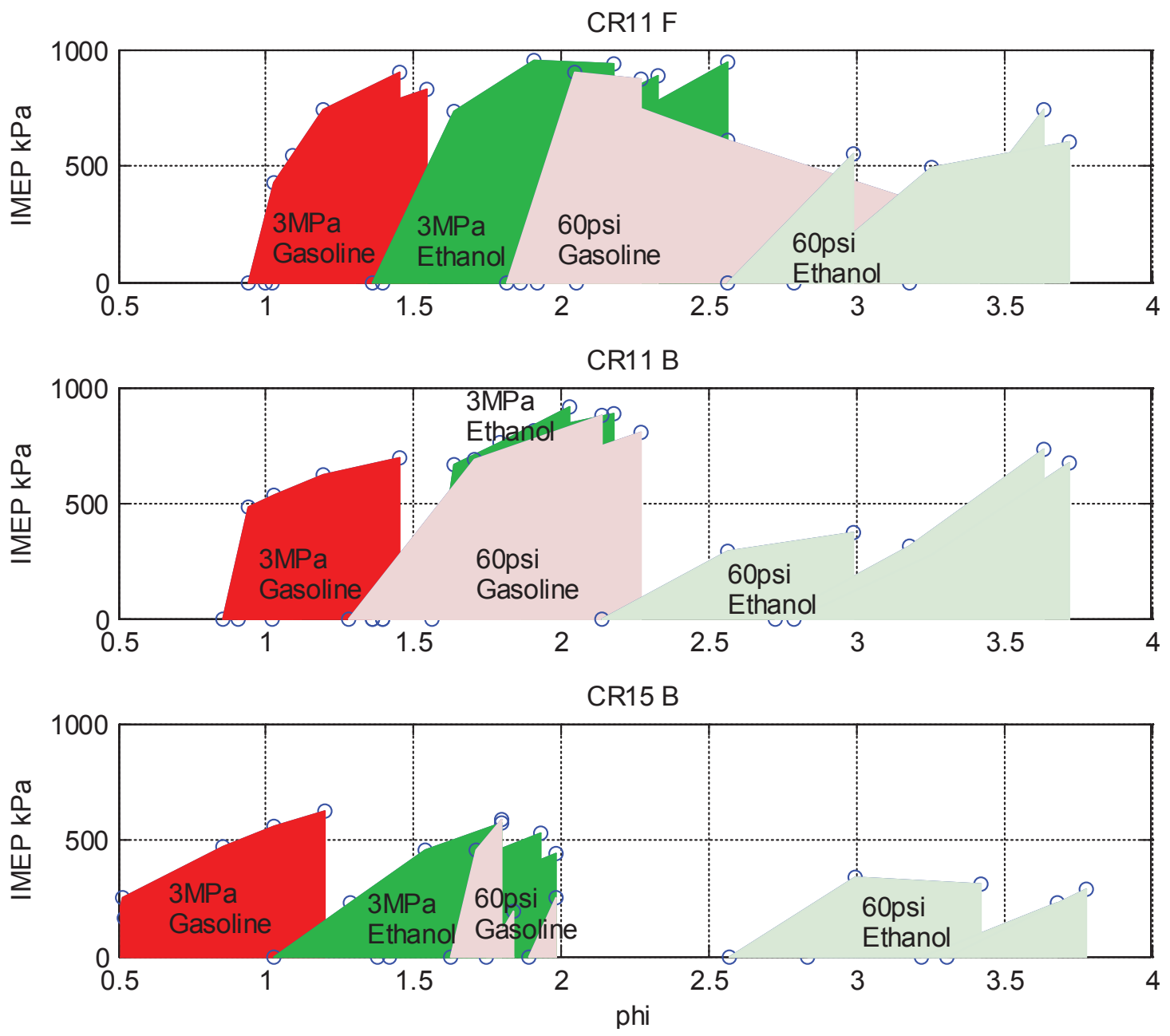

Figure 51: Updated IMEP envelope for all data 


\subsection{Advanced Startability Simulation and Testing}

\subsubsection{Advanced Startability Simulation work}

The second phase of testing was focused on emissions of $2^{\text {nd }}$ and $3^{\text {rd }}$ cycle. Since residuals gases affect the in-cylinder temperature and fuel residuals, the previous test points at EMOP $-126^{\circ}$ aTDC were not directly comparable to each other due to their difference in residual levels. Thus it was necessary to shift the test points at IMOP 110, IMOP125 which were in lower residuals zone to the same residual levels as IMOP 100 point (which is the LAF cam park position). They are highlighted as purple points in the Figure 52 with an additional objective of going higher in residuals.

Additionally during the period between the first phase testing and second phase testing, there was a change in testcell. The second testcell dynamometer did not robustly support skip-firing at low engine speeds such as $180 \mathrm{rpm}$, which was the speed at which testing was done in phase 1 . Hence the $1^{\text {st }}$ cycle rpm was increased to $225 \mathrm{rpm}$, which remains within the capability of current engine starters. Thus the simulations were rerun for $1^{\text {st }}$ cycle analysis at $225 \mathrm{rpm}$.

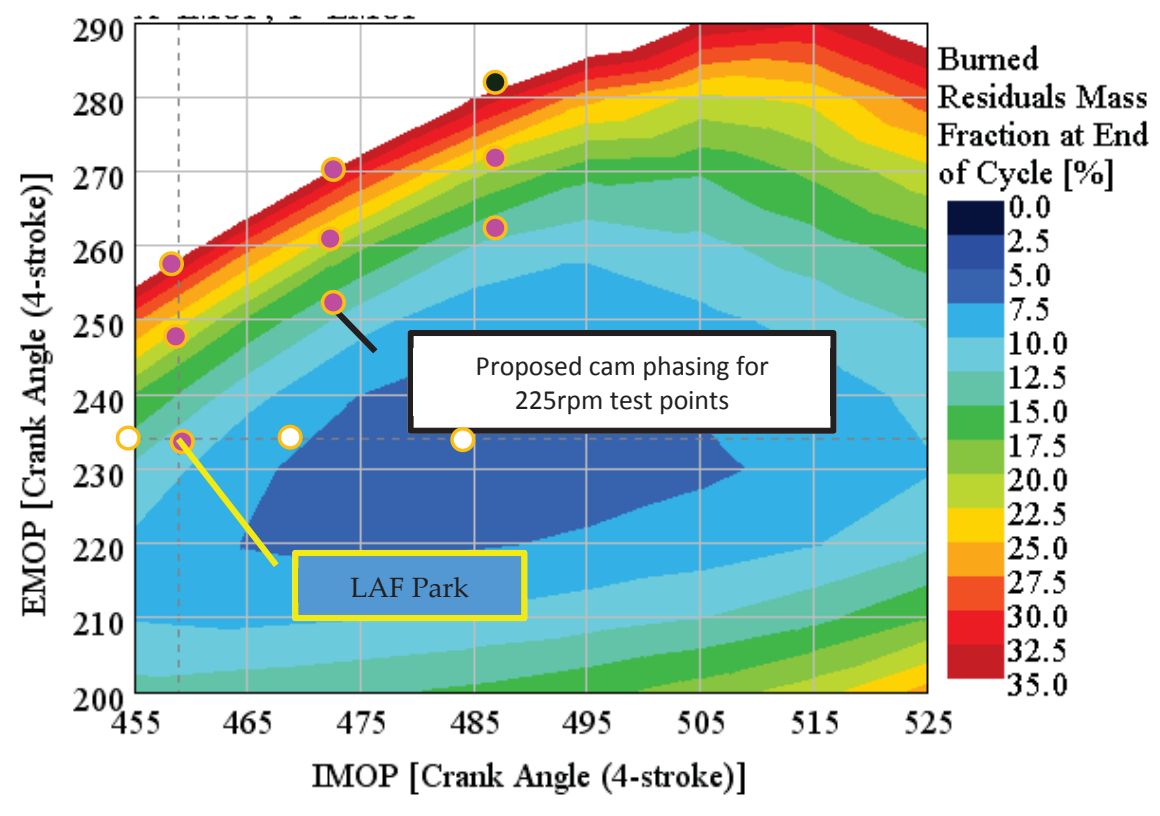

Figure 52: Residuals in cam phasing space at $225 \mathrm{rpm}, 0.95$ bar MAP

Shown in Figure 52 is the result for the internal residuals at $225 \mathrm{rpm}, 0.95$ bar MAP after firing the $1^{\text {st }}$ cycle. It was seen that the existing test points at EMOP of $234^{\circ}$ aTDCF (shown in yellow with white fill markers) were at different residual levels. It was proposed to add more test points to cover a larger cam phasing space than previously done for the $1^{\text {st }}$ cycle testing. The new test points cover estimated residual levels of $14 \%$, 
$22 \%$ and $34 \%$. One test point was infeasible (shown in black in figure) due to the cam phasing range restrictions and was hence eliminated.

Further contour plots in the cam phasing space were created for max cycle temperature (non-fired case) shown in Figure 53 and Volumetric Efficiency (VE) air (non-fired case) shown in Figure 54.

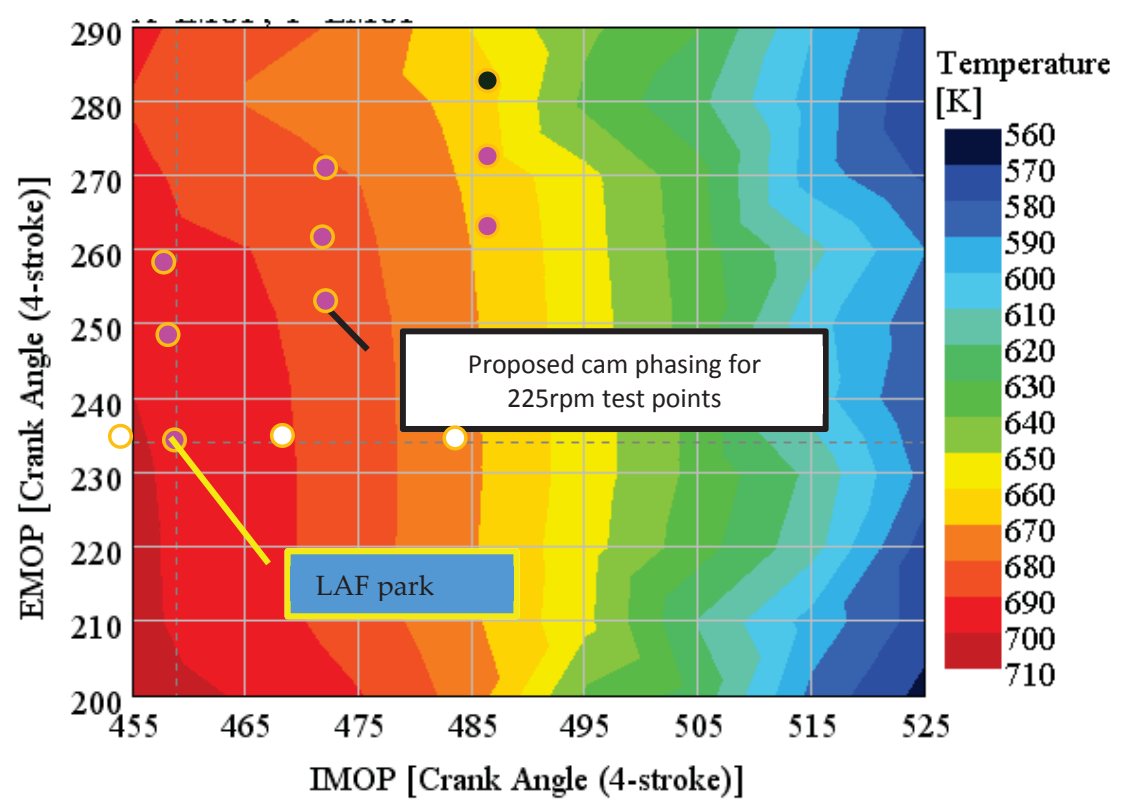

Figure 53: Maximum cycle temperature at 225 RPM - nonfiring case.

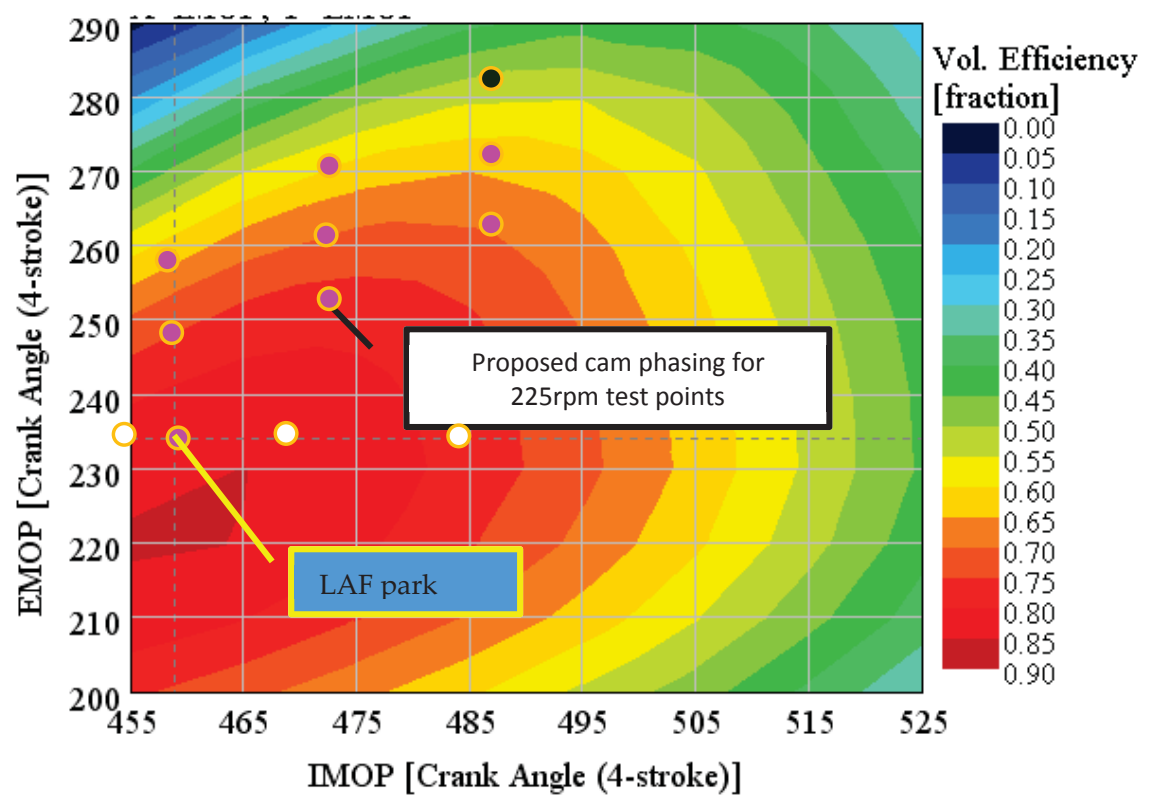

Figure 54: Volumetric efficiency at 225 RPM- nonfiring case. 
The max cycle temperature contours indicate vertical patterns directly related to the IMOP position. The more advance an IMOP position, the higher maximum cycle temperature. While the Volumetric efficiency (VE) contours show oval patterns, with most of our test points with VE more than 0.6.

The IMEP plot shown in Figure 55 indicates the maximum IMEP of approx. 7.5 bar might be achievable at the chosen cam phasing test points. The test points at different EMOP but same IMOP show that IMEP is directly related to IMOP positions rather than EMOP position. This is expected since there are no residuals for the $1^{\text {st }}$ fired cycle. Our most retarded IMOP test points are located at the threshold of 6.5 bar IMEP. Based upon engineering experience [70] a 6 bar IMEP threshold is set as the minimal work output required for successful start and run-up from the first fired cycle. Further the air charge drawn into the engine is dependent on the altitude above sea level. At high altitudes the density reduces significantly; at an altitude of 2000 meters the density is reduced $18 \%$. With 6 bar IMEP as the engineering target, a safety factor is considered for high altitude where density can be $20 \%$ less. Thus a good park cam position strategy for the intake cam will be to park the intake cam advanced.

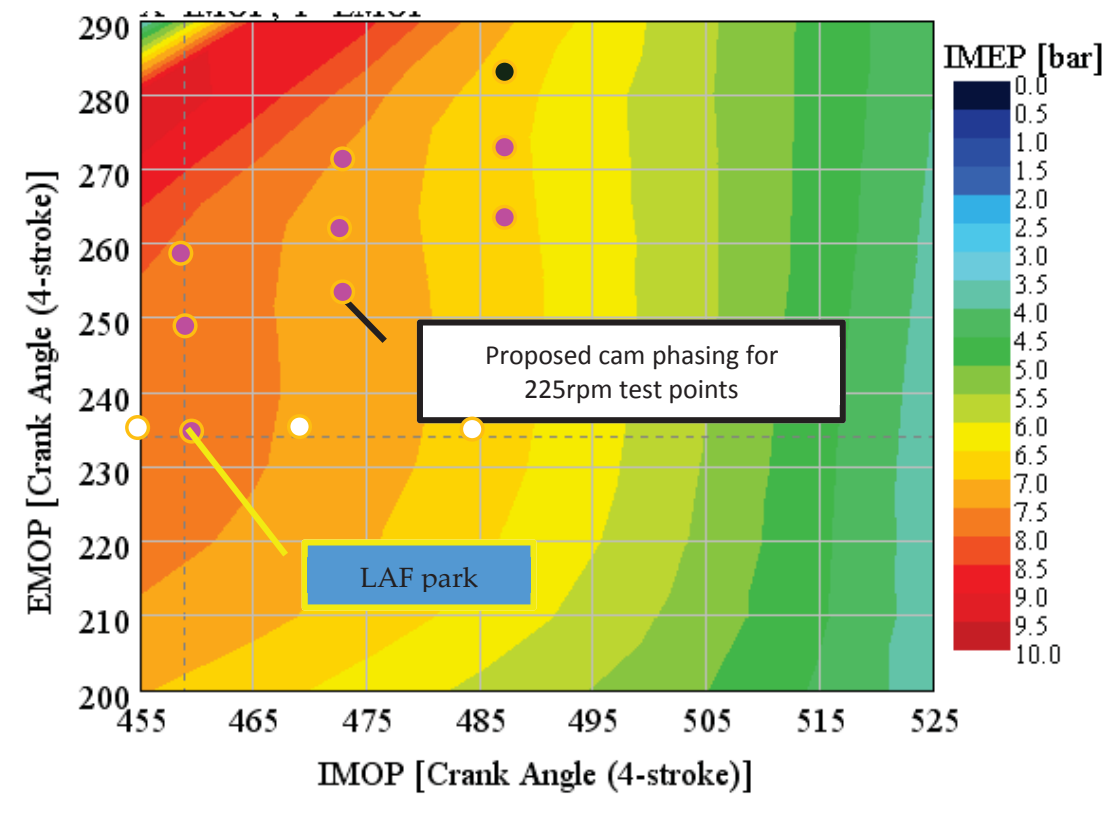

Figure 55: Maximum IMEP possible for $1^{\text {st }}$ cycle

Further, benefits can be derived for the next $2^{\text {nd }}$ and $3^{\text {rd }}$ cycle by retarding the EMOP so as to capture more residuals and enable better vaporization of the fuel for those cycles by increasing the charge temperature. The amount of EMOP retard is thought to be limited by the increase in COV/variation in IMEP and increase in residuals for the next cycle. Thus at large EMOP retarded conditions, increased IMEP can be seen by capturing more of the work output; keeping constant IMOP in such a case, it might also 
increase variability in the following cycle by increasing the residuals to a point where reliable combustion might not be possible at startup conditions. Overall it is noted that for a given MAP, residuals decrease as engine speed increases. Thus it is thought that a continuous 3 cycle firing at cranking speed represents a worst case startup scenario where misfires/combustion instabilities due to high residuals cause the engine to be unable to speed up.

\subsubsection{Experimental Testing}

The test points marked out in simulations are tested experimentally for $1^{\text {st }}$ cycle firing and beyond by firing for 3 consecutive cycles at 225 RPM. This thus serves to trim down on the test matrix for the next phase of testing. This exercise is only done for the CR11F piston, E10 fuel and $3 \mathrm{MPa}$ fuel pressure.

\section{Table 20: Advanced startability baselines}

\begin{tabular}{|c|c|c|c|c|c|c|c|}
\hline \multicolumn{8}{|c|}{ Constant Parameters: CR:11F, RPM :225, Coolant temp 25C, Cycle of Interest:1,2,3 } \\
\hline \multirow{3}{*}{$\begin{array}{c}\text { Test } \\
\text { No }\end{array}$} & \multirow{3}{*}{ Fuel Type } & \multicolumn{6}{|c|}{ Control Parameters } \\
\hline & & MAP & EMOP & IMOP & SA & SOI & $\begin{array}{c}\varnothing \\
\text { Cycle1-2-3 }\end{array}$ \\
\hline & & $\mathrm{kPa}$ & ${ }^{\circ}$ ATDC & ${ }^{\circ}$ ATDC & ${ }^{\circ} \mathrm{ATDC}$ & ${ }^{\circ} \mathrm{BTDC}$ & \\
\hline & \multicolumn{7}{|l|}{ Baselines } \\
\hline 1 & E10 & 98 & -126 & 100 & 10 & $\mathrm{SOl}^{*}$ & $1.4-1-1$ \\
\hline 2 & E10 & 98 & -112 & 100 & 10 & $\mathrm{SOl}^{*}$ & $1.4-1-1$ \\
\hline 3 & E10 & 98 & -102 & 100 & 10 & $\mathrm{SOl}^{*}$ & $1.4-1-1$ \\
\hline 4 & E10 & 98 & -93 & 110 & 10 & $\mathrm{SOl}^{*}$ & $1.4-1-1$ \\
\hline 5 & E10 & 98 & -97 & 113 & 10 & $\mathrm{SOl}^{*}$ & $1.4-1-1$ \\
\hline 6 & E10 & 98 & -87 & 113 & 10 & $\mathrm{SOl}^{*}$ & $1.4-1-1$ \\
\hline 7 & E10 & 98 & -126 & 110 & 10 & $\mathrm{SOl}^{*}$ & $1.4-1-1$ \\
\hline 8 & E10 & 98 & -126 & 125 & 10 & $\mathrm{SOl}^{*}$ & $1.4-1-1$ \\
\hline 9 & E10 & 98 & -97 & 128 & 10 & $\mathrm{SOl}^{*}$ & $1.4-1-1$ \\
\hline 10 & E10 & 98 & -87 & 128 & 10 & $\mathrm{SOl}^{*}$ & $1.4-1-1$ \\
\hline
\end{tabular}

Since this is still the $1^{\text {st }}$ cycle testing it is termed as Advanced Startability Testing, the baselines for it is shown in Table 20. The only parameter changed from the baseline during its testing is the $1^{\text {st }}$ cycle $\varnothing$. This is illustrated in Table 21 where we sweep the $1^{\text {st }}$ cycle $\varnothing$ starting at $1.4 \varnothing$ in increments of 0.1 to determine the lowest $\varnothing$ at which robust combustion is supported. 


\section{Table 21: Test matrix for baseline 1}

\begin{tabular}{|c|c|c|c|c|c|c|c|c|}
\hline \multirow{2}{*}{\multicolumn{9}{|c|}{$\begin{array}{l}\text { Constant Parameters: CR:11F, RPM:225, Coolant temp 25C, Cycle of Interest:1,2,3 } \\
\text { Control Parameters }\end{array}$}} \\
\hline & & & & & & & & \\
\hline \multirow[t]{3}{*}{$\begin{array}{l}\text { Test } \\
\text { No }\end{array}$} & \multirow[t]{2}{*}{ Fuel Type } & MAP & EMOP & IMOP & SA & SoI Cycle1-2-3 & \multirow[t]{2}{*}{$\varnothing$} & \multirow[t]{2}{*}{$\begin{array}{l}\text { Cycle1- } \\
2-3\end{array}$} \\
\hline & & $\mathrm{kPa}$ & ${ }^{\circ}$ ATDC & ${ }^{\circ}$ ATDC & ${ }^{\circ}$ ATDC & ${ }^{\circ} \mathrm{BTDC}$ & & \\
\hline & \multicolumn{8}{|l|}{ Baseline 1} \\
\hline 1 & E10 & 98 & -126 & 100 & 10 & $70-70-70$ & & $1.4-1-1$ \\
\hline 2 & E10 & 98 & -126 & 100 & 10 & $70-70-70$ & & 1.3-1-1 \\
\hline 3 & E10 & 98 & -126 & 100 & 10 & $70-70-70$ & & $1.2-1-1$ \\
\hline 4 & E10 & 98 & -126 & 100 & 10 & $70-70-70$ & & 1.1-1-1 \\
\hline 10 & E10 & 98 & -126 & 100 & 10 & $70-70-70$ & V & $1-1-1$ \\
\hline
\end{tabular}

The process followed in experimental testing is as follows; First SOI sweep is conducted for the fuel E10 at fueling $\varnothing$ of 1.4-1-1 (cycle1 $\varnothing$-cycle2 $\varnothing$-cycle3 $\varnothing$ ) and cam position of EMOP $-126^{\circ}$ aTDC, IMOP $110^{\circ}$ aTDC.

The results are plotted in Figure 56 against cycle number for the following parameters:

- IMEP (higher is better)

- Misfires \% (lower is better)

- Pressure at ignition (gives fuel vaporization information)

- CA50 (lower is better)

- IMEP/Injection duration (higher is better)

- IMEP/Airflow (higher is better)

- Cycle maximum HC \% (lower is better)

- Cycle maximum CO \% (lower is better)

- Cycle maximum $\mathrm{CO} 2 \%$ (higher is better)

Based on the IMEP and emissions seen at SOI $70^{\circ} \mathrm{bTDC}$, it is chosen as the optimum SOI for $1^{\text {st }}$ cycle testing. This SOI has the maximum IMEP for the $1^{\text {st }}$ fired cycle, high CO2 and low HC emissions. 

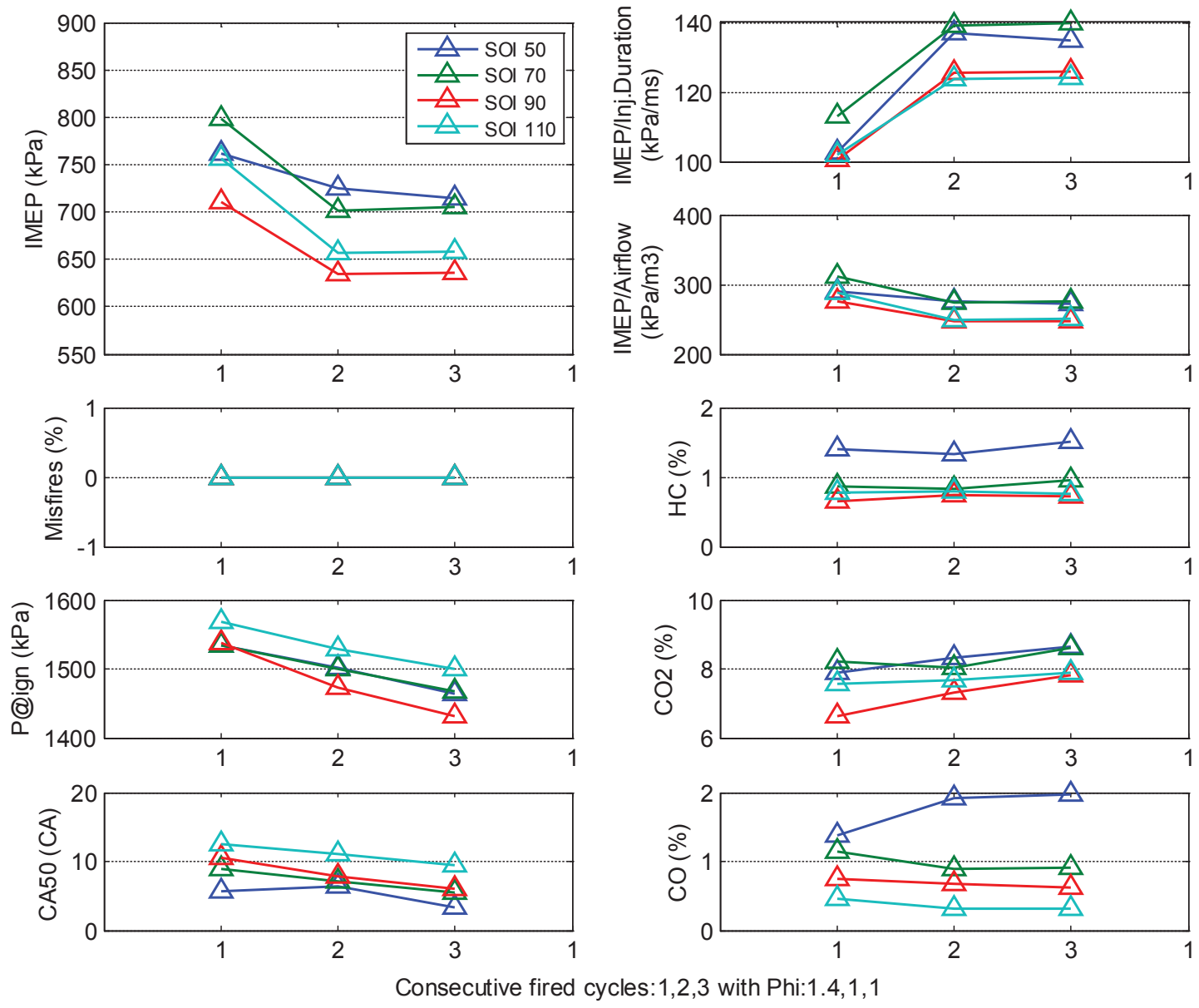

Figure 56: 3MPa fuel pressure SOI sweep for E10 fuel CR11F at 225 RPM

Using the optimum SOI of $70^{\circ}$ bTDC chosen from Figure 56, experimental testing is done at cam positions previously chosen in the simulation analysis at $225 \mathrm{rpm}$ and shown in the test matrix.

The results are plotted in Figure 57 against cycle number for the following parameters:

- IMEP (higher is better) - left top graph

- IMEP/Airflow (higher is better) - left middle graph

- IMEP/Injection duration (higher is better) - left bottom graph

- Cycle maximum HC \% (lower is better) - right top graph

- Cycle maximum CO \% (lower is better) - right middle graph

- Cycle maximum $\mathrm{CO} 2 \%$ (higher is better) - right bottom graph 
The legend shows the information in $\varnothing$ IMOP (I) EMOP (E) format. The x-axis shows cycle numbers 1,2,3, and these are repeated. This was done to space different IMOP results apart so as to better visualize all the results while at the same time being able to compare same IMOP but different EMOP results. From the IMEP subgraph it's seen that IMEP decreases as IMOP position is retarded. IMEP/Airflow, CO2 also decreases as IMOP position is retarded indicating less fuel burn efficiency. CO2 also decreases with more retarded EMOP positions.

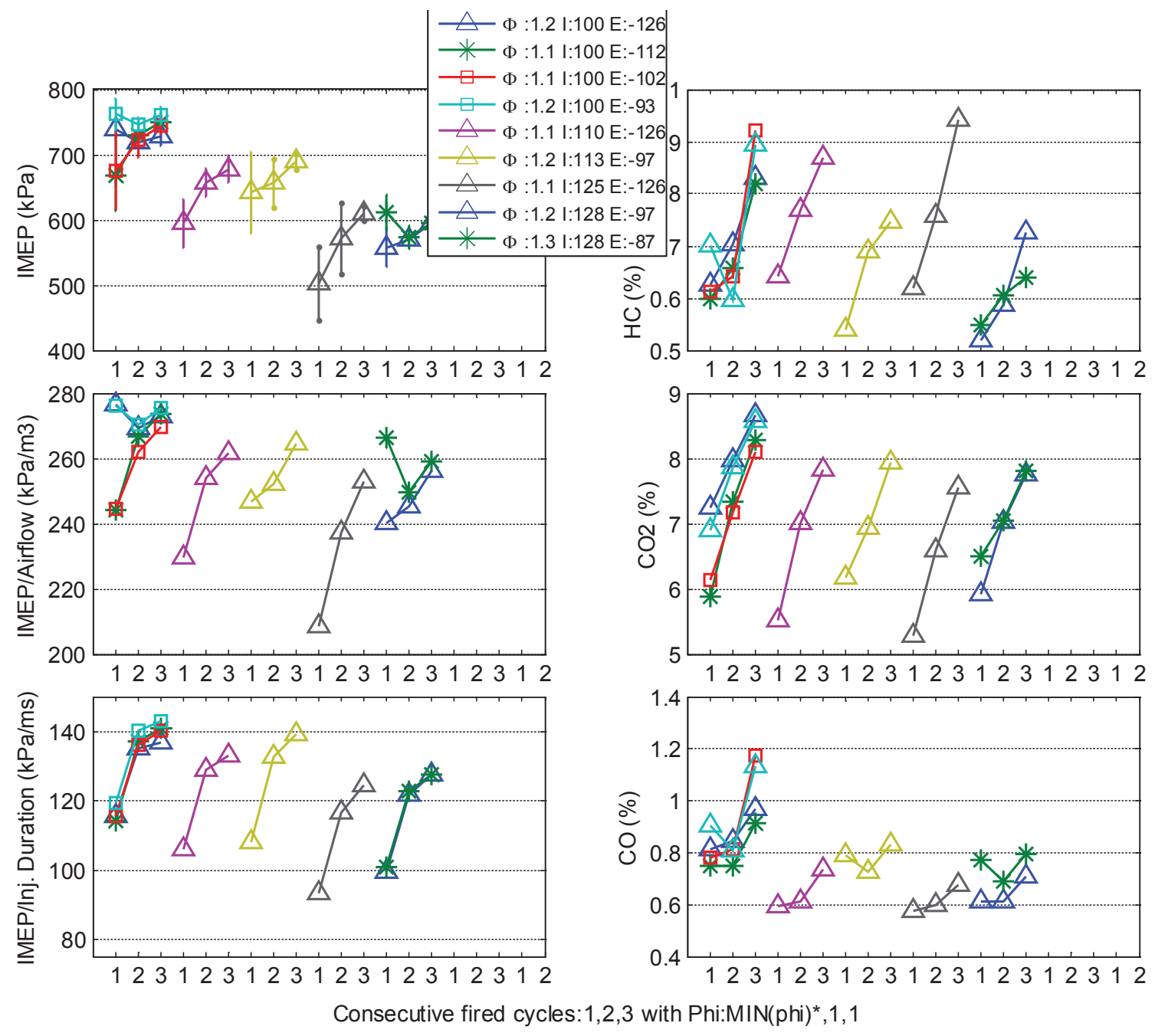

Figure 57: Test points at 3MPa fuel pressure for E10 fuel CR11F at 225 RPM

Based on the fact that there is less variability in IMEP for cam position $100^{\circ}$ aTDC,-112 and lowest HC and CO emissions, it is chosen as the optimum for this case of 
$1^{\text {st }}$ cycle firing at $225 \mathrm{rpm}$ with E10 fuel and 3MPa fuel pressure. Also it is clearly seen that the intake positions less advanced then IMOP 113 are unsuitable for startup since the $1^{\text {st }}$ cycle IMEP is below the threshold of around $600 \mathrm{kPa}$. Thus we choose to remove IMOP 125 and 128 test points from our test matrix for $2^{\text {nd }}$ and $3^{\text {rd }}$ fired cycle. For reference an engine cycle in which the air fuel mixture fails to ignite would lead to $6.79 \%$ $\mathrm{HC}$ based on stoichiometric fueling.

The results for $\varnothing^{\prime}$ s at each cam position are tabulated in Table 22, also the estimated actual $\varnothing$ is also calculated based on the residuals computed in the simulations. The test points removed from further consideration for testing are shown in red in the table.

Table 22: Actual $\varnothing$ computed from simulation residuals and injected fuel at 225 RPM 3MPa fuel pressure.

\begin{tabular}{ccccc}
\hline IMOP & EMOP & $\varnothing$ & $\begin{array}{c}\text { Estimated } \\
\text { Actual } \varnothing\end{array}$ & Comments \\
\hline $\mathbf{1 0 0}$ & $\mathbf{- 1 2 6}$ & 1.2 & 1.09 & \\
\hline$\underline{\mathbf{1 0 0}}$ & $\underline{\mathbf{- 1 1 2}}$ & $\underline{1.1}$ & $\underline{\mathbf{1 . 0 0 * *}}$ & $\underline{\text { Optimal based on lower HC/CO emissions }}$ \\
\hline $\mathbf{1 0 0}$ & $\mathbf{- 1 0 2}$ & 1.1 & 1.00 & $\begin{array}{c}\text { Min } \varnothing=0.91 \text {, has too much variability } \\
\text { Hence } \varnothing=1 \text { plotted for comparison }\end{array}$ \\
\hline $\mathbf{1 0 0}$ & $\mathbf{- 9 3}$ & 1.2 & 1.09 & \\
\hline $\mathbf{1 1 0}$ & $\mathbf{- 1 2 6}$ & 1.1 & 1.03 & \\
\hline $\mathbf{1 1 3}$ & $\mathbf{- 9 7}$ & 1.2 & 1.07 & \\
\hline $\mathbf{1 2 5}$ & $-\mathbf{1 2 6}$ & 1.1 & 1.04 & \\
\hline $\mathbf{1 2 8}$ & $\mathbf{- 9 7}$ & 1.2 & 0.98 & \\
\hline $\mathbf{1 2 8}$ & -87 & 1.3 & 1.07 & \\
\hline
\end{tabular}

Thus a basis was established for the range of cam phasing's we want to run in our test matrix for the $2^{\text {nd }}$ and $3^{\text {rd }}$ fired cycle analysis. 


\subsection{Phase 2 - Simulation and Experimental Emissions Testing for $2^{\text {nd }} \& 3^{\text {rd }}$ Engine Startup Cycle}

For a given intake and exhaust cam position, the internal residuals trapped change across engine speed. In general, residuals decrease as engine speed increases at the same MAP. Hence if we intend to study the effect of $1^{\text {st }}$ cycle residuals on the second and third cycle by means of continuous firing at $1000 \mathrm{rpm}$, it is necessary to find cam positions that have residuals equivalent to that of the $225 \mathrm{rpm}$ case.

Simulations were used to find the residual levels at $1000 \mathrm{rpm}$ and the chosen cam position test points. The Table 23 shows the residuals at the test points for both 1000rpm and 225rpm cases. It is observed that for an IMOP, EMOP combination, maintaining equivalent residuals at $1000 \mathrm{rpm}$ would entail retarding the EMOP by approximately $10^{\circ}$ more. Thus internal residuals at $225 \mathrm{rpm}$, MAP: 0.97bar and IMOP: 100 aTDC, EMOP: $-112^{\circ}$ aTDC are within $4 \%$ of the internal residuals at 1000rpm, MAP: 0.8bar at IMOP: $100^{\circ}$ aTDC, EMOP: $-102^{\circ}$ aTDC.

Having established this equivalency, we only need to run at the next EMOP test point to have the same residuals as the equivalent 225rpm case. This also needs to be considered when making final optimal cam timing conclusions.

Table 23: Residuals at chosen cam phasing test points at both $225 \mathrm{rpm}$ and $1000 \mathrm{rpm}$ (test points crossed out for cam positions not feasible to run)

\begin{tabular}{|c|c|c|c|}
\hline $\begin{array}{c}\text { EMOP } \\
\text { aTDC }\end{array}$ & $\begin{array}{c}\text { IMOP } \\
\text { aTDC }\end{array}$ & $\begin{array}{c}\text { Residuals } \\
225 \text { RPM } \\
(\%)\end{array}$ & $\begin{array}{c}\text { Residuals } \\
1000 \text { RPM } \\
(\%)\end{array}$ \\
\hline-126 & 110 & 6.2 & 5.3 \\
-126 & 125 & 5.8 & 5.0 \\
-126 & 100 & 8.8 & 6.5 \\
\hline-112 & 100 & 15.5 & 8.7 \\
\hline-102 & 100 & 24.7 & 13.2 \\
\hline-93 & 100 & 35.9 & 20.2 \\
\hline-83 & 100 & 49.9 & 32.2 \\
\hline-107 & 113 & 10.8 & 7.2 \\
\hline-97 & 113 & 18.0 & 10.3 \\
\hline-87 & 113 & 29.2 & 16.1 \\
\hline 77 & 113 & & 26.3 \\
\hline
\end{tabular}




\subsubsection{Test plan}

Based on the simulation test points from before we construct baselines similar to the ones followed in the cycle 1 testing. Shown in Table 24 are the baselines for the emission testing, which total to 14 baselines with two fuels E10 and E85, and 6 different paired intake and exhaust cam positions.

Table 24: Baselines for phase 2 emissions testing for $2^{\text {nd }}$ and $3^{\text {rd }}$ cycle testing

\begin{tabular}{|c|c|c|c|c|c|}
\hline \multicolumn{6}{|c|}{ Baseline Conditions for Emissions Testing } \\
\hline \multicolumn{6}{|c|}{ Constant Parameters: 1000 rpm, MAP:80kPa, FP: 6 Mpa, CR11F SA:-10 } \\
\hline $\begin{array}{l}\text { Name } \\
\text { Units }\end{array}$ & Fuel Type & $\begin{array}{l}\text { EMOP } \\
{ }^{\circ} \text { aTDC }\end{array}$ & $\begin{array}{l}\text { IMOP } \\
{ }^{\circ} \text { aTDC }\end{array}$ & $\begin{array}{c}\text { SOI } \\
{ }^{\circ} \text { bTDC }\end{array}$ & $\varnothing$ \\
\hline Range & E85/E10 & & & $300: 150$ & E10:1.15,1.05 \\
\hline & & & & & E85:1.4,1.2 \\
\hline $\begin{array}{c}\text { Tncrement/ } \\
\text { Switch(S) }\end{array}$ & S & & & 30 & \\
\hline 1 & E85 & -126 & 100 & 300 & 1.4 \\
\hline 2 & E85 & -112 & 100 & 300 & 1.4 \\
\hline 3 & E85 & -102 & 100 & 300 & 1.4 \\
\hline 4 & E85 & -93 & 100 & 300 & 1.4 \\
\hline 5 & E85 & -126 & 110 & 300 & 1.4 \\
\hline 6 & E85 & -97 & 113 & 300 & 1.4 \\
\hline 7 & E85 & -87 & 113 & 300 & 1.4 \\
\hline 8 & E10 & -126 & 100 & 300 & 1.15 \\
\hline 9 & E10 & -112 & 100 & 300 & 1.15 \\
\hline 10 & E10 & -102 & 100 & 300 & 1.15 \\
\hline 11 & E10 & -93 & 100 & 300 & 1.15 \\
\hline 12 & E10 & -126 & 110 & 300 & 1.15 \\
\hline 13 & E10 & -97 & 113 & 300 & 1.15 \\
\hline 14 & E10 & -87 & 113 & 300 & 1.15 \\
\hline
\end{tabular}

Each baseline is further expanded in terms of a test matrix, which is shown in Table 25 for baseline number 8 . 
Two $\varnothing$ levels are tested for each test point 1.15 and 1.05 for the $2^{\text {nd }}$ and $3^{\text {rd }}$ cycle respectively. The first cycle fueling is kept constant across the test points at a level where the fuel is sufficient to ensure a misfire free first cycle firing without over fueling. The optimum SOI for the first cycle is determined by a quick SOI sweep, though data is not logged due to the time consuming nature of the additional emissions testing work.

Table 25: Testpoints for baseline 8 (EMOP:-126 and IMOP:100)

\begin{tabular}{|c|c|c|c|c|c|c|c|}
\hline Cons & ant Parame & eters: CF & F, RPM & , Coo & temp 2 & C, Cycle of Inte & st:2,3 \\
\hline & & Control & rameter & & & & \\
\hline $\begin{array}{c}\text { Test } \\
\text { No }\end{array}$ & Fuel Type & $\begin{array}{l}\text { MAP } \\
\mathrm{kPa}\end{array}$ & $\begin{array}{l}\text { EMOP } \\
{ }^{\circ} \text { ATDC }\end{array}$ & $\begin{array}{l}\text { IMOP } \\
{ }^{\circ} \text { ATDC }\end{array}$ & $\begin{array}{c}\text { SA } \\
{ }^{\circ} \text { ATDC }\end{array}$ & $\begin{array}{c}\text { sol Cycle1-2-3 } \\
{ }^{\circ} \text { BTDC }\end{array}$ & $\begin{array}{l}\text { Cycle1 } \\
2-3\end{array}$ \\
\hline & Baseline 8 & & & & & & \\
\hline 1 & E10 & 80 & -126 & 100 & 10 & $150-300-300$ & $x-1.15-1.15$ \\
\hline 2 & E10 & & & & & & $x-1.05-1.05$ \\
\hline 3 & E10 & 80 & -126 & 100 & 10 & $150-270-270$ & $x-1.15-1.15$ \\
\hline 4 & E10 & & & & & & $x-1.05-1.05$ \\
\hline 5 & E10 & 80 & -126 & 100 & 10 & $150-240-240$ & $x-1.15-1.15$ \\
\hline 6 & E10 & & & & & & $x-1.05-1.05$ \\
\hline 7 & E10 & 80 & -126 & 100 & 10 & 150-210-210 & $x-1.15-1.15$ \\
\hline 8 & E10 & & & & & & $x-1.05-1.05$ \\
\hline 9 & E10 & 80 & -126 & 100 & 10 & $150-180-180$ & $x-1.15-1.15$ \\
\hline 10 & E10 & & & & & & $x-1.05-1.05$ \\
\hline 11 & E10 & 80 & -126 & 100 & 10 & $150-150-150$ & $x-1.15-1.15$ \\
\hline 12 & E10 & & & & & & $x-1.05-1.05$ \\
\hline 13 & E10 & 80 & -126 & 100 & 10 & $150-120-120$ & $x-1.15-1.15$ \\
\hline 14 & E10 & & & & & & $x-1.05-1.05$ \\
\hline
\end{tabular}

\subsubsection{Results}

Testing is completed with both the instantaneous $\mathrm{HC}$ and $\mathrm{CO} / \mathrm{CO} 2$ measurements available from the Fast FID and NDIR respectively. The results are plotted (format same as advanced startability results) vs. cycle number for the IMEP, CA50, IMEP/Injection duration and Instantaneous $\mathrm{HC}, \mathrm{CO}, \mathrm{CO} 2$ in percent. The standard deviation of IMEP is shown in the error bars in the IMEP plot. The higher the standard deviation, higher is the chance or occurrence of a misfire. The SOI in ${ }^{\circ} \mathrm{bTDC}$ for cycle 1, 2, 3 is indicated in SOIcycle1-SOIcycle2-SOIcycle3 format in the legend for the figure. Spark advance for the cycle 1 is fixed at an optimum value, while cycle 2 and 3 is fixed at 10 bTDC. 

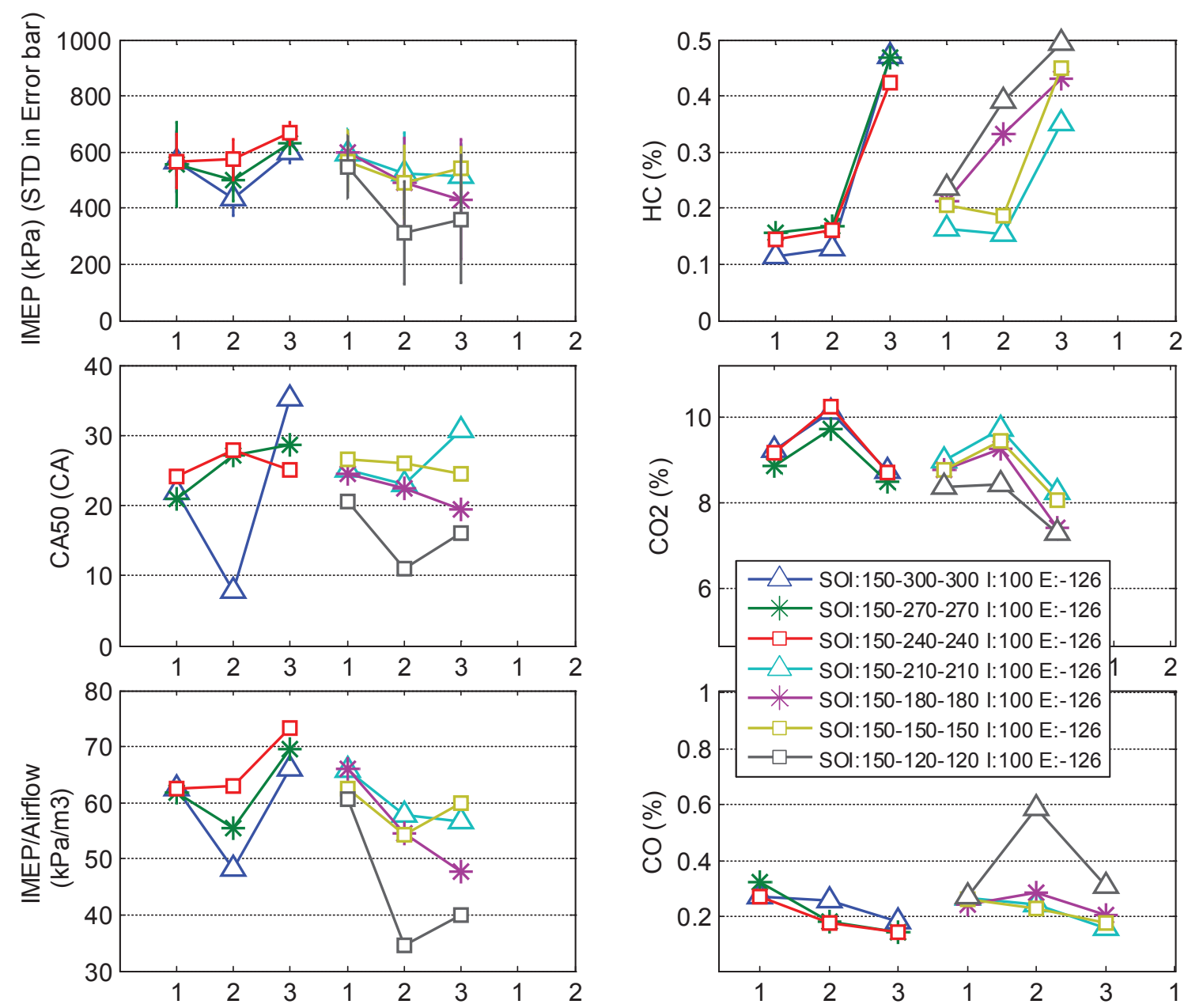

Figure 58: Second and third cycle combustion and emissions data for baseline 8 and phi=1.15

Overall it's seen that IMEP/Airflow metric decreases at SOI's closer to TDC while also reducing the $\mathrm{CO} 2$ emissions and increasing the $\mathrm{HC}$ emissions. $\mathrm{CO}$ emissions do not increase significantly until there are misfires and IMEP STD increases. The IMEP/Airflow metric gives a good basis for comparison of the relative efficiency of each testpoint.

The results for a selected test point with cam phasing position of EMOP -126 and IMOP 100 (baseline 8 in Table 24) and $\varnothing=1.15$ are shown Figure 58. The results indicate that SOI 240 is optimal at this particular baseline since it has the highest IMEP while having low $\mathrm{CO}$ and $\mathrm{HC}$ emissions, while its $\mathrm{CO} 2$ emissions are highest indicating better combustion efficiency and hence more complete combustion of fuel.

Overall it is observed that the CA50 for majority of the dataset lies between $20^{\circ}$ and $30^{\circ}$ aTDC. SOI 240 and 270 are among the top two SOI's from the set due to their higher $2^{\text {nd }}$ and $3^{\text {rd }}$ cycle IMEP's and low CO and HC numbers. The reduced CO2 
emissions for SOI 270 are indicative of less complete combustion; this is substantiated by the smaller IMEP/Airflow numbers it has compared to SOI 240.

Data collected at $\varnothing=1.05$ shows that the only two SOI's that showed no misfires were SOI 240 and 270, which were also the two best SOI's at $\varnothing=1.15$. Further the IMEP's are extremely low for the $2^{\text {nd }}$ cycle close to $200 \mathrm{kPa}$. Hence those results are not used for comparison or discussions.

Similarly plots are made for the rest of the baselines for E10 fuel and the best SOI's for each baseline were selected for $\varnothing=1.15$.
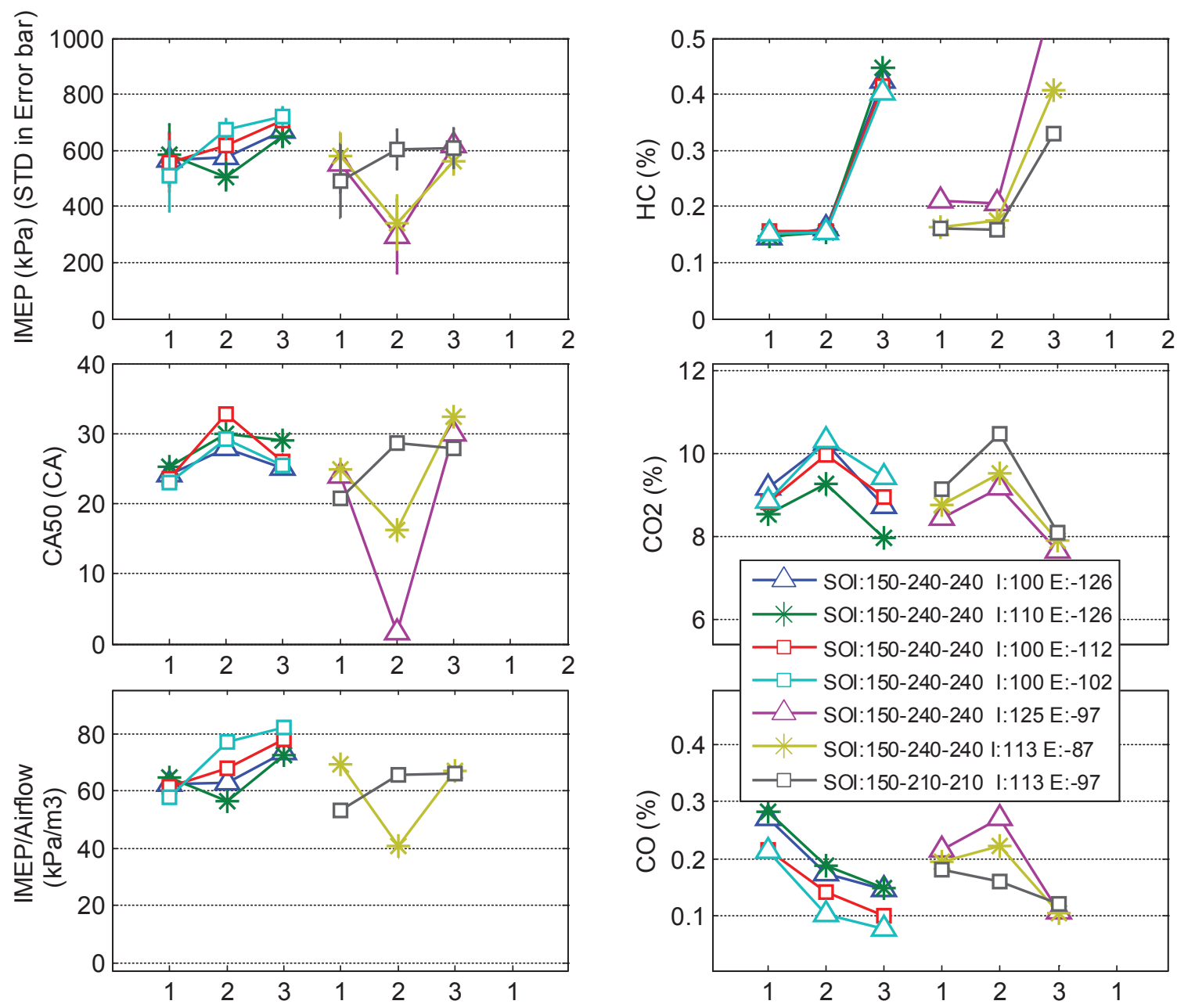

Figure 59: Comparison of E10 fuel baselines with optimal SOI's and Ø=1.15

Shown in Figure 59 are the optimum SOI results for all the baselines for E10 fuel. Same figure format as the previous results figure is followed. It is seen from the results that IMOP: 100, EMOP:-102,-112 are among the highest IMEP test points, while also showing low $\mathrm{CO}$ and HC emissions. The best cam position is thought to be IMOP: 100, 
EMOP:-102, but the results are confounded by the lower $1^{\text {st }}$ cycle IMEP of the IMOP: 100 , EMOP:-102 test point.

Further it is seen that highly retarded EMOP positions -87,-97 show high variability in IMEP for the second cycle. Thus there seems to be a limit to the amount of residuals tolerated. This could also potentially be from the slower flame speed causing higher amount of variability in IMEP in cases where the exhaust valve is opened later.
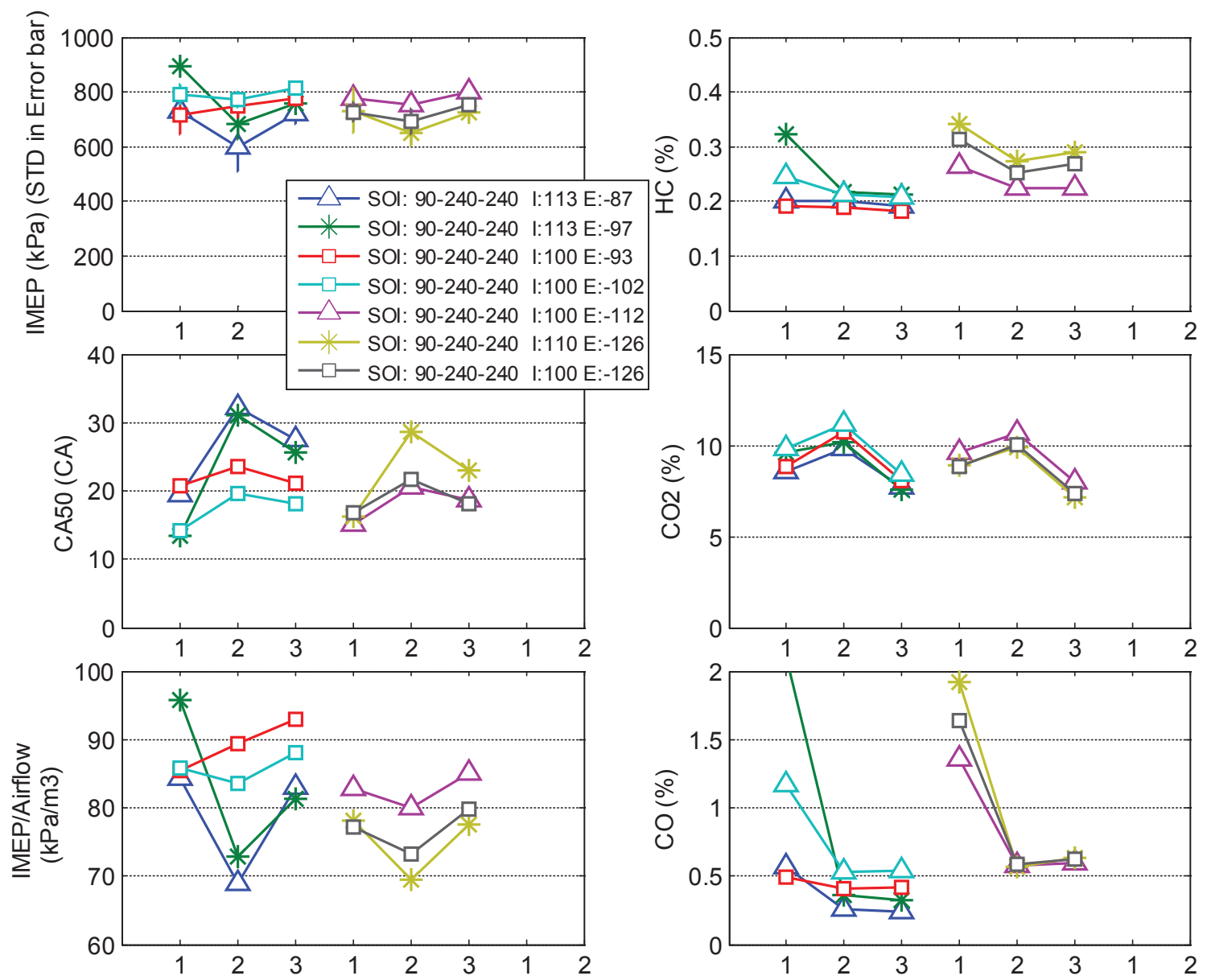

Figure 60: Comparison of E85 fuel baselines with optimal SOI and $\varnothing=1.15$

Similarly results with optimum SOI's for the baselines with E85 fuel are plotted in Figure 60. Here cam positions IMOP: 100, EMOP:-112,-102, -93 are found to be the ones with highest IMEP/airflow and low emissions numbers. Thus IMOP 100 which is an advance IMOP position is preferred over any other IMOP positions from our test points. IMOP: 100, EMOP:-93 cam position is found to be the optimal point based on its low emissions for $\mathrm{HC}$ and $\mathrm{CO}$, while showing the highest IMEP/airflow metric for the $2^{\text {nd }}$ and $3^{\text {rd }}$ cycle. 
The optimal cam positions for the 2nd and 3rd cycle testing for both fuels are tabulated in Table 26. It's seen that both the fuels prefer the same IMOP of $100^{\circ}$ aTDC, but prefer slightly different EMOP's.

Overall the difference between the two EMOP positions is in terms of the residuals, with EMOP -102 showing residuals of $13.2 \%$ in simulations, while EMOP -93 shows residuals of $20 \%$. Since E85 is vaporization limited, it stands to benefit more by the higher residuals driving the in-cylinder air charge temperature higher.

Further both the fuels prefer the same SOI of $240^{\circ} \mathrm{bTDC}$, even though the fuels have a large difference in ethanol content. Thus flat top piston seems to be insensitive to fuel properties for the mixture preparation process at high injection pressures.

Table 26 : Optimum SOI and cam position for 2 nd and 3rd cycle testing for E10 and E85 for CR11F

\begin{tabular}{|c|c|c|c|}
\hline Fuel & $\begin{array}{c}\text { SOI } \\
{ }^{\circ} \text { bTDC }\end{array}$ & $\begin{array}{c}\text { IMOP } \\
{ }^{\circ} \text { aTDC }\end{array}$ & $\begin{array}{c}\text { EMOP } \\
{ }^{\circ} \text { aTDC }\end{array}$ \\
\hline E10 & 240 & 100 & -102 \\
\hline E85 & 240 & 100 & -93 \\
\hline
\end{tabular}

Based on test points that successfully fired without any misfires it is seen that higher residuals or retarded EMOP enables better IMEP's and less misfires compared to the next advanced EMOP.

Comparing the results from the advanced startability where the optimum cam position for E10 was IMOP: 100, EMOP: -112 at 225 rpm, it's noted that this corresponds to IMOP: 100, EMOP: -102 cam position at $1000 \mathrm{rpm}$ based on equivalent residual level. Which are also the optimal cam positions for E10 at $1000 \mathrm{rpm}$. Thus it's reasonable to conclude that the optimum cam phasing position at startup speeds for an engine could be derived from finding equivalent residual EMOP positions. An electric VCT mechanism would be able to change the cam positions as the rpm changed and thus enable optimized engine startup.

Further the results also impress upon the closeness of $\mathrm{HC}$ and $\mathrm{CO}$ emissions numbers between test points. It is observed that low $\mathrm{CO}$ numbers for a test point can be either from combustion being very efficient or it being so inefficient that there is very small amount of partial oxidation of the fuel. Thus $\mathrm{CO}$ alone cannot be used as a differentiation criterion. It has to be considered in conjunction with $\mathrm{HC}$ and $\mathrm{CO} 2$ numbers. Further trapped residuals affect all the emissions metrics when comparing test points across changing EMOP. In this work the peak $\mathrm{CO}, \mathrm{HC}, \mathrm{CO} 2$ percent numbers during the exhaust event have been used. Finding total emissions in grams presents a high level of difficulty in terms of trying to get integration of exhaust HC mass for the $1^{\text {st }}$ $/ 2^{\text {nd }} / 3^{\text {rd }}$ cycle. Further exhaust mass flow rates need to be accurately derived from the simulation model; hence a high fidelity model is needed for the same, also needing accurate engine hardware valve lift curves in the simulation model. 
Overall it is seen that simulations can be successfully used to generate engine combustion metrics at engine start even without accurate fuel burned fraction being known. The general trends from simulations can successfully be used to design and test experimental test matrices.

Finally the results in terms of comparison from the baseline LAF engine park position indicates large reduction in terms of $\mathrm{CO}$ emissions for both E85 and E10 fuel as shown in Table 27, large reductions are seem for E85 fuel HC emissions. In terms of enabling compliance with the next EPA emissions legislation level, this will be an incremental step towards enabling compliance for E85, as the reduction in HC's required by the standard is many times more than the reductions achieved from this work. But it might be able to get us towards the next EPA tier level, depending on the vehicle platform on which implementation is carried out.

\begin{tabular}{|c|c|c|c|c|c|c|c|}
\hline \multicolumn{8}{|c|}{ CR11 Flat top piston } \\
\hline \multicolumn{4}{|c|}{$\varnothing=1.15$} & \multicolumn{4}{|c|}{$\varnothing=1.4$} \\
\hline \multicolumn{4}{|c|}{ E10 } & \multicolumn{4}{|c|}{ E85 } \\
\hline \multicolumn{4}{|c|}{ New optimal Cam positions vs LAF park } & \multicolumn{4}{|c|}{ New optimal Cam positions vs LAF park } \\
\hline \multicolumn{2}{|c|}{ Cycle2 } & \multicolumn{2}{|c|}{ Cycle3 } & \multicolumn{2}{|c|}{ Cycle2 } & \multicolumn{2}{|c|}{ Cycle3 } \\
\hline $\mathrm{HC}$ & $\mathrm{CO}$ & $\mathrm{HC}$ & $\mathrm{CO}$ & $\mathrm{HC}$ & $\mathrm{CO}$ & $\mathrm{HC}$ & $\mathrm{CO}$ \\
\hline $\begin{array}{c}4 \% \\
\text { reduction }\end{array}$ & $\begin{array}{c}44 \% \\
\text { reduction }\end{array}$ & $\begin{array}{c}5 \% \\
\text { reduction }\end{array}$ & $\begin{array}{c}48 \% \\
\text { reduction }\end{array}$ & $\begin{array}{c}25 \% \\
\text { reduction }\end{array}$ & $\begin{array}{c}31 \% \\
\text { reduction }\end{array}$ & $\begin{array}{c}32 \% \\
\text { reduction }\end{array}$ & $\begin{array}{c}32 \% \\
\text { reduction }\end{array}$ \\
\hline
\end{tabular}

Table 27 : HC and CO reductions for CR11 flat top piston with new optimal cam positions vs. LAF park 


\section{Summary and Conclusions:}

Engine startup up to the $3^{\text {rd }}$ fired cycle was successfully simulated and tested on a single cylinder spark-ignition direct-injection engine. All the goals and objectives outlined in research were successfully completed. The engine conditions from a startup trace were replicated on a single cylinder engine. The first cycle testing included three different pistons, CR11, CR11B, CR15.5B, low (0.4 MPa) and high (3 MPa) fuel pressure and three different intake cam positions (95,110,125 IMOP). Optimized SOI for the high pressure injection for each of these pistons was found. Further optimal IMOP positions for the respective pistons were found for both low and high pressure fuel injection. The minimum fueling $\varnothing$ required for both gasoline and E85 was found. This work enables us to understand the difference between Gasoline and E85 under engine startup conditions. By finding the minimal $\varnothing$, we are able to reduce over fueling and hence emissions.

Simulation work was also successduflly used to provide results that allowed an understanding of the relative residual levels, VE \& IMEP in the cam phasing space. This allowed selecting additional test points that enabled use of higher residual levels for the $2^{\text {nd }}$ and $3^{\text {rd }}$ cycle tests. The stability of these points was tested in the startability testing with E10 fuel at $225 \mathrm{rpm}$. This enabled to reduce the number of our test points by means of eliminating those with smaller trapped mass incapable of producing required IMEP. Using the reduced list of test points a new list of baselines and test matrices was designed for the $2^{\text {nd }}$ and $3^{\text {rd }}$ cycle emissions or phase 2 testing.

Phase 2 testing with E10 and E85 included results for instantaneous $\mathrm{HC}, \mathrm{CO}$ and CO2 measurements. This allowed selection of optimal SOI by means of combustion metrics like IMEP as well as emission metrics. Further the comparison of the test points at optimal SOI allowed further understanding into the behavior of E10 and E85 under startup conditions at $1000 \mathrm{rpm}$.

Conclusions drawn from this work are:

- Dynamometer testing of engine startup on a single cylinder engine, enables repeatable testing at low IMEP conditions which are below the threshold for speed run-up in a normal engine. Further there is no cylinder to cylinder variability involved.

- Independent hydraulic system allows cam phasing at startup speeds, this is again not possible on a cold start cart unless the hardware has been modified to support such testing.

- Skip fire method of testing allows repeatable testing at startup, since the variability in the engine speed run up at start is eliminated. Thus excellent control over MAP, fuel pressure and engine temperature is obtained. Further it allows rapid testing of different test points without the significant thermal cool down time required with a cold start cart. 
- Engine simulation can be successfully used to generate engine combustion metrics at engine startup. The general trends from simulations can successfully be used to design and test experimental test matrices.

- Full factorial analysis of parameters such as cam phasing was possible using simulation, further in-cylinder residuals and VE analysis can be performed which was infeasible due to time and resource constraints in experimental testing.

For the $1^{\text {st }}$ phase of testing the following conclusions are drawn

- Bowl piston requires reduced fueling $\varnothing$ for the first cycle: for low pressure fuel injection it allows $12 \%$ lower fuel for gasoline, no benefit for E85, for high pressure fuel injection it allows 10\% lower fuel for gasoline and again no benefit for E85.

- E85 is thought to form fuel puddles leading to large piston wetting and reduced vaporization, thus not benefiting from the use of bowl piston.

- Low pressure injection sees no benefit from increase in compression ratio; higher in-cylinder pressure is hypothesized to reduce the fuel vaporization in this case, suggesting in-cylinder pressure being the dominant variable for fuel vaporization.

- Increase in compression ratio from 11 to 15.5 with bowl piston, high pressure fuel injection reduces the $\varnothing$ for gasoline by $45 \%$ and for E85 by $28 \%$. This is attributed to higher pressure inside the cylinder allowing better fuel spray breakup in case of higher fuel injection pressures and reduced spray penetration length, increased vaporization and mixing due to higher in-cylinder temperatures.

- Higher pressure injection compared to low pressures with flat top piston allows $46 \%$ reduction in $\varnothing$ for gasoline and $47 \%$ for E85. This is again attributed to less piston wetting and better fuel air mixing.

- Flat top piston prefers the same IMOP position across fuels and hence is suitable for flex fuel engines.

- Bowl piston prefers 95 IMOP for low pressure gasoline and 125 IMOP for low pressure E85, while for high pressure E85 it is IMOP 110. It is thought that more stratification inhibits vaporization for low volatility fuel such as E85 at low pressure injections. But higher compression ratio or higher injection pressure ameliorates this as seen by 95 IMOP for high pressure E85 and 15.5 CR bowl.

- Bowl piston allows high pressure injections closer to TDC due to ability to form stratified mixtures, while flat top piston might be hindered by reflection of fuel off of the piston surface for late injections. 
For the $2^{\text {st }}$ phase of testing the following conclusions are drawn

- An intricate link is present between residuals and emissions seen at startup, thus $\mathrm{CO}_{2}, \mathrm{CO}$ and $\mathrm{HC}$ cannot be considered in isolation for optimal point selection without an understanding of the amount of internal residuals trapped at the respective cam phasing position.

- An alternate metric for efficiency like IMEP/Airflow is helpful to understand the results at cold start since there is discontinuous injection of fuel leading to inability to accurately measure fuel injected quantity.

- Both E10 and E85 prefer the same SOI of $240^{\circ}$ bTDC at startup for the flat top piston, thus SOI is not fuel dependent for the flat top piston and high fuel injection pressures.

- E10 optimum cam position shows it tolerates internal residuals levels up to estimated 13\% without variations in IMEP that lead to misfires. E85 optimum cam position show it tolerates residuals levels up to estimated $20 \%$. This difference is thought to be driven by increased energy requirements for fuel vaporization at startup for E85.

- Higher internal residual drives down the $\varnothing$ requirement for both fuels up to their combustion stability limit, this is thought to be direct benefit to vaporization due to increased cycle start temperature.

- Excess retard in exhaust timing leads to higher residuals, increased IMEP variability at startup when the combustion is greatly susceptible to stochastic variation and fuel air mixing process variation and hence requires higher $\varnothing$ to ensure misfire free combustion.

- Advance intake cam position along with retarded exhaust cam position up to IMEP stability limits shows benefits for engine startup.

- The amount of residuals preferred by an engine for E10 fuel at startup is thought to be constant across engine speed, thus could enable easier selection of optimized cam positions across the startup speeds.

- This work successfully established optimal cam positions for both E10 and E85 for the second and third startup cycle. 


\section{Future work}

- Current experimental research needs to be extended from a single cylinder engine to a multi-cylinder engine.

- A complete engine startup analysis upto 10 cycles can also to be performed, in order to understand the cumulative effect of over fueling required initially.

- Given the new understanding of the relative internal residual gas fractions preferred by different fuels at startup from the current work, reducing the current cam position increment will allow better optimization of the fueling and emissions results.

- Lack of a good spray model for GT-POWER work prevented an accurate estimation of fuel vaporized fraction at different cam positions; hence developing a spray model to understand this correlation between cam positions and fuel vaporization is recommended

- Simulations and experimental startup testing for a low lift intake cam is suggested as the next step for cam and phasing effects study, preliminary work done showed encouraging results.

- With the use of start stop technology there is significant oil dilution due to extended low temperature engine running, studying the effect of this at repeated engine starts in terms of oil lubrication properties and emissions is suggested.

- Finally testing the cam phasing and fueling strategy on a production engine is recommended.

\section{Publications based on this Thesis work}

Combustion Robustness Characterization of Gasoline and E85 for Startability in a Direct Injection Spark-Ignition Engine, SAE 2012-01-1073, Kale, V., Santoso, H., Marriott, C., Worm, J., Naber,J.

\section{Yet to be published:}

Engines startup simulation for a Dual Independent Cam Phasing SI Engine with a View on Optimizing Cam Park Positions - Vaibhav Kale, Jeremy Worm, Jeffrey Naber

Engine startup emissions analysis for a Dual Independent Cam Phasing SI Engine Vaibhav Kale, Jeremy Worm, Jeffrey Naber 


\section{References}

1. $\quad$ Andersen, V.F., et al., Vapor pressures of alcohol-gasoline blends. Energy \& Fuels, 2010. 24(6): p. 3647-3654.

2. Stein, R.A., J.E. Anderson, and T.J. Wallington, An Overview of the Effects of Ethanol-Gasoline Blends on SI Engine Performance, Fuel Efficiency, and Emissions. SAE Int. J. Engines, 2013. 6(1): p. 470-487.

3. Russ, S., M. Thiel, and G. Lavoie, SI Engine Operation with Retarded Ignition: Part 2 -HC Emissions and Oxidation. 1999, SAE International.

4. Inoue, K. and S. Mitsuishi, Development of Atmospheric Air-level Emission Vehicle Technology for Gasoline Engines. 2009, SAE International.

5. $\mathrm{Xu}, \mathrm{Z}$., et al., Modeling the Cold Start of the Ford 3.5L V6 EcoBoost Engine. SAE Int. J. Engines, 2009. 2(1): p. 1367-1387.

6. Winkler, M. Particle Number Emissions of Direct Injected Gasoline. 2012 [cited 2013 7/21/2013].

7. Board, C.A.R. Low-Emission Vehicle Program - LEV III. 2013; Available from: http://www.arb.ca.gov/msprog/levprog/leviii/leviii.htm.

8. (EPA), U.S.E.P.A. Tier 3 Vehicle Emission and Fuel Standards Program. 2013; Available from: http://www.epa.gov/otaq/tier3.htm.

9. Reduction of pollutant emissions from light vehicles. 2013; Available from: http://europa.eu/legislation_summaries/environment/air_pollution/128186_en.htm.

10. Kale, V., et al., Combustion Robustness Characterization of Gasoline and E85 for Startability in a Direct Injection Spark-Ignition Engine. 2012, SAE International.

11. Davis, P. and M. Peckham, Cycle-by-Cycle Gasoline Engine Cold Start Measurement of Residual Gas and AFR using a Fast Response CO\&CO2 Analyzer. 2008.

12. Gandhi, A.H., et al., Spray Characterization in a DISI Engine During Cold Start: (1) Imaging Investigation. 2006, SAE International.

13. Johnson, T.V., Diesel Emissions in Review. SAE Int. J. Engines, 2011. 4(1): p. 143-157.

14. Johnson, T.V., Vehicular Emissions in Review. SAE Int. J. Engines, 2012. 5(2): p. 216-234.

15. Johnson, T., Vehicular Emissions in Review. SAE Int. J. Engines, 2013. 6(2): p. 699-715.

16. Davis, P. and M. Peckham, The Analysis of Gasoline Transient Emissions Behavior Using Fast Response Gas Analyzers. 2007.

17. Bielaczyc, P., A. Szczotka, and J. Woodburn, The effect of a low ambient temperature on the cold-start emissions and fuel consumption of passenger cars. Proceedings of the Institution of Mechanical Engineers, Part D: Journal of Automobile Engineering, 2011. 225(9): p. 1253-1264.

18. Marriott, C., et al., Development of a naturally aspirated spark ignition directinjection flex-fuel engine. SAE International Journal of Engines, 2009. 1(1): p. 267. 
19. Aikawa, K., T. Sakurai, and A. Hayashi, Study of Ethanol-Blended Fuel (E85) Effects Under Cold-Start Conditions. SAE International Journal of Fuels and Lubricants, 2009. 2(1): p. 196.

20. Rouse, B.T., Part Load Combustion Characterization of Ethanol-Gasoline Fuel Blends in a Single Cylinder Spark Ignition Direct Injection Variable Cam Timing Variable Compression Ratio Engine, in MEEM. 2010, Michigan Technological University.

21. Russ, S., G. Lavoie, and W. Dai, SI Engine Operation with Retarded Ignition: Part 1 - Cyclic Variations. 1999, SAE International.

22. Nakata, K., et al., The Effect of Ethanol Fuel on a Spark Ignition Engine. 2006, SAE International.

23. Miura, T., et al., Development of a Hydraulic Variable Valve Timing Control System with an Optimum Angular Position Locking Mechanism. 2012, SAE International.

24. Cheever Jr, G., et al., Design of an Electric Variable CAM Phaser Controller. SAE Int. J. Passeng. Cars - Electron. Electr. Syst., 2012. 5(2): p. 403-413.

25. Schäfer, J. and J. Balko, High Performance Electric Camshaft Phasing System. 2007, SAE International.

26. Wheeler, J., et al., Design of a 4-Cylinder GTDI Engine with Part-Load HCCI Capability. SAE Int. J. Engines, 2013. 6(1): p. 184-196.

27. Suzuki, N., et al., Development of New V6 3.5L Gasoline Engine for ACURA $R L X$. SAE Int. J. Engines, 2013. 6(1): p. 629-636.

28. Abe, S., et al., Combustion Analysis on Piston Cavity Shape of a Gasoline Direct Injection Engine. 2001, SAE International.

29. Li, Y. Numerical Simulation on a New Solution to Cold-Start Emission for Gasoline Direct Injection Engine. in Intelligent Computation Technology and Automation (ICICTA), 2010 International Conference on. 2010. IEEE.

30. Durat, M., et al., The effects of coating materials in spark ignition engine design. Materials \& Design, 2012. 36: p. 540-545.

31. Cerit, M., et al., Thermal analysis of a partially ceramic coated piston: Effect on cold start HC emission in a spark ignition engine. Applied Thermal Engineering, 2011. 31(2): p. 336-341.

32. Spegar, T.D., D. Burke, and L. Lavan, Delphi's Heated Injector Technology: The Efficient Solution for Fast Ethanol Cold Starts and Reduced Emissions. 2012, SAE International.

33. Kabasin, D., et al., Heated Injectors for Ethanol Cold Starts. SAE Int. J. Fuels Lubr., 2009. 2(1): p. 172-179.

34. Sales, L.C.M., et al., Heating System for Ethanol and Intake Air - Numerical Model and Experimental Validation at Cold Start in a Flex Fuel Vehicle with Emissions Analysis. 2010, SAE International.

35. Marriott, C.D., et al., Development of a Naturally Aspirated Spark Ignition Direct-Injection Flex-Fuel Engine. SAE Int. J. Engines, 2008. 1(1): p. 267-295. 
36. Skiba, S. and J. Melbert, Dosing Performance of Piezo Injectors and Sensorless Closed-Loop Controlled Solenoid Injectors for Gasoline Direct Injection. SAE Int. J. Engines, 2012. 5(2): p. 330-335.

37. Will, F. Comparison of advanced waste heat recovery systems with a novel oil heating system. in JSAE 2012: Book of summarized papers of the 2012 JSAE

Annual Congress (Autumn)-The best way to monitor the latest trends in cuttingedge technology. JSAE.

38. Will, F. and A. Boretti, A New Method to Warm Up Lubricating Oil to Improve the Fuel Efficiency During Cold Start. SAE Int. J. Engines, 2011. 4(1): p. 175187.

39. Johnson, B. and C. Edwards, Exploring the Pathway to High Efficiency IC Engines through Exergy Analysis of Heat Transfer Reduction. SAE Int. J. Engines, 2013. 6(1): p. 150-166.

40. Burke, D., et al., Fuel Rail Pressure Rise during Cold Start of a Gasoline Direct Injection Engine. 2012, SAE International.

41. Koga, N., K. Takeda, and N. Imatake, An experimental study on fuel behavior during the cold-start period of a direct-injection spark-ignition engine. 2001.

42. Bruno, B.A., D.A. Santavicca, and J.V. Zello, 2003-01-3163 Fuel Injection Pressure Effects on the Cold Start Performance of a GDI Engine. SAE SP, 2003: p. 153-164.

43. Gandhi, A.H., et al., Spray Characterization in a DISI Engine During Cold Start: (2) PDPA Investigation. 2006, SAE International.

44. Liebsch, S., et al., Model Based E85 Cold Start Optimization for DISI Engines. SAE Int. J. Fuels Lubr., 2009. 2(1): p. 902-910.

45. Aikawa, K., T. Sakurai, and A. Hayashi, Study of Ethanol-Blended Fuel (E85) Effects Under Cold-Start Conditions. SAE Int. J. Fuels Lubr., 2009. 2(1): p. 196203.

46. Morgenstern, D.A., J.C. Wheeler, and R.A. Stein, High Efficiency, Low Feedgas NOx, and Improved Cold Start Enabled by Low-Temperature Ethanol Reforming. SAE Int. J. Engines, 2010. 3(1): p. 529-545.

47. Wheeler, J.C., et al., Low-Temperature Ethanol Reforming: A Multi-Cylinder Engine Demonstration. 2011, SAE International.

48. Hülser, T., et al., Optical Investigation on the Origin of Pre-Ignition in a Highly Boosted SI Engine Using Bio-Fuels. 2013, SAE International.

49. Malaguti, S., S. Fontanesi, and E. Severi, Numerical Analysis of GDI Engine Cold-Start at Low Ambient Temperatures. 2010, SAE International.

50. Kapus, P.E., et al., Ethanol Direct Injection on Turbocharged SI EnginesPotential and Challenges. 2007.

51. Kapus, P.E., et al., 2007-01-1408 Ethanol Direct Injection on Turbocharged SI Engines-Potential and Challenges. SAE SP, 2007. 2084: p. 71.

52. Lee, S., et al., Effects of Swirl and Tumble on Mixture Preparation During Cold Start of a Gasoline Direct-Injection Engine. 2000.

53. Lee, S., et al., Effects of Swirl and Tumble on Mixture Preparation During Cold Start of a Gasoline Direct-Injection Engine. 2000, SAE International. 
54. Krishna, B.M. and J. Mallikarjuna, Characterization of Flow through the Intake Valve of a Single Cylinder Engine Using Particle Image Velocimetry. Journal of Applied Fluid Mechanics, 2010. 3(2): p. 23-32.

55. Wheeler, J., et al., Increasing EGR Tolerance using High Tumble in a Modern GTDI Engine for Improved Low-Speed Performance. 2013, SAE International.

56. Heywood, J.B., Internal combustion engine fundamentals. Vol. 930. 1988: McGraw-Hill New York.

57. Lee, D. and J.B. Heywood, Effects of Charge Motion Control During Cold Start of SI Engines. 2006, SAE International.

58. Pontoppidan, M., et al., Detailed Study of Ethanol In-cylinder Combustion Behavior by means of a Numerical Virtual Engine Model Approach. 2005, SAE International.

59. Begg, S., et al., Vortex ring-like structures in gasoline fuel sprays under cold-start conditions. International Journal of Engine Research, 2009. 10(4): p. 195-214.

60. Caton, J.A., A Comparison of Lean Operation and Exhaust Gas Recirculation: Thermodynamic Reasons for the Increases of Efficiency. 2013, SAE International.

61. Schumann, F., et al., Potential of spray-guided gasoline direct injection for reduction of fuel consumption and simultaneous compliance with stricter emissions regulations. International Journal of Engine Research, 2013. 14(1): p. 80-91.

62. Alger, T., et al., A Continuous Discharge Ignition System for EGR Limit Extension in SI Engines. SAE Int. J. Engines, 2011. 4(1): p. 677-692.

63. Köpple, F., et al., Investigation of the Parameters Influencing the Spray-Wall Interaction in a GDI Engine - Prerequisite for the Prediction of Particulate Emissions by Numerical Simulation. SAE Int. J. Engines, 2013. 6(2): p. 911-925.

64. Jainski, C., et al., High-speed micro particle image velocimetry studies of boundary-layer flows in a direct-injection engine. International Journal of Engine Research, 2013. 14(3): p. 247-259.

65. Laget, O., et al., Experiments and Modeling of Flame/Wall Interaction in SparkIgnition (SI) Engine Conditions. 2013, SAE International.

66. Eng, J.A., The Effect of Spark Retard on Engine-out Hydrocarbon Emissions. 2005, SAE International.

67. Shaw, B. and J.K. Hedrick. Coldstart engine combustion modelling to control hydrocarbon emissions. in Proceedings of 15th Triennial World Congress of the International Federation of Automatic Control. 2002. Barcelona Spain, 21-26 July.

68. Cavina, N., et al., Development of a Multi-Spark Ignition System for Reducing Fuel Consumption and Exhaust Emissions of a High Performance GDI Engine. 2011, SAE International.

69. Cao, Y. and L. Li, A Novel Closed Loop Control based on Ionization Current in Combustion Cycle at Cold Start in a GDI Engine. 2012, SAE International.

70. Santoso, H., Discussions on engine start and IMEP requirements. 2010. 
71. MCS, W. ECU Datasheet. 2013; Available from:

http://www.woodward.com/publicationsdownload.aspx?DocumentNumber=3632 1. 


\section{Appendix ECU1 - ECU Program Modifications for Skip- Fire Testing}

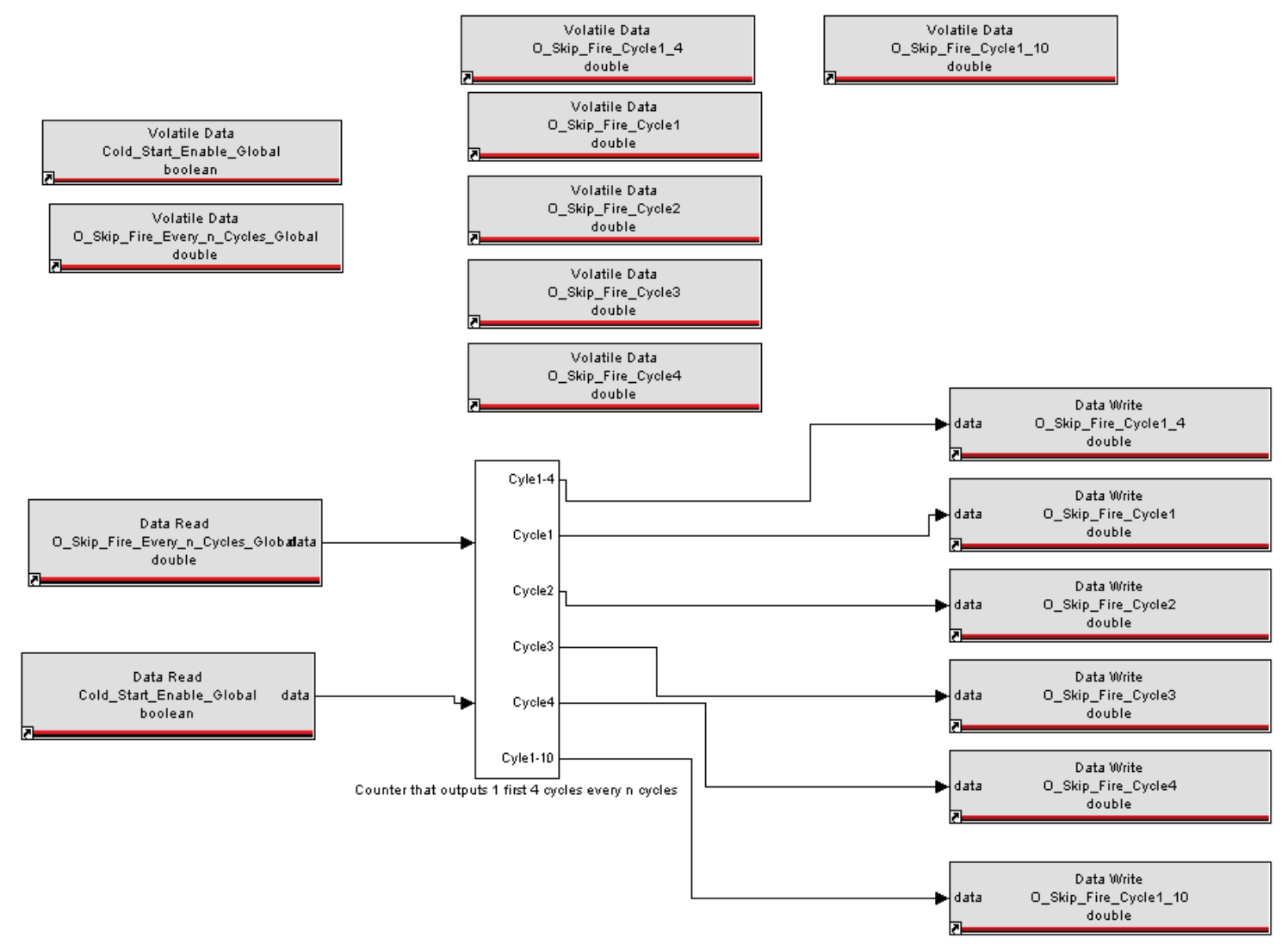

Figure 61: Cycle counter data being fed into variables

Shown in Figure 61 is the program subsystem used to feed the cycle number data into variables. Thus when the cycle counter resets and counts to 1 , the O_Skip_Fire_Cycle1 variable is set to 1 , it is reset to 0 when the cycle counter moves to 2 . Similarly O_Skip_Fire_Cycle2 is set to 1 when the cycle counter moves to 2, and so on.

Further there is a higher level variable O_Skip_Fire_Cycle1_4 that is set to value of 1 when the counter is count is between 1 and 4 . 


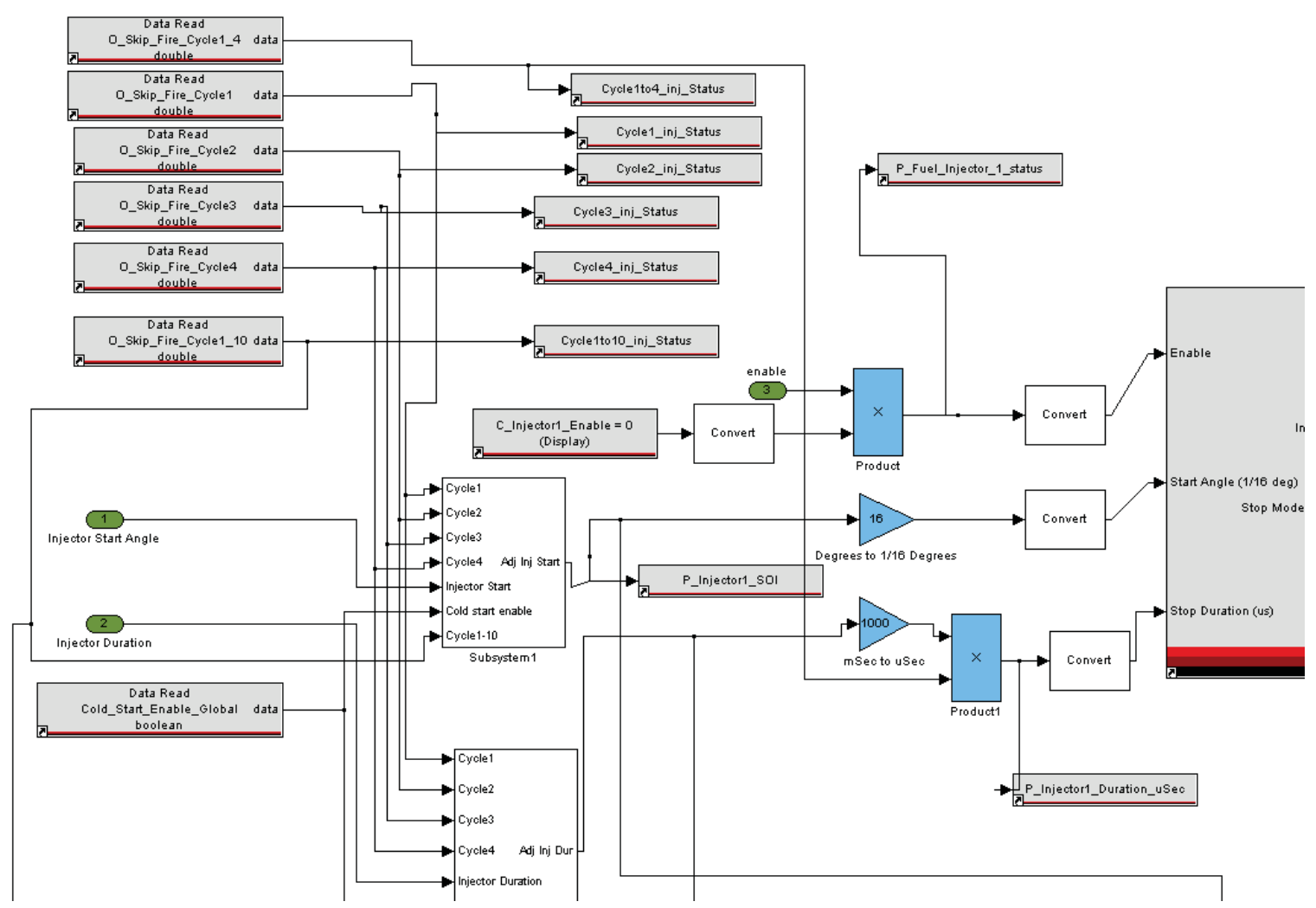

Figure 62: Cycle number data read and processed to select injection duration and start angle

The details of the subsystem to select injection duration and start angle are shown in Figure 62. The inputs to this subsystem are injector start angle and injector duration. This signal is routed through a signal override subsystem(e.x subsystem 1 shown in figure) where depending on the cycle number, the steady state injector start angle/injector duration are replaced by the corresponding values for cycle $1 / 2 / 3$ as the case may be. The data from the cycle counter in terms of variables including O_Skip_Fire_Cycle1 is routed through read operations for variables in the memory of the ECU. This was implemented since the cycle counter runs once each engine cycle, and depending on when which subsystem executes, if the signals are routed through signal cables, previous cycle information was seen to be passed to some subsystems. But by performing read and write operation on a particular variable stored in memory this difficulty was bypassed. 


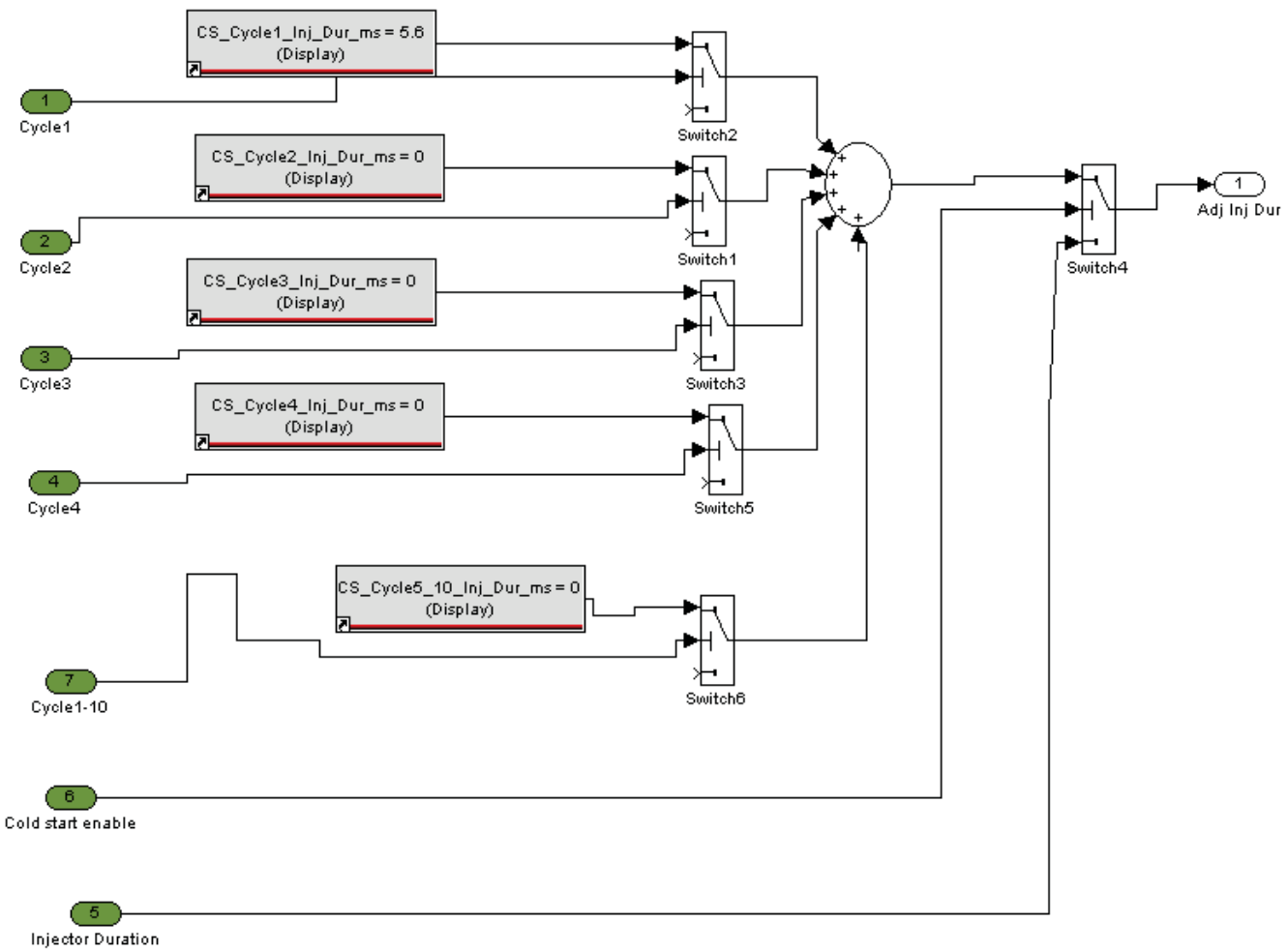

Figure 63: Subsystem 1 in more details, chooses the current injector duration based on cycle number

The Injector duration override system is shown in Figure 63. The inputs are the cycle variables including cycle1, cycle2, etc. and cold start enable boolean variable and injector duration variable for steady state operation. The program works by switching the output of the subsystem for injector duration to CA_Cycle1_Inj_Dur_ms value when cycle1 variable is has value of one, and CA_Cycle1_Inj_Dur_ms when cycle2 is one and so on ... further this value is only passed to the output of the subsystem if the cold start enable has been set to value of one. 


\section{Appendix ECU2 - ECU Specifications}

Shown below is the data for the ECU used with the Hydra single cylinder engine. There are a number of inputs including for 2 lambda sensors along with standard analog voltage inputs and output options include 6 injector drivers, 16 ignitions outputs, and PWM outputs. It also features CAN datalinks, but these are not currently used in the ECU program. The ECU is ECM 565-128 manufactured by Woodward Inc.

The inputs and outputs in detail are listed as below [71]

- 34 Analog Inputs

- 8 Low Frequency Digital Inputs

- 4 VR Frequency Inputs

- 2 Wide Range $0_{2}$ Sensor Inputs (Bosch LSU4.2)

- 1 Dual Sensor Wide Band Knock Detector

- 63A Peak/lA Hold Injector Drivers

- 66A Peak/2A Hold Injector Drivers

- 16 TTL Level Ignition System Outputs

- 10 6A Low Side PWMs

- $\quad 11.5 \mathrm{~A}$ Tachometer Output

- 2 5A H-Bridge PWMs

- 1 10A H-Bridge PWM

- 1 Relay Driver (Main Power) 